\title{
Efeitos da terapia miofuncional orofacial em pacientes com ronco primário e apneia obstrutiva do sono na anatomia e função da via aérea
}

\author{
Tese apresentada à Faculdade de Medicina da Universidade \\ de São Paulo para obtenção do título de Doutor em Ciências \\ Programa de Pneumologia \\ Orientador: Prof. Dr.Geraldo Lorenzi Filho
}

Versão corrigida a original encontra disponível na FMUSP

São Paulo

2015 
Dados Internacionais de Catalogação na Publicação (CIP)

Preparada pela Biblioteca da

Faculdade de Medicina da Universidade de São Paulo

Creprodução autorizada pelo autor

Kayamori, Fabiane

Efeitos da terapia miofuncional orofacial em pacientes com ronco primário e apneia obstrutiva do sono na anatomia e função da via aérea / Fabiane Kayamori . -São Paulo, 2015.

Tese (doutorado)-Faculdade de Medicina da Universidade de São Paulo. Programa de Pneumologia.

Orientador: Geraldo Lorenzi Filho.

Descritores: 1.Terapia miofuncional 2.Apneia do sono tipo obstrutiva 3.Resultado do tratamento 4.Ensaio clínico controlado 5.Imagem por ressonância magnética 6.Língua 7.Força muscular 8.Fadiga 9.Faringe/fisiopatologia 


\section{Dedicatória}

Aos meus pais que são meus exemplos de vida e minha eterna inspiração. Por toda a dedicação ao trabalho e as pessoas, me ensinando sobre humildade, caráter, coragem e amor.

Ao meu amor Vladimir, meu cúmplice, que me apoia e me reconforta nos momentos difíceis e pelos momentos prazerosos.

À minha irmã Luciana que me faz amadurecer nas longas conversas, a buscar sempre crescer como pessoa e espiritualmente.

As famílias Kayamori e Yamashita que são meus exemplos de luta e superação.

À Deus que faz com que tudo isso seja possível. 


\section{Agradecimentos}

Ao Dr Geraldo Lorenzi Filho que com sua didática e ideias nos inspira. Obrigada pela oportunidade e pelo apoio.

Ao Dr Pedro Rodrigues Genta que com sua inteligência nos instiga a curiosidade. Obrigada pela dedicação e apoio.

À Maria Isabel Montes pela muitas e muitas polissonografias laudadas nas horas vagas.

À Fabíola Schorr pela amizade e ajuda sem a qual não seria possível realizar os exames de Pcrit.

Ao Dr Marcelo Gervilla Gregório pelos exames realizados.

À Prof Dra Esther Bianchini pelo conhecimento fonoaudiológico compartilhado que me inspira.

À Dra Katia Guimarães pelo conhecimento fonoaudiológico compartilhado e por me dar esta oportunidade. 
À Dra Eloisa Gebrim e ao Dr Mauro Miguel Daniel pela contribuição indispensável na aquisição das imagens de ressonância magnética.

Ao Dr Richard Schwab e equipe sem os quais não seria possível a realização das análises dos dados de ressonância magnética.

À Vanessa Ieto que incentivou a ter coragem para iniciar esta tese e pela amizade e companheirismo.

À Raquel Hirata quem me acompanhou nas coletas, pela amizade e companheirismo.

Ao engenheiro Henrique Takachi Moriya pelo desenvolvimento dos softwares de força e fadiga e ajuda com os equipamentos e programas.

Aos técnicos de polissonografia Paulo Henrique, Robson e Fabiana pelos exames realizados.

À secretária Vanderléa pela apoio e amizade.

Aos amigos e companheiros de pós-graduação que tive ao longo desses anos:

Lilian de Paula, Flavia Nerbass, Vivien Piccin, Carlos Uchoa, Rafaela Garcia, Juliana Araújo, Aline Heidemann, Fernanda Madeiro, Fabiana 
Yagihara, Melania Marques, Sofia Furlan e Lunara Freitas, pelo imenso suporte e amizade.

Aos coordenadores de pesquisa do Laboratório do Sono: Daniel Queiroz e Gabriela Souza pelo imenso suporte e amizade.

A todos os fellows do Laboratório do Sono que passaram ao longo desses anos pelo suporte apoio e amizade

À equipe da Comissão Científica: Elaine, Fabiana, Deborah, Márcio e Klaus que auxiliaram na submissão do projeto e orientação em relação processo FAPESP.

Aos pacientes pelo comprometimento e sem os quais nada disso seria possível.

À Fundação de Amparo à Pesquisa do Estado de São Paulo (FAPESP) e Coordenação de Aperfeiçoamento de Pessoal de Nível Superior (CAPES) pelo apoio financeiro para a realização desta pesquisa. 
Lista de abreviaturas

\begin{tabular}{ll} 
AOS & Apneia Obstrutiva do Sono \\
$\mathrm{cmH}_{2} \mathrm{O}$ & Centímetros de água \\
$\mathrm{CPAP}$ & Continuous positive airway pressure \\
Events/h & Eventos/hora \\
$\mathrm{ECG}$ & Eletrocardiograma \\
$\mathrm{EEG}$ & Eletroencefalograma \\
$\mathrm{EMG}$ & Eletromiografia \\
$\mathrm{EOG}$ & Eletro-oculograma \\
$\mathrm{IAH}$ & Índice de apneia e hipopneia \\
$\mathrm{IMC}$ & Índice de massa corpórea \\
$\mathrm{IOPI}$ & Iowa Oral Performance Instrument \\
$\mathrm{kPa}$ & Quilopascal \\
$\mathrm{mg}$ & Miligramas \\
$\mathrm{min}$ & Minutos \\
$\mathrm{mm}$ & \\
$\mathrm{Pcrit}$ & Milímetros cúbicos \\
$\mathrm{PSG}$ & Pressão crítica de fechamento \\
$\mathrm{RM}$ & Polissonografia \\
$\mathrm{s}$ & Ressonância magnética \\
$\mathrm{SpO}$ & segundos \\
$\mathrm{TMO}$ & Saturação periférica de oxihemoglobina \\
$\mathrm{VAS}$ & Terapia miofuncional orofacial \\
& Via aérea superior \\
\hline
\end{tabular}




\section{Lista de figura}

Figura 1 - Desenho dos músculos da língua. A- Longitudinal superior; B- Longitudinal inferior; C- Vertical e transverso; D- Genioglosso; E- Estiloglosso; F- Hioglosso.

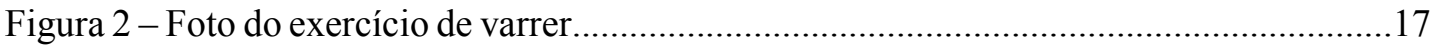

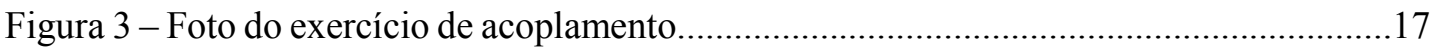

Figura 4 - Foto do exercício de abaixar o dorso da língua......................................................18

Figura 5 - Foto do exercício de dedo na bochecha..................................................................18

Figura 6 - Foto do exercício de elevação do palato mole e úvula

Figura 7 - Reconstrução volumétrica da VAS; A: VAS com estruturas em visão 3D; B: VAS com estruturas visão posterior; C: VAS com estruturas em visão mais posterior

Figura 8 - Reconstrução volumétrica da VAS; A: volume das estruturas contidas dentro da mandíbula; B: volume das estruturas contidas dentro mandíbula até as pregas vocais

Figura - 9 Equipamento do IOPI conectado com bulbo lingual e modelo com bulbo na posição correta com indicação de seta preta do movimento de pressão que deve ser exercido pela língua

Figura - 10 Imagem (print screen) da tela demonstrando o Pico de Força .32

Figura - 11 Imagem (print screen) da tela demonstrando o tempo de fadiga considerado a partir do momento 27 segundo até o momento 47 segundos, com fadiga 0,5 de 27 segundos, neste caso.

Figura - 12 Foto demonstrando: 1: Computador; 2: Sistema de aquisição de dados; 3 IOPI; 4: paciente com bulbo posicionado dentro da boca.

Figura - 13 Desenho da demonstração da realização do exame de Pcrit

Figura - 14 Imagem (print screen) das telas demonstrando as reduções na pressão e consequentes restrições de fluxo.

Figura - 15 Imagem (print screen) da tela de determinação da Pcrit utilizando a regressão linear com extrapolação para o fluxo zero. .36

Figura - 16 Fluoxograma dos sujeitos randomizados, alocados para grupo, perda de seguimento e finalizados no grupo Controle e TMO.

Figura - 17 Fluoxograma dos sujeitos randomizados, alocados para grupo, perda de seguimento e finalizados no grupo Controle e TMO, de acordo com dados do exame de RM de via aérea superior.

Figura - 18 Reconstrução volumétrica da língua e gordura da língua; A: no basal; B: após 3 meses de TMO 
Figura - 19 Fluoxograma dos sujeitos randomizados, alocados para grupo, perda de seguimento e finalizados no grupo Controle e TMO, de acordo com dados e força e fadiga de língua...

Figura - 20 Fluoxograma dos sujeitos randomizados, alocados para grupo, perda de seguimento e finalizados no grupo Controle e TMO no exame de Pcrit. .58

Figura - 21 Desenho demonstrando pressão negativa intraoral com posicionamento da língua estabilizada em palato e fechamento dos compartimentos. 
Lista de tabelas

Tabela 1 - Características demográficas, antropométricas, clínicas e polissonográficas dos sujeitos incluídos nos grupos Controle e TMO no basal

Tabela 2 - Características antropométricas e clínicas dos sujeitos incluídos nos grupos Controle e TMO no basal e após 3 meses de randomização...

Tabela 3 - Características demográficas, antropométricas e clínicas dos sujeitos incluídos nos grupos Controle e TMO no basal no exame de RM das vias aéreas superiores.

Tabela 4 - Características polissonográficas dos sujeitos incluídos nos grupos Controle e TMO no basal no exame de RM das vias aéreas superiores.

Tabela 5 - Análise volumétrica dos sujeitos incluídos nos grupos Controle e TMO no basal no exame de RM das vias aéreas superiores

Tabela 6 - Características antropométricas e clínicas dos sujeitos incluídos nos grupos Controle e TMO no basal e após 3 meses de randomização no exame de RM das vias aéreas superiores

Tabela 7 - Características polissonográficas dos sujeitos incluídos nos grupos Controle e TMO no basal e após 3 meses de randomização no exame de RM das vias aéreas superiores.

Tabela 8 - Análise volumétrica dos sujeitos incluídos nos grupos Controle e TMO no basal e após 3 meses de randomização no exame de $\mathrm{RM}$ das vias aéreas superiores 46

Tabela 9 - Características demográficas, antropométricas e clínicas dos sujeitos incluídos nos grupos Controle e TMO no basal no exame de força da língua e fadiga da língua...

Tabela 10 - Características polissonográficas dos sujeitos incluídos nos grupos Controle e TMO no basal no exame de força da língua e fadiga da língua......

Tabela 11 - Características antropométricas e clínicas dos pacientes incluídos nos grupos Controle e TMO no basal e após 3 meses de randomização no exame de força da língua e fadiga da língua

Tabela 12 - Características polissonográficas e do exame de força e fadiga de língua nos sujeitos incluídos nos grupos Controle e TMO no basal e após 3 meses de randomização no exame de força e fadiga de língua.

Tabela 13 - Características demográficas, antropométricas, clínicas e Pcrit dos sujeitos incluídos nos grupos Controle e TMO no basal no exame de Pcrit. .55

Tabela 14 - Características polissonográficas dos sujeitos incluídos nos grupos Controle e TMO no basal do exame de Pcrit. 
Tabela 15 - Características antropométricas e clínicas dos sujeitos incluídos nos grupos Controle e TMO no basal e após 3 meses de randomização no exame de Pcrit.

Tabela 16 - Características polissonográficas e do exame de Pcrit dos sujeitos dos grupos Controle e TMO no basal e após 3 meses de randomização no exame de Pcrit. 58

Tabela 17 - Comparação da melhora do IAH em porcentagem nos estudos de Guimarães e presente estudo. . .61

Tabela 18 - Comparação dos dados do grupo terapia nos diversos estudos 67 


\section{RESUMO}

KayamoriL F. Efeitos da terapia miofuncional orofacial em pacientes com ronco primário, apneia obstrutiva do sono na anatomia e função da via aérea [Tese]. São Paulo: Faculdade de Medicina, Universidade de São Paulo; 2015.

INTRODUÇÃO: A apneia obstrutiva do sono (AOS) é um problema de saúde pública, com grande prevalência e graves consequências. O tratamento considerado padrão-ouro para AOS grave é a aplicação do aparelho de pressão positiva aérea contínua (CPAP) durante o sono. Porém a adesão ao CPAP é baixa, em especial nos pacientes com ronco primário e AOS leve. Estudo prévio do nosso laboratório demonstrou que a terapia miofuncional orofacial (TMO) é efetiva em pacientes com AOS moderada (Guimaraes et. al, AJRCCM 2009:(179);962-966). No entanto, no trabalho inicial o número de pacientes foi relativamente pequeno $(n=31)$, avaliou-se apenas pacientes com AOS moderada. Adicionalmente, a quantidade de exercícios orofaríngeos realizados foi relativamente grande $(n=10)$ dificultando a adesão ao tratamento e os potenciais mecanismos de ação da terapia não foram elucidados. OBJETIVO: O objetivo primário do trabalho é avaliar a efetividade na redução da gravidade da AOS de um programa com um número reduzido de exercícios de TMO (6 exercícios) em pacientes com ronco primário, AOS leve, moderada e grave. Os objetivos secundários foram avaliar o impacto da TMO no índice de apneia hipopneia (IAH) em pacientes estratificados pelo IAH basal, a anatomia da via aérea superior (VAS) por meio da ressonância magnética (RM), a fisiologia da VAS por meio da força e fadiga da língua e a pressão crítica de fechamento (Pcrit). METODOLOGIA: Foram incluídos pacientes de ambos os sexos, com idade entre 20 e 65 anos, recentemente diagnosticados com ronco primário, AOS leve, moderada ou pacientes com AOS grave que se recusaram a utilizar o CPAP. Foram excluídos pacientes com índice de massa corpórea (IMC) $\geq 35 \mathrm{~kg} / \mathrm{m}^{2}$, malformações craniofaciais, desdentados, uso regular de medicação hipnótica, doença obstrutiva nasal grave, pacientes já submetidos a outros tipos de tratamentos e pacientes com indisponibilidade de comparecimento semanal durante o estudo. Os pacientes foram avaliados no início e final do estudo por questionário de sonolência (Epworth, variando de 0 a 24 pontos), qualidade de sono (Pittsburgh, variando de 0 a 21 pontos), avaliação fonoaudiológica específica para AOS (variando de 0 a 20 pontos), RM da via aérea superior, força e fadiga de língua, Pcrit e polissonografia. Os pacientes foram sorteados para 3 meses de TMO (6 exercícios) ou controle (dilatador nasal durante o sono e exercícios respiratórios inespecíficos). Todos os pacientes foram acompanhados semanalmente por uma fonoaudióloga e orientados a realizar os exercícios três vezes por dia. Foi realizada ANOVA de dois caminhos para medidas repetidas para avaliar a eficácia dos tratamentos nos diferentes desfechos. Secundariamente também avaliamos o efeito dos tratamentos por meio do teste $t$ pareado. RESULTADOS: Inicialmente 251 pacientes foram avaliados, e após avaliação dos 
critérios de inclusão e exclusão, 60 pacientes entraram no estudo, sendo que 30 foram randomizados para TMO e 30 para o grupo Controle. Os dois grupos foram semelhantes para todos os parâmetros na entrada. Finalizaram o estudo 58 pacientes ( $58,6 \%$ do sexo masculino, média de idade $45,9 \pm 12,2$ anos, IMC $28,8 \pm 4,3 \mathrm{~kg} / \mathrm{m}^{2}$, IAH=18,4 $\pm 12,6$ eventos/h e saturação mínima de oxigênio 84,6 $\pm 6,4 \%$ ). O grupo Controle não teve modificações em nenhuma das variáveis ao longo do estudo. O grupo TMO não modificou o IMC e não apresentou mudança significativa nos questionários Epworth e Pittsburgh. Em relação ao início do estudo, o grupo TMO apresentou uma redução significativa na circunferência cervical $(38,8 \pm 3,3$ vs $38,4 \pm 4 \mathrm{~cm})$, índice de despertar $(21,3 \pm 10,9$ vs $16,9 \pm 7,9$ despertares/h), IAH (19,5 514,2 vs $15 \pm 10,2$ eventos/h) e avaliação fonoaudiológica específica para AOS $(9,3 \pm 2,9$ vs $3,6 \pm 2,4)$. O efeito da TMO sobre o IAH foi significativo somente nos pacientes que apresentavam na entrada AOS moderada $(23,8 \pm 5,2$ vs $17,7 \pm 5,2)$ e grave $(43,9 \pm 19,5$ vs $24,7 \pm 21,4)$. Não foram observadas modificações significativas quando avaliado por meio do teste de ANOVA de duas vias para medidas repetidas na RM da via aérea superior em 24 pacientes (10 Controle e 14 TMO) e fisiologia avaliados por força e fadiga de língua em 38 pacientes (19 Controle e 19 TMO) e Pcrit em 17 pacientes (7 Controle e 10 TMO). No entanto, observamos uma redução significativa (teste $\mathrm{t}$ pareado) com diminuição do volume da língua $(\mathrm{p}=0.031)$, quantidade de gordura da língua $(\mathrm{p}=0.008)$ e aumento significativo da força da língua $(\mathrm{p}=0,046)$ no grupo TMO. CONCLUSÃO: Um programa reduzido de TMO é efetivo e capaz de reduzir a gravidade da apneia do sono em pacientes com AOS moderada e grave. A tendência ao aumento da força de língua e redução da gordura de língua podem auxiliar a explicar os efeitos benéficos da TMO em pacientes com AOS.

Descritores: 1.Terapia Miofuncional, 2.Apneia do Sono Tipo Obstrutiva, 3. Resultado do Tratamento, 4.Ensaio Clínico Controlado, 5.Imagem por Ressonância Magnética, 6. Língua, 7.Força Muscular, 8.Fadiga, 9.Faringe/fisiologia 


\begin{abstract}
Kayamori F. Effects of myofunctional therapy in patients with primary snoring, obstructive sleep apnea on upper airway anatomy and function of the upper airway [Thesis]. São Paulo: "Faculdade de Medicina, Universidade de São Paulo"; 2015.
\end{abstract}

INTRODUCTION: Obstructive sleep apnea (OSA) is a public health problem, with high prevalence and severe consequences. The gold standard treatment for severe OSA is the application of continuous positive airway pressure (CPAP) during sleep. However, adherence to CPAP is low, especially in patients with primary snore and mild OSA. A previous study from our laboratory demonstrated that oropharyngeal exercises are effective in patients with moderate OSA (Guimaraes et. al, AJRCCM 2009:(179);962-966). Nonetheless, in this first study the number of patients included in the randomized trial was relatively small $(n=31)$ and evaluated only patients with moderate OSA. Moreover, the number of oropharyngeal exercises the patients had to do 3 times a day was large $(n=10)$ and raised doubt about the compliance to treatment, and the mechanism by which the therapy was effective was not elucidated. OBJECTIVE: The primary objective was to evaluate the effectiveness to reduce OSA severity of a short program of oropharyngeal exercises (6 exercises) in patients with primary snore, mild, moderate and severe OSA. The secondary objective was to evaluate the impact of reduced oropharyngeal exercises program on apnea hypopnea index (AHI) in patients stratified by baseline AHI, the anatomy of upper airway by magnetic resonance (MR), strength and fatigue of the tongue and critical closing pressure (Pcrit). METHODOLOGY: Patients of both sexes, with age between 20 and 65 years old, recently diagnosed with primary snore, mild, moderate or severe OSA who refused to use CPAP were included. Patients with body mass index $(\mathrm{BMI}) \geq 35 \mathrm{~kg} / \mathrm{m}^{2}$, craniofacial deformities, edentulous, regular use of hypnotic medication, severe nasal obstruction, patients undergoing other treatments for OSA and patients with unavailability to comply with the protocol were excluded. The patients were evaluated at the beginning and end of the study by questionnaire of daytime sleepiness (Epworth, ranging from 0 to 24 points), quality of sleep (Pittsburgh, ranging from 0 to 21 points), oral myofunctional evaluation for OSA (ranging from 0 to 20 points), MR of the upper airway, tongue strength and fatigue, critical closing pressure (Pcrit) and polysomnography. The patients were randomized to 3 months of oropharyngeal exercises (6 exercises) or Control (use of nasal dilator strip and respiratory non specific respiratory exercises). All patients were instructed to perform the exercises 3 times a day and evaluated by a speech pathologist once a week. The primary endpoints were evaluated primarily by two-way repeated-measures ANOVA. A paired $t$ test was also used as a secondary evaluation. RESULTS: A total of 251 patients were evaluated and 60 patients were randomized. The 2 groups $(n=30)$ were similar at study entry for all the parameters and 58 patients completed the study $(58.6 \%$ 
males, age: $45.9 \pm 12.2$ years, BMI: $28.8 \pm 4.3 \mathrm{~kg} / \mathrm{m}^{2}, \mathrm{AHI}=18.4 \pm 12.6$ events $/ \mathrm{h}$ and minimum saturation $84.9 \pm 6.4 \%)$. All variables remained unchanged in the Control group. There were no changes in Epworth and Pittsburgh questionnaires as well as BMI in patients randomized to oropharyngeal exercises. As compared to study entry, there was a significantly reduction on neck circumference $(38.8 \pm 3.3$ vs $38.4 \pm 4.4 \mathrm{~cm})$, arousals index ( $21.3 \pm 10.9$ vs $16.9 \pm 7.9$ arousals $/ \mathrm{h})$, AHI $(19.5 \pm 14.2$ vs $15 \pm 10.2$ events/h), oral myofunctional evaluation for OSA $(9.3 \pm 2.9$ vs $3.6 \pm 2.4)$ in the patients randomized for oropharyngeal exercises. Oropharyngeal exercises only reduced AHI significantly among patients with moderate OSA (23.8 \pm 5.2 vs $17.7 \pm 5.2)$ and severe OSA $(43.9 \pm 19.5$ vs $24.7 \pm 21.4)$ at study entry. No significantly changes as evaluated by two-way repeated-measures ANOVA were observed on upper airway MR anatomy (10 Control and 14 oropharyngeal exercises), tongue force and fatigue (19 Control and 19 oropharyngeal exercises) and Pcrit (7 Control and 10 oropharyngeal exercises). As compared to study entry there was a significant reduction as evaluated by paired $\mathrm{T}$ test on tongue volume $(\mathrm{p}=0.031)$, tongue fat $(\mathrm{p}=0.008)$ and a significant increase of tongue strength $(\mathrm{p}=0.046)$ of patients randomized to oropharyngeal exercises. CONCLUSION: A short program of oropharyngeal exercises is effective to reduce OSA severity in patients with moderate and severe OSA. The trend to increase tongue strength and reduce tongue fat may explain the beneficial effects of oropharyngeal exercises.

Descriptors:1.Myofunctional Therapy, 2.Sleep Apnea, Obstructive, 3.Treatment Outcome, 4.Controlled Clinical Trials, 5. Magnetic Resonance Imaging, 6. Tongue, 7 Muscle Strength, 8.Fatigue, 9.Pharynx/physiology 


\section{Sumário}

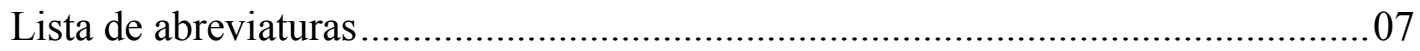

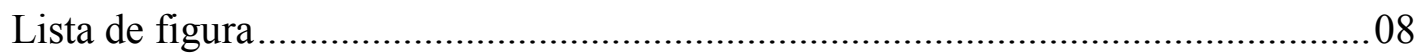

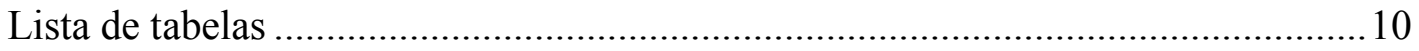

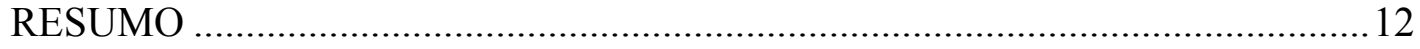

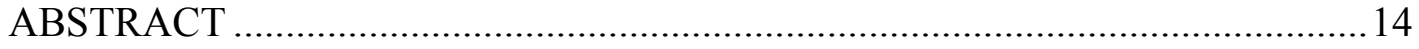

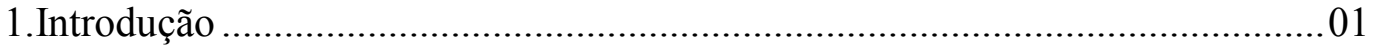

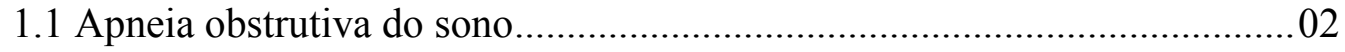

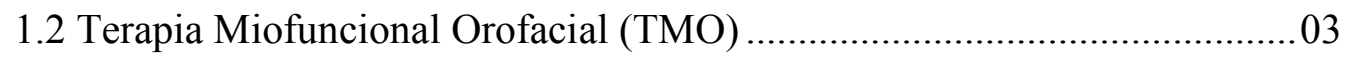

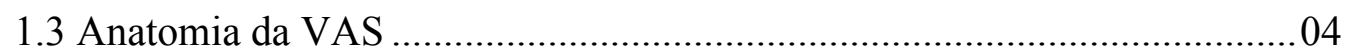

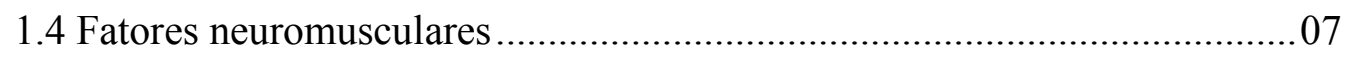

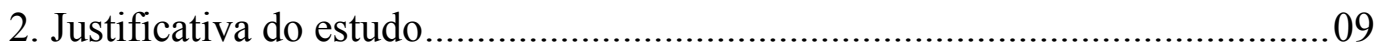

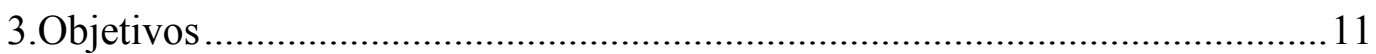

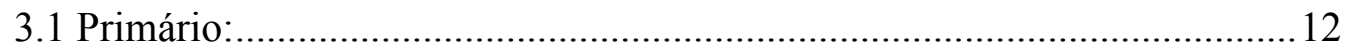

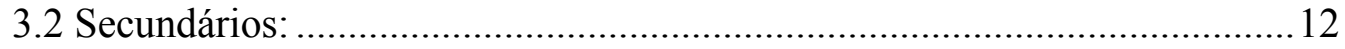

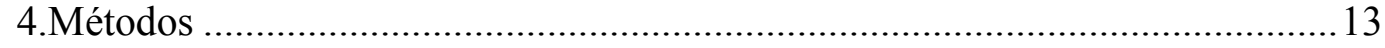

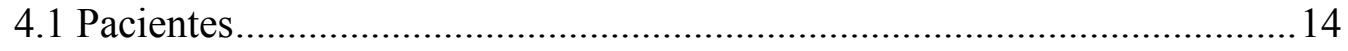

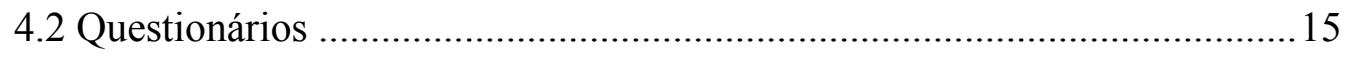

4.3 Avaliação fonoaudiológica ................................................................ 16

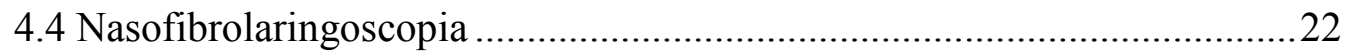

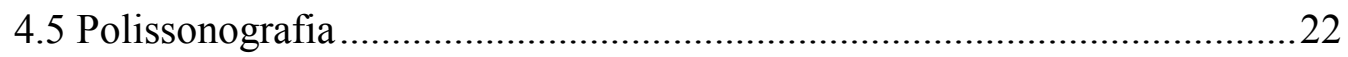

4.6 Ressonância magnética $(\mathrm{RM})$ da via aérea superior ................................22

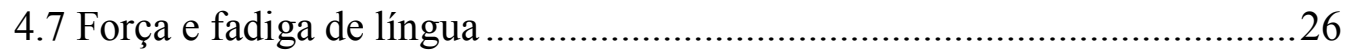

4.8 Pressão crítica de fechamento (Pcrit) ......................................................29

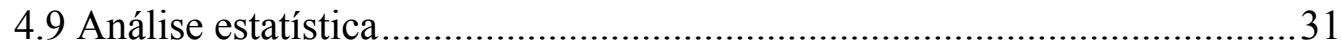

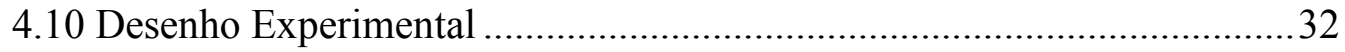

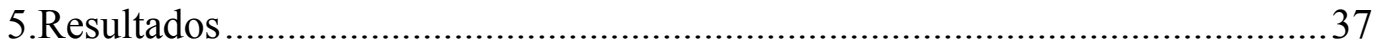


5.1 Polissonografia

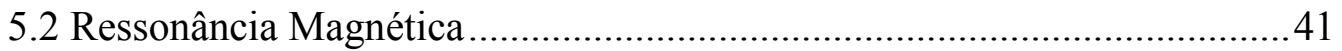

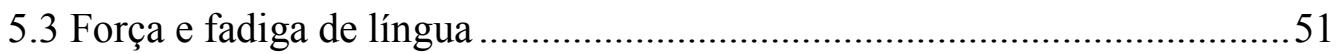

5.4 Pressão Crítica de Fechamento (Pcrit) ….................................................55

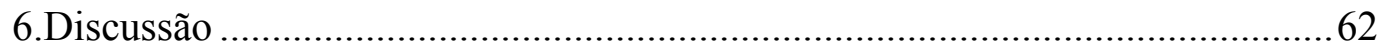

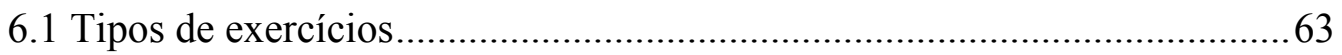

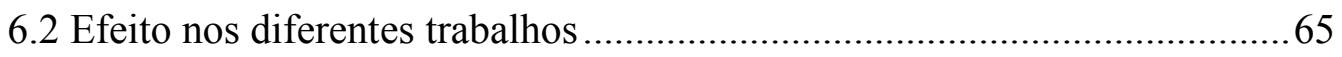

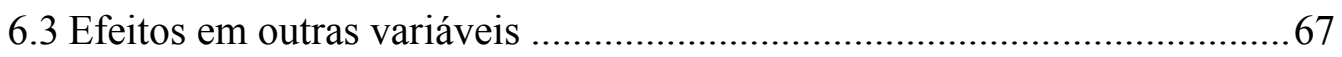

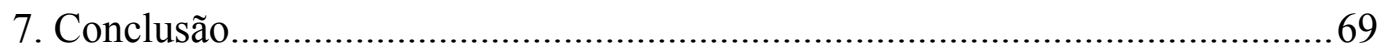

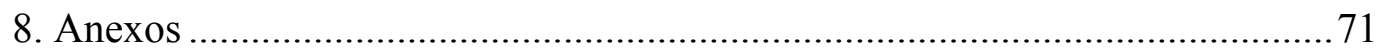

Anexo A: Parecer do Comitê de Ética em pesquisa......................................... 72

Anexo B: Termo de Consentimento Livre Esclarecido ...................................73

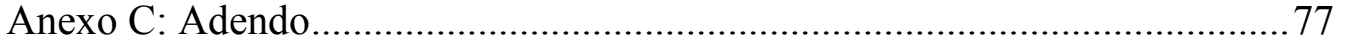

Anexo D: Tabela de adesão ao tratamento grupo Terapia ...............................78

Anexo E: Tabela de adesão ao tratamento grupo controle............................... 79

Anexo F: Questionário para ronco (parte do questionário de Berlim) ..............8 80

Anexo G: Questionário de sonolência: Escala de Sonolência de Epworth.......81

Anexo H: Questionário da qualidade de sono - Questionário de qualidade de vida

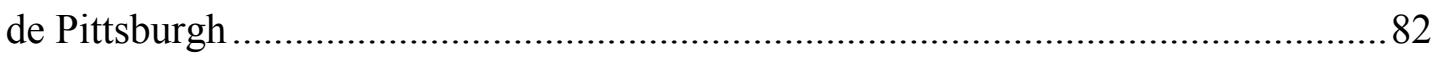

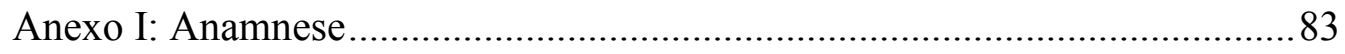

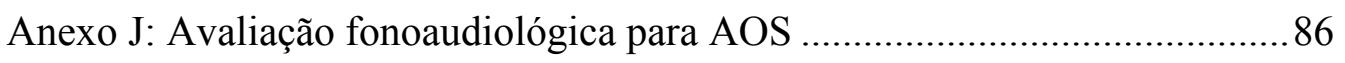

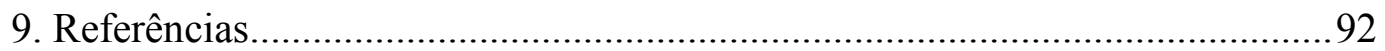



1.Introdução 


\subsection{Apneia obstrutiva do sono}

A apneia obstrutiva do sono (AOS) é caracterizada por episódios recorrentes de obstrução quase total ou parcial na via aérea superior (VAS) durante o sono, resultando em apneias e/ou hipopneias respectivamente. ${ }^{[1]}$ Os eventos respiratórios obstrutivos ocasionam fragmentação do sono e hipóxia intermitente. ${ }^{[1]}$ A AOS pode ter vários sintomas e consequências que vão desde ronco alto, sonolência diurna excessiva, ${ }^{[2]}$ diminuição da produtividade ${ }^{[3]}$ e qualidade de vida, ${ }^{[4]}$ risco aumentado de depressão ${ }^{[5]}$ e risco aumentado de doenças cardiovasculares. ${ }^{[6]}$

A polissonografia (PSG) é considerada padrão-ouro no diagnóstico da AOS, rotineiramente indicada para o diagnóstico dos distúrbios respiratórios do sono. ${ }^{[7]}$ Múltiplos sinais fisiológicos são monitorados durante uma noite inteira, relacionados ao reconhecimento do sono (eletroencefalograma (EEG), eletro-oculograma (EOG), eletromiograma submentoniano (EMG)), monitorização cardíaca (eletrocardiograma (ECG) e a respiração (fluxo aéreo, movimentação torácica e abdominal e oximetria). ${ }^{[1]}$ A gravidade da AOS é determinada pelo índice de apneia e hipopneia (IAH), que é o número de apneias mais hipopneias dividido por hora de sono. ${ }^{[8]} \mathrm{O}$ ronco primário é definido por $\mathrm{IAH}<5 .{ }^{[9]} \mathrm{A}$ AOS leve é definida por IAH $\geq 5$ e $<15$ eventos/hora, a AOS moderada por IAH $\geq 15$ e $<30$ eventos/hora, e a AOS grave por IAH $\geq 30$ eventos/hora de sono. ${ }^{[8]}$

A AOS é compreendida como um problema de saúde pública, por sua alta prevalência e grave consequência. ${ }^{[1]}$ Em estudo realizado na cidade de São Paulo, com 1042 voluntários submetidos a PSG, a prevalência para o sexo masculino foi de $21,7 \%$ de AOS leve e $24,8 \%$ de AOS moderada e grave, já para a população do sexo feminino foi de $20,9 \%$ de apneia leve e $9,6 \%$ de apneia moderada e grave. ${ }^{[10]}$

Atualmente o dispositivo que gera pressão positiva contínua na via aérea (CPAP continuous positive airway pressure) aplicada por meio de máscara é o tratamento padrãoouro para AOS grave. O CPAP é considerado um tratamento altamente eficaz ${ }^{[11]}$ porque normaliza a estrutura do sono, reduz a sonolência excessiva diurna, melhora as funções diárias, o humor, reduz acidentes automobilísticos, diminui a pressão arterial e reduz a ocorrência de acidente vascular cerebral e morte. ${ }^{[12]}$ Apesar das tecnologias dos equipamentos estarem cada vez mais aprimoradas, a aceitação e adesão (considerada por uso maior do que 4 horas por noite) é um desafio, ${ }^{[11][13]}$ com variação de $30-60 \%$, altamente reconhecidos como fatores limitantes. ${ }^{[14]}$

Entre $5-50 \%$ dos pacientes rejeitam o tratamento inicialmente ou logo após uso inicial e $12-25 \%$ abandonam após três anos. Entre os fatores relatados estão: rejeição inicial devido ao custo e também ao custo a longo prazo, relação entre a gravidade da doença e sintomas, experiência inicial e alívio dos sintomas, educação adequada e oportuna, apoio, fatores 
comportamentais e psicológicos e efeitos colaterais (ajuste irregular da máscara e desconforto, irritação da pele, vazamentos da máscara e dor nos olhos, ressecamento das vias aéreas, problemas nasais, queixas de ruído e despertares frequentes, claustrofobia, e outros que não gostam do CPAP). ${ }^{[15]}$ Nos casos de ronco habitual, AOS leve, a adesão costuma ser ainda mais baixa, optando-se por modalidades de terapia alternativas.

A modificação postural no sono (dormir de decúbito lateral e evitar posição supina) é indicada para AOS leve e moderada nos casos de apneia posicional ( 65 a $87 \%$ dos casos), uma solução simples e barata, porém com necessidade de demostrar-se a eficácia. ${ }^{[16]}$

Aparelhos intra-orais avançam a mandíbula prevenindo e minimizando o colapso da VAS durante o sono. Demonstrou-se eficácia para apneia obstrutiva leve e moderada. Porém, as principais queixas consistem em dor na boca, dor em articulação temporomandibular, perda do aparelho durante a noite e desconforto geral. ${ }^{[17][18]}$

A perda de peso é uma das opções de tratamento. A obesidade é o maior fator de risco de desenvolvimento e de progressão da AOS ${ }^{[19]}$ Modificações modestas no peso estão relacionadas com aumento ou diminuição de AOS. Em homens, a perda de peso de $10 \mathrm{~kg}$ ou mais aumenta em cinco vezes a chance de redução de 15 eventos respiratórios/hora. As mulheres, no entanto, apresentam uma probabilidade de redução do IAH menor com a redução do peso. ${ }^{[20]}$

\subsection{Terapia Miofuncional Orofacial (TMO)}

A TMO consiste em um conjunto de procedimentos e técnicas (utilizando exercícios e função) para reeducação dos padrões musculares inadequados utilizados dentro dos vários enfoques da Motricidade Orofacial. Neste caso, com enfoque principalmente para musculatura que acredita ser necessário trabalho para a AOS (facial, da língua, do palato mole e paredes laterais faríngeas), por meio do treinamento da musculatura da VAS com exercícios isométricos e isotônicos, o que diminui as interferências nos padrões normais de mastigação, deglutição, fala e respiração ${ }^{[21]}$ ou simplificadamente denominada de exercícios orofaríngeos, citando os exercícios realizados para AOS. ${ }^{[22]}$

O trabalho de fonoaudiologia com a TMO surgiu como alternativa de tratamento para AOS. Em estudo randomizado em pacientes com AOS moderada, 16 sujeitos foram submetidos a TMO e 15 sujeitos submetidos a terapia placebo (Controle) por três meses. O primeiro grupo fez exercícios por aproximadamente 30 minutos diariamente e, após três meses, foram observadas redução da circunferência cervical em aproximadamente $1 \mathrm{~cm}$, redução na intensidade e frequência do ronco, redução da sonolência diurna, melhora na 
qualidade do sono e redução de aproximadamente $40 \%$ no IAH $(22,4 \pm 4,8$ vs. $13,7 \pm 8,5$ eventos/h), sem modificações significativas no grupo Controle. ${ }^{[22]}$

Outro estudo ${ }^{[23]}$ avaliou a qualidade de vida de 185 pacientes com AOS antes, após quatro tipos de 'tratamentos' e após washout de 3 semanas. Os 'tratamentos' foram: tratamento fonoaudiológico (TF); TF em associação com o uso de CPAP; terapia placebo; apenas uso de CPAP. Mostrou-se melhoras no domínio físico mensurado pelo questionário WHOQOL abreviado nos grupos TF e TF em associação com o uso de CPAP, após os tratamentos e após washout. Além disso, observou-se melhoras na capacidade funcional mensurado por questionário SF-36 abreviado no grupo TF. O IAH no grupo TF reduziu aproximadamente $50 \%$ (28 \pm 22.7 vs. $13.9 \pm 18.5$ ). O grupo TF em associação com o uso de CPAP demonstrou um maior tempo no uso do CPAP $(5.1 \pm 2.3)$ comparado com o grupo CPAP $(3.6 \pm 1.8 \mathrm{~h})$, com uma melhor adesão ao uso de CPAP. Porém os exercícios utilizados não foram relatados, apenas citados para quais funções e que músculos foram utilizados, no caso para otimizar a tensão e mobilidade dos músculos e ajustar a posição dos tecidos moles (palato mole, músculos constritores da faringe, músculos supra hióideos, ponta e base da língua, bochechas e lábios) e adequar as funções de mastigação, sucção, deglutição e respiração. ${ }^{[24]}$ Buscando o estudo que gerou este artigo, no caso uma tese de mestrado, observou-se uma ampla gama de exercícios utilizados, porém com muitos exercícios para serem realizados rotineiramente.$^{[23]}$

Estudo recente do nosso grupo mostrou melhora na redução do ronco nos pacientes com ronco primário, AOS leve e moderado. Porém em relação ao IAH observou-se um efeito chão, sem redução esperada em relação ao IAH nos pacientes com apneia leve e ronco primário. ${ }^{[25]}$

\subsection{Anatomia da VAS}

O homem durante a evolução apresentou modificações que fizeram da faringe humana um tubo mais susceptível ao colapso. Entre as modificações, podemos destacar o encurtamento dos ossos da maxila, etmoide, palato e mandíbula; menor angulação entre a cavidade oral e a base do crânio; migração anterior do forame magno; posteriorização da língua na faringe; abaixamento da laringe; encurtamento do palato mole; perda da conexão entre palato mole e epiglote. ${ }^{[26]}$ Além disso, a faringe apresenta de um osso hioide flutuante, uma via aérea mais longa e com uma rota de ar menos direta para passagem do ar, ${ }^{[1]}$ favorecendo o aparecimento da AOS.

A faringe humana é uma estrutura que compreende vários músculos cuja integração é essencial para as funções de deglutição, fala e respiração. A musculatura da VAS será subdividida em grupos para melhor compreensão. ${ }^{[27]}$ 
Os músculos do palato são cinco: elevador do palato, tensor do palato, palatoglosso, palatofaríngeo e o músculo da úvula. A ação destes músculos é dependente do fluxo da respiração nasal ou oral. O músculo elevador do palato fecha a via nasal promovendo a respiração oral. O músculo da úvula influencia na forma do palato mole e melhora o fechamento da região retropalatal durante a respiração oral e a deglutição. Os músculos palatoglosso e palatofaríngeo atuam na abertura da via nasal puxando o palato para a base da língua, que tende a constringir ou fechar a via oral. $\mathrm{O}$ tensor do palato enrijece o palato facilitando a ventilação nasal. ${ }^{[27]}$

Vários músculos controlam a posição do hioide e contribuem para dilatar a VAS. Os músculos geniohioideo, milohioideo e digástrico puxam o hioide anteriormente; o estilohioideo puxa o hioide posteriormente; enquanto o esternohioideo, omohioideo e tireohioideo executam força em direção inferior. ${ }^{[27]}$

Os músculos constritores da faringe são constritor superior, constritor médio e constritor inferior, os quais atuam na constrição da faringe para auxiliarem a deglutição. ${ }^{[27]}$

Os músculos denominados extrínsecos da língua são três (genioglosso, hioglosso e estiloglosso) (Figura 1) e controlam sua posição. O genioglosso é o músculo protrusor e depressor da língua. O estiloglosso retrai e eleva os lados da língua. O hioglosso retrai e deprime a língua. ${ }^{28]}$

Os músculos intrínsecos da língua são quatro (Figura 1) e estão relacionados com a sua forma. A contração do músculo longitudinal superior encurta a língua e vira o ápice para cima, além de auxiliar a virar as margens laterais para cima. O longitudinal inferior encurta a língua ou empurra o ápice para baixo. $\mathrm{O}$ transverso faz com que a língua se estreite e alongue. $\mathrm{O}$ músculo vertical achata a língua. ${ }^{[28]}$ 

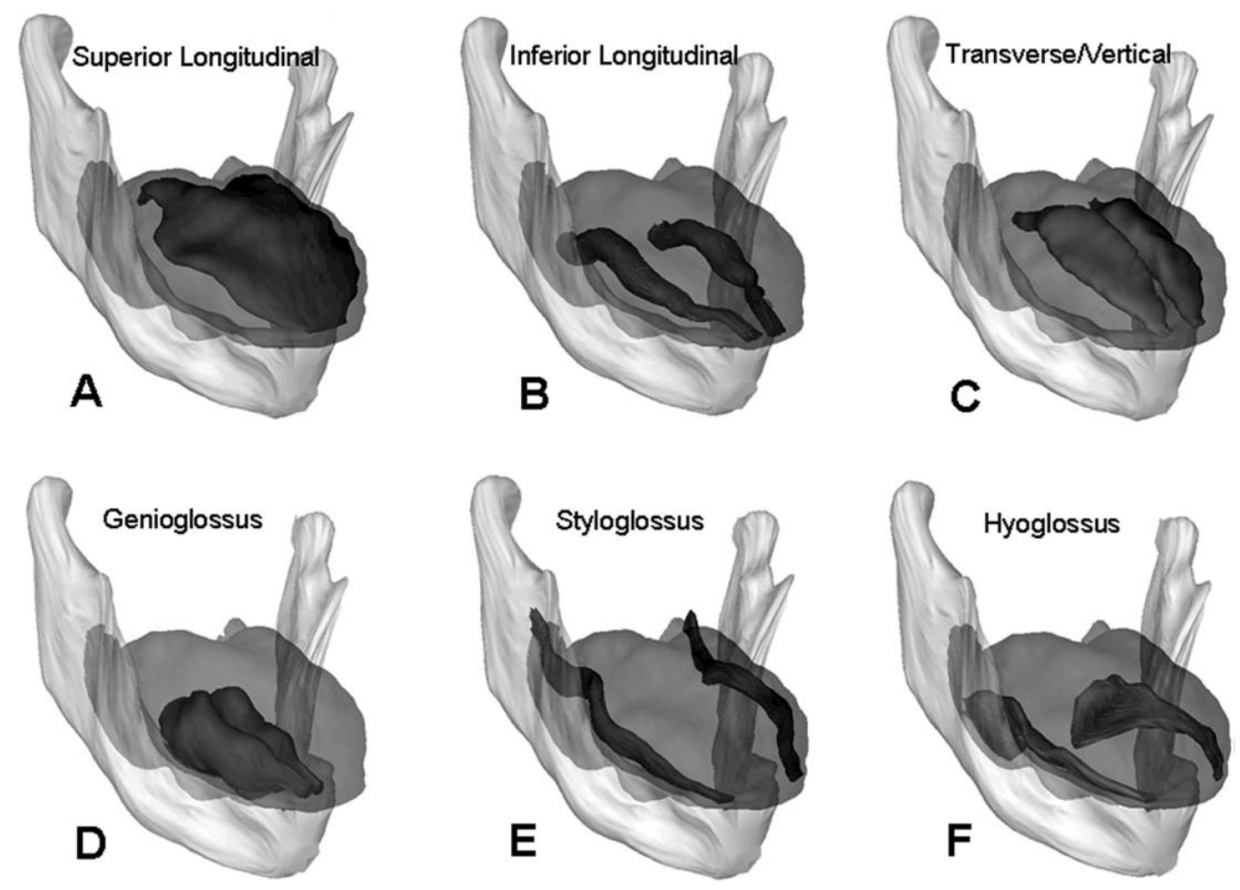

FONTE: Sanders I, 2013.[29]

Figura 1: Desenho dos músculos da língua. A - Longitudinal superior; B - Longitudinal inferior; C - Vertical e transverso; D - Genioglosso; E - Estiloglosso; F - Hioglosso

A patogênese da AOS está relacionada com a redução do tamanho da VAS. As predisposições anatômicas presentes em pacientes com AOS podem ser divididas em: alteração da estrutura craniofacial (principalmente com a redução da mandíbula no comprimento e profundidade e deslocamento do osso hioide póstero inferior ${ }^{[30]} \mathrm{e}$ aumento das estruturas moles principalmente língua, palato mole e paredes laterais da faringe e aumento do tecido adiposo da gordura parafaríngea. ${ }^{[31]}$

Além disso, em relação a outros músculos, a língua apresenta uma grande quantidade de gordura, distribuída em aproximadamente $10-12 \%$ de gordura na região anterior, $28-32 \%$ na região posterior e $28-33 \%$ na região sublingual. Com aumento do índice de massa corpórea (IMC) observa-se aumento na quantidade de gordura na região posterior. ${ }^{[32]}$ Analisando a língua de sujeitos com e sem AOS, com IMC semelhantes por meio de imagens da ressonância magnética (RM), observou-se uma maior língua e maior quantidade de gordura intramuscular nos pacientes com AOS. Supõe-se que o acúmulo de gordura intramuscular deve alterar a forma e reduzir a força de contração, alterando a maneira como a língua atua como dilatador da faringe. ${ }^{[33]}$ 


\subsubsection{Imagens de Ressonância Magnética (RM)}

As imagens de RM da VAS são ideais para examinar a anatomia da faringe, estrutura craniofacial e estruturas moles. ${ }^{[34]}$ A RM permite a realização de medidas cefalométricas, ${ }^{[35]}$, além da reconstrução volumétrica tridimensional da VAS como espaço aéreo, gordura parafaríngea, palato mole, língua, paredes laterais da faringe e definições anatômicas dos segmentos da VAS em regiões como velofaringe, orofaringe e hipofaringe ${ }^{[30]}$ Além de ser um método não-invasivo, ${ }^{[36]}$ é considerado um dos métodos mais sofisticados. ${ }^{[37]}$

As imagens de RM tem sido utilizada para demonstrar modificações na VAS em pacientes com e sem AOS ${ }^{[30]}$ Recentemente novos métodos que mensuram a quantidade de gordura, separando gordura e água, foram utilizados mensurando a gordura na língua. ${ }^{[38]}$

Além disso, a RM tem sido utilizada para mensurar modificações na VAS de pacientes com AOS, de acordo com os tratamentos como: perda de peso, ${ }^{[34]}$ no uso de placa de avanço mandibular, ${ }^{[35]}$ uso de novo dispositivo que gera pressão negativa intra-oral ${ }^{[39]}$ e cirurgia na $\mathrm{VAS}^{[40]}$ demonstrando as modificações anatômicas.

\subsection{Fatores neuromusculares}

Entre as diversas contribuições da fisiopatologia da obstrução da VAS existem os efeitos do sono nos fatores neuromusculares e fatores neuroventilatórios, entre outros fatores. ${ }^{[1][41]}$

Os fatores neuromusculares envolvem os músculos dilatadores da faringe que mantém a patência da VAS devido à reflexos do sistema nervoso central (SNC) na faringe. ${ }^{[1]}$

Durante o ciclo inspiratório alguns músculos são ativados genericamente de forma tônica (contínua) e fásica (intermitente). O músculo genioglosso apresenta ativação fásica (intermitente) na inspiração, que consequentemente, neutraliza as pressões negativas geradas pelo diafragma. Já na expiração, ocorre a ativação tônica (contínua) mantendo assim, a espessura e tamanho da VAS. ${ }^{[42]}$ A pressão negativa na faringe estimula as fibras proprioceptivas e aumenta sua resposta de ativação ${ }^{[33]}$ Durante momentos de hipóxia e hipercapnia a ativação do genioglosso é aumentada. ${ }^{[44]}$

Os músculos palatoglosso e palatofaríngeo aumentam sua ativação em respostas a breve pulsos de pressões negativas ou resistência inspiratória. ${ }^{[45]}$ Além disso, o palatoglosso aumenta sua atividade fásica (intermitente) em resposta a hipercapnia. ${ }^{[46]}$

O músculo tensor do palato apresenta atividade tônica que não é modulada pela respiração, ${ }^{[46]}$ entretanto, outros estudos sugerem atividade fásica durante a inspiração. ${ }^{[47]}$

Pacientes com AOS têm maior ativação dos músculos dilatadores da faringe quando acordados, comparado com pacientes saudáveis. ${ }^{[48][49]}$ Conforme o aprofundamento dos estágios do sono, os pacientes com AOS demonstram grandes quedas na ativação muscular 
principalmente no genioglosso, refletindo numa perda da compensação neuromuscular presente quando acordado. ${ }^{[50][51][52][53][54][55]}$

\subsubsection{Força e fadiga de língua}

Pouco se sabe sobre a força e a fadiga da musculatura da língua em pacientes com AOS ou mesmo após exercícios de TMO. Estudos demonstraram que os pacientes com AOS possuem uma musculatura protrusora de língua mais forte. ${ }^{[56][57]}$ No entanto, essa musculatura teria uma tendência a fadigar mais rápido do que em indivíduos normais. ${ }^{[57][58]}$

\subsubsection{Pressão crítica de fechamento (Pcrit)}

A colapsabilidade da via aérea é relacionada com os fatores anatômicos como anormalidades dos tecidos moles da faringe e anormalidades da estrutura craniofacial e comumente mensurada pela pressão crítica de fechamento (Pcrit). ${ }^{[59][60]}$ A Pcrit é definida como a pressão nasal na qual ocorre o colapso da faringe. ${ }^{[61]}$

A Pcrit utiliza o modelo do resistor de Starling, que pode ser explicado como um tubo colapsável (faringe) dentro de uma caixa selada (tecidos moles) com dois segmentos rígidos nas pontas (região nasal e região traqueal). Com a diferença de pressão entre essas duas regiões, o fluxo de ar irá ocorrer dentro desse tubo. Se a pressão interna do tubo for maior que a pressão externa, há abertura da faringe (fluxo normal). Caso a pressão interna do tubo seja menor do que a pressão externa, haverá colapso (apneia). Na condição de limitação de fluxo, a pressão nasal é maior que a pressão traqueal, mas a pressão traqueal é igual à pressão externa (hipopneia). ${ }^{[61]}$

A Pcrit é um índice útil na gravidade da apneia obstrutiva do sono. ${ }^{[62]}$ Baixa Pcrit indica uma via aérea mais resistente ao colapso e alta Pcrit indica uma VAS menos resistente ao colapso. Sujeitos saudáveis apresentam Pcrit $-15,4 \pm 6,1 \mathrm{cmH}_{2} \mathrm{O}$; sujeitos com síndrome de resistência de VAS, Pcrit $-4 \pm 2,1 \mathrm{cmH}_{2} \mathrm{O}$; AOS leve/moderada, Pcrit -1,6 $2,6 \mathrm{cmH}_{2} 0$; e AOS moderada/grave, Pcrit 2,4 $42,8 \mathrm{cmH}_{2} \mathrm{O}^{[63]}$

A Pcrit tem sido estudada em diferentes condições. O homem tem uma Pcrit mais positiva que a mulher. Nas mulheres, a Pcrit fica mais positiva com o aumento da idade e principalmente após a menopausa. ${ }^{[64]}$ Após redução de peso observa-se Pcrit mais negativa em ambos os sexos. ${ }^{[65]}$ Pacientes mais velhos (64.7 \pm 1.2 idade) apresentam uma maior Pcrit (3.4 \pm 0.9 vs $\left.1.5 \pm 0.7 \mathrm{cmH}_{2} 0\right)$ em relação a pacientes mais jovens ( $32.1 \pm 1.8$ idade). ${ }^{[66]}$

Em relação à posição, a Pcrit é mais positiva em supino $\left(2.02 \pm 2.55 \mathrm{cmH}_{2} \mathrm{O}\right)$ do que em posições laterais $\left(-1.92 \pm 3.87 \mathrm{cmH}_{2} \mathrm{O}\right) \cdot{ }^{[67]}$ Porém não demonstra sofrer modificações de acordo com os estágios do sono. ${ }^{[68]}$ 
2. Justificativa do estudo 
Em estudo prévio randomizado com 31 pacientes com apneia obstrutiva do sono (AOS) moderada realizaram exercícios para musculatura orofaríngea, também denominada terapia miofuncional orofacial (TMO) ${ }^{[22]}$. Nesse trabalho inicial o número de pacientes foi relativamente pequeno, restringiu-se a pacientes com AOS moderada e a quantidade de exercícios que precisavam ser realizados 3 vezes ao dia foi muito grande $(n=10)^{[22]}$. No entanto, apenas o IAH moderado foi avaliado, não sendo explorado os diversos níveis de gravidade da AOS. ${ }^{[22]}$ Especulamos qual será o efeito de um programa reduzido de TMO (número total de exercícios de 6) em pacientes com AOS leve, moderada e grave. Além disso, os mecanismos pelo qual essa nova terapêutica ${ }^{[22][25]}$ atua não estão esclarecidos. A anatomia avaliada por meio de imagens de ressonância magnética (RM) demonstrou grande quantidade de gordura na língua ${ }^{[33]}$ e especula-se modificações nas estruturas da via aérea superior (VAS) e provavelmente na quantidade de gordura da língua. Na fisiologia da VAS especificamente em relação a língua (força e fadiga) observa-se aumento da força e redução do tempo da fadiga nos sujeitos com AOS e espera-se um aumento do tempo de fadiga da musculatura após a TMO. Na fisiologia da VAS por meio da avaliação da pressão crítica de fechamento (Pcrit) espera-se redução da colapsabilidade da VAS. 
3.Objetivos 
Avaliar a efetividade de um programa reduzido de TMO para AOS

\subsection{Primário:}

- Na redução da gravidade da AOS;

\subsection{Secundários:}

- Na redução da gravidade da AOS estratificado por gravidade;

- Na avaliação fonoaudiológica específica para AOS;

- $\mathrm{Na}$ anatomia da via aérea superior avaliada por meio da ressonância magnética (RM);

- Na força e fadiga da língua;

- Na pressão crítica de fechamento (Pcrit). 
4.Métodos 
O projeto foi aprovado pelo Comitê de Ética em pesquisa do Incor sob número CAPesq 0140/11 (Anexo A).

\subsection{Pacientes}

Os pacientes foram informados sobre a pesquisa e os que concordaram em participar assinaram o assinaram o Termo de Consentimento Livre Esclarecido (Anexo B).

Posteriormente foi realizado pedido de adendo aos critérios de inclusão de pacientes com apneia grave (Anexo C).

Consideramos elegíveis pacientes do Ambulatório de sono do Incor de ambos os sexos, com idade entre 20 e 65 anos, com diagnóstico clínico e polissonográfico recente de ronco primário, AOS leve e moderada e pacientes com AOS grave que se recusaram a utilizar o CPAP.

Foram excluídos pacientes que apresentassem uma das seguintes condições: IMC superior ou igual a $35 \mathrm{~kg} / \mathrm{m}^{2}$; tabagistas; etilistas; malformações craniofaciais que restringissem a realização do tratamento (sinais de deformidades dentoesqueléticas, traumatismos crânioencefálicos e síndromes genéticas); desdentados e/ou usuários de próteses dentárias totais; uso regular de medicações hipnóticas do sistema nervoso central; história pregressa de acidente vascular cerebral; distrofias neuromusculares; insuficiência cardíaca congestiva; doença coronariana; uso de implante metálico (válvula cardíaca, clip de aneurisma cerebral, estilhaço metálico no corpo); uso de implante eletrônico (marcapasso cardíaco, neuroestimulador, implante coclear); claustrofobia (medo de lugares fechados); tatuagens; doença obstrutiva nasal grave que restrinjam o tratamento (foram excluídos pacientes com as seguintes alterações isoladas ou associadas, no exame de nasofibrolaringoscopia: septo nasal com desvio grau 3 associado à hipertrofia de conchas nasais, adenoide hipertrófica, hipertrofia de tonsila palatina grau 3 e 4 e pólipo nasal); pacientes que já tivessem iniciado outras formas de tratamento da apneia (placa de avanço mandibular ou CPAP); pacientes já submetidos à cirurgia faríngea e pacientes que não tivessem disponibilidade para comparecer semanalmente no Laboratório do Sono. Estas alterações foram excluídas pois poderiam limitar ou comprometer a pesquisa.

Os pacientes foram avaliados ao início e final do estudo, avaliados no Laboratório do Sono da Disciplina de Pneumologia do Instituto do Coração do Hospital das Clínicas da Faculdade de Medicina da Universidade de São Paulo, por meio dos seguintes instrumentos. 


\subsection{Questionários}

\subsubsection{Ronco}

O ronco foi avaliado em frequência e intensidade por meio da aplicação de parte das perguntas derivadas do questionário de Berlim. Para intensidade do ronco, utilizou-se a contagem de 1 a 3: (1) tão alto quanto a respiração; (2) tão alto quanto falar; (3) muito alto, ouve-se do outro quarto. Para frequência, utilizou-se contagem de 0 a 4: (0) nunca ou quase nunca; (1) 1 a 2 vezes por mês; (2) 1 a 2 vezes por semana; (3) 3 a 4 vezes por semana; (4) quase todo dia ${ }^{[69]}$ (Anexo F).

\subsubsection{Sonolência: Escala de Sonolência de Epworth (ESS)}

A sonolência diurna foi avaliada por meio do questionário da Escala de Sonolência de Epworth (ESS), que é um questionário simples, auto administrado, apresentado para proporcionar uma medição geral do nível de sonolência diurna dos pacientes. Avalia-se a chance de cochilar com a pontuação de 0 a 3 , sendo (0) nenhuma, (1) pequena chance de cochilar, (2) moderada chance de cochilar e (3) alta chance de cochilar. Em situações específicas como: chance de cochilar sentado e lendo; assistindo televisão; sentado em lugar público (cinema, igreja, sala de espera); como passageiro de trem, carro ou ônibus andando uma hora sem parar; deitando-se para descansar à tarde quando as circunstâncias permitem; conversando com alguém; sentado calmamente após o almoço (sem álcool); dirigindo um carro enquanto para por alguns minutos ao pegar um trânsito intenso. A ESS com pontuação até 10 é considerado dentro da normalidade, acima de dez pontos é considerada sonolência diurna excessiva ${ }^{[70]}$ (Anexo G).

\subsubsection{Qualidade de sono: Pittsburgh}

Avaliou-se a qualidade do sono por meio do questionário de Pittsburgh. O questionário padrão foi estruturado especificamente para avaliar a qualidade do sono. Segundo o autor possui alta sensibilidade e especificidade, permitindo distinguir indivíduos com distúrbio do sono e com boa qualidade de sono (Anexo $\mathrm{H})$.

A pontuação global é composta pela soma de sete componentes, que podem ser considerados individualmente e que recebem valores que variam de zero a três. Os componentes: 1- Qualidade subjetiva do sono; 2- Latência do sono; 3- Duração do sono; 4Eficiência habitual do sono; 5-Distúrbios do sono; 6- Uso de medicação para dormir; 7Sonolência diurna e distúrbios durante o dia. ${ }^{[71]}$

Pontuação global superior a cinco pontos é indicativa de sono de má qualidade e da presença de distúrbios. ${ }^{[71]}$ 


\subsection{Avaliação fonoaudiológica}

Antes da avaliação foi realizada uma anamnese com dados do histórico do paciente (Anexo I).

A avaliação fonoaudiológica foi realizada por meio da Avaliação fonoaudiológica para AOS (Anexo J). Baseada no protocolo MGBR usado na área de motricidade orofacial com escores por meio da atribuição de aspectos quantitativos e qualitativos. Maior pontuação significa maior alteração apresentada pelo paciente, menor pontuação resulta na menor alteração. Ela permite em avaliação pós terapêutica a comprovação da eficácia da terapêutica empregada nos diferentes distúrbios miofuncionais orofaciais. ${ }^{[72]}$

O protocolo de exame clínico avalia a postura corporal, análise morfológica extra e intraoral, avaliação da mobilidade, tonicidade e sensibilidade orofacial, além das funções de respiração, mastigação, deglutição, fala e voz. Incluiu aspectos avaliados por profissionais da área de Medicina do Sono e excluiu subitens pouco relacionados a AOS.

Foram incluídas medidas antropométricas como peso e altura e derivando-se o índice de massa corpórea (IMC), circunferência abdominal (CA) e circunferência cervical (CC). Adicionou-se a classificação de Friedman para tonsilas palatinas e posicionamento da língua em relação ao palato, ${ }^{[73]}$ altura do dorso lingual, forma da úvula, mobilidade de língua com abaixamento do dorso lingual espontâneo e por estimulação do reflexo, contração da úvula no bocejo e na emissão do [a] e ativação da musculatura propulsora e retratora da língua. Foram excluídas algumas medidas de face, movimento mandibular e alguns aspectos do frênulo lingual, além de simplificar alterações nos distúrbios da fala e da voz.

Após as adaptações realizadas a esse protocolo, a avaliação fonoaudiológica foi padronizada e realizada sempre pelo mesmo pesquisador por meio da observação, palpação da musculatura e visualização da mobilidade da musculatura e das funções orofaciais.

A avaliação fonoaudiológica orofacial para AOS é composto pelos seguintes ítens:

\subsubsection{Medidas antropométricas:}

Peso e altura e derivando-se o índice de massa corpórea (IMC) calculado como peso $(\mathrm{Kg}) /$ altura $\left(\mathrm{m}^{2}\right)$, circunferência abdominal (CA) (medida medial entre a asa do ílio e a última costela flutuante) e circunferência cervical (CC) (padrão na proeminência laríngea).

\subsubsection{Medidas faciais, oclusais e movimento mandibular}

Foi mensurado com paquímetro dos terços superior, médio e inferior da face; trespasse vertical e trespasse horizontal; abertura máxima da boca e abertura máxima da boca com a ponta da língua na papila incisiva. 
Para os itens que se seguem foi realizada a somatória dos escores obtidos em cada um dos itens da avaliação, quanto maior o valor obtido, pior o resultado. O resultado final da avaliação é a pontuação.

A seguir, cada item da avaliação será explicado e o valor da pontuação, atribuído ao que foi observado e classificado, estará entre parênteses.

4.3.3. Pontuação da análise da postura corporal:

Na observação do paciente em posição frontal foram avaliadas e pontuadas: posição da cabeça (normal (0), com rotação à direita (1), com rotação à esquerda (1), com inclinação à direita (1), com inclinação à direita (1)); posição dos ombros (normal (0), com elevação à direita (1) e com elevação à esquerda (1)).

Na observação do paciente em posição lateral, avaliou-se e pontuou-se: posição da cabeça (normal (0), com elevação à direita (1), com elevação à esquerda (1)); posição dos ombros (normal (0) e com rotação anteriorizada (1)).

A pontuação pode variar entre 0 e 7 .

\subsubsection{Pontuação do exame extraoral:}

Na palpação dos músculos temporal e masseter ao solicitar apertar os dentes. Avaliou-se e pontuou-se seguindo os critérios: normal (0), contração primeiro à direita (1), contração primeiro à esquerda (1).

$\mathrm{Na}$ observação da postura de mandíbula e pontuação seguiu-se os seguintes critérios: normal (0), semi abaixada (1), abaixada (2) ou em apertamento dentário (2).

Na visualização dos lábios e pontuação seguiu-se os critérios: posição habitual (fechados (0), fechados com tensão (1), entreabertos (2), ora abertos ora fechados (2), fechados em contato dentário (3) ou abertos (4)); presença de saliva (deglutida (0), acumulada na comissura direita (1), acumulada na comissura esquerda (1), acumulada no lábio inferior (1) e presença de baba (2)); aspecto da mucosa (normal (0), com marcas dentárias (1), ressecada (1) e ferida (1)); forma e comprimento (lábio superior normal (0), lábio superior em asa de gaivota (1), lábio inferior normal (0), lábio inferior com eversão discreta (1) e comprimento do lábio superior (cobre $2 / 3$ dos incisivos, cobre mais que $2 / 3$ dos incisivos (1) e cobre menos que $2 / 3$ dos incisivos (1)).

A pontuação variar entre 0 e 21. 


\subsubsection{Pontuação do exame intraoral}

$\mathrm{Na}$ inspeção da mucosa e frênulos labiais e pontuação seguiu-se os critérios: aspecto da mucosa (normal (0), ferida (1)); fixação do frênulo superior (normal (0) ou baixa (1)); espessura do frênulo superior (normal (0) ou alterada (1)).

$\mathrm{Na}$ visualização da mucosa das bochechas e pontuação seguiu os critérios: normal (0), marcas dentárias à direita (1), marcas dentárias à esquerda (1), linha alba à direita (1), linha alba à esquerda (1), ressecamento à direita (1), ressecamento à esquerda (1), ferida à direita (1), ferida à esquerda (1).

$\mathrm{Na}$ visualização da língua foram pontuados os critérios: presença de sulco longitudinal (adequado (0) ou profundo (1)); posição habitual (acoplada (0), no assoalho (1) ou interdental (1)); simetria (presente (0) ou ausente (1)); largura (adequada (0) ou aumentada (1)); altura do dorso (adequada (0), aumentada (1) ou muito aumentada (2)); tremor (ausente (0), na posição habitual (1), ao protrair (1), nos movimentos (1)); mucosa (normal (0), geográfica (1), fissurada (1), marcada por dentes (1), marcada por aparelho (1), ferida (1)); extensão do frênulo (extensão normal (0), curto (1), fixação na parte média (0), fixação anterior à parte média (1), fixação no ápice (2)).

Na classificação de Friedman para língua (Friedman Tongue Position - FTP) após solicitar ao paciente para que degluta e abra a boca mantendo a língua relaxada dentro da boca, a pontuação seguiu os critérios: FTP 1 (0), FTP 2 (1), FTP 3 (2), FTP 4 (3).

$\mathrm{Na}$ visualização do palato duro e pontuação seguiu-se os critérios: profundidade (normal (0), reduzida (1) ou aumentada (2)); largura (normal (0), aumentada (1) ou reduzida (2)).

Na visualização do palato mole e pontuação seguiu-se os critérios: simetria (presente (0) ou ausente (1)); extensão (adequada (0), longa (1) ou muito longa (2)).

Na visualização da úvula e pontuação seguiu-se os critérios: normal (0), longa (1), muito longa (2), desviada para direita (1), desviada para esquerda (1).

Na classificação de Friedman para tonsilas palatinas e pontuação seguiu-se os critérios: tonsilas ausentes (0), tonsila grau 1 (1), tonsila grau 2 (2), tonsila grau 3 (3) e tonsila grau 4 (4).

$\mathrm{Na}$ avaliação e pontuação dos aspectos dentais e da oclusão seguiu-se os critérios: conservação dentária (boa (0), regular (1) ou ruim (2)); conservação gengival (boa (0), regular (1) ou ruim (2)); linha média (adequada (0), desviada para a direita (1) ou desviada para a esquerda(1)); oclusão (normal (0) ou alterada (1)); classificação de Angle para os lados direito e esquerdo (Classe 1 (0), Classe II (1) ou Classe III (1)); alteração vertical (ausente (0), mordida em topo (1), sobremordida (1), mordida aberta anterior (1), mordida aberta posterior (1)); alteração transversal (ausente (0) ou mordida cruzada posterior (1)). 
A pontuação varia entre 0 e 60 .

\subsubsection{Mobilidade}

$\mathrm{Na}$ avaliação da mobilidade de lábios, solicitou-se os movimentos de: protrusão labial com lábios fechados (bico fechado), protrusão labial com lábios abertos (bico aberto), retração labial com lábios fechados (sorriso aberto), retração labial com lábios abertos (sorriso aberto), lábios estirados para dentro, abaixar o lábio inferior ("mostrar dentes inferiores") e elevar lábio superior e asa do nariz ("cara de cheiro ruim"). A pontuação seguiu os critérios: normal (0), aproximado (1), tenta realizar (2) ou não realiza (3).

$\mathrm{Na}$ avaliação da mobilidade da língua, solicitou-se os movimentos de: protrair, elevar na papila incisiva, elevar no lábio superior, tocar a comissura labial direita, tocar a comissura labial esquerda, tocar internamente a bochecha direita, tocar internamente a bochecha esquerda, estalar o ápice, estalar o corpo, sugar a língua no palato e vibrar. A pontuação seguiu os critérios: normal (0), aproximado (1), tenta realizar (2) ou não realiza (3). Avaliou-se o abaixamento do dorso espontaneamente e o abaixamento do dorso através da estimulação do reflexo, utilizando toques de espátula na região do dorso da língua. A pontuação os critérios: normal (0), lentificado (1), muito lentificado (2) ou ausente (3).

$\mathrm{Na}$ avaliação da mobilidade de bochechas, solicitou os movimentos de inflar as bochechas simultaneamente e alternadamente. A pontuação seguiu os critérios: normal (0), aproximado (1), tenta realizar (2) ou não realiza (3).

$\mathrm{Na}$ avaliação da mobilidade de véu palatino, solicitou-se a emissão da vogal [a]. A classificação e a pontuação seguiram os critérios: movimento normal (0), movimento reduzido (1) ou movimento ausente (2).

$\mathrm{Na}$ avaliação da mobilidade da úvula, solicitou-se: emissão da vogal [a] e bocejo. A classificação e a pontuação seguiram os critérios: movimento normal (0), movimento reduzido (1) ou movimento ausente (2).

$\mathrm{Na}$ avaliação da mobilidade mandibular, solicitou-se: os movimentos de abertura, lateralidade à direita e à esquerda. A classificação e a pontuação seguiram os critérios: normal (0), reduzido (1), aumentado (1) ou não realiza (2). Observou-se e pontuou-se, também: presença de desvio (1) e dor (1).

A pontuação da mobilidade varia entre 0 e 87.

\subsubsection{Tônus}

Na observação visual e palpação do lábio superior e inferior, mento, sulco mento labial, assoalho da boca e bochechas direita e esquerda. Para pontuação da musculatura da bochecha, 
observou-se a ação da contração do músculo bucinador, com o dedo indicador posicionado internamente à bochecha e solicitou-se a contração A classificação e a pontuação seguiu os critérios: normal (0), reduzido (1) ou aumentado (1).

A pontuação dos tônus varia entre 0 e 7 .

4.3.8 Ativação da musculatura da língua:

$\mathrm{Na}$ ativação da musculatura extrínseca propulsora e retratora da língua, solicitou-se a manutenção da língua no assoalho bucal e abaixamento o dorso da língua. Observou-se (ou não) a ativação da musculatura retratora da língua. A classificação e a pontuação seguiram os critérios: normal (0), tônus da musculatura retratora reduzido (1), tônus da musculatura propulsora aumentado (1).

A pontuação varia entre 0 e 2 .

4.3.9 Dor à palpação:

Pressionou bilateral as estruturas mais próxima possíveis do temporal anterior, masseter superficial, trapézio, esternocleidomastoideo e articulação temporomandibular. A classificação e a pontuação obedeceram aos critérios: dor ausente (0), dor presente à direita (1), dor presente à esquerda (1).

A pontuação varia entre 0 e 10.

\subsubsection{Funções orais}

$\mathrm{Na}$ avaliação da respiração observou-se: tipo respiratório (médio/inferior (0) ou médio/superior (1)); modo (nasal (0), oronasal (1) ou oral (2)); fluxo nasal utilizou-se o espelho de Glatzel (simétrico ao chegar (0), reduzido à direita (1), reduzido à esquerda (1), simétrico após a limpeza (0), reduzido à direita após a limpeza (1), reduzido à esquerda após a limpeza (1)); possibilidade de uso nasal (2 minutos ou mais (0), entre 1 e 2 minutos (1) ou menos que 1 minuto (2)).

$\mathrm{Na}$ avaliação da mastigação, ofereceu-se bolacha ao paciente. A incisão do alimento classificou-se e pontuou-se de acordo com o local da incisão: anterior (0) e lateral (1). A trituração do alimento classificou-se e pontou-se de acordo com os seguintes critérios: eficiente (0), ineficiente (1), com dentes posteriores (0), com dentes anteriores (1) e com a língua (1). O padrão mastigatório classificou-se e pontuou-se de acordo com os seguintes critérios: bilateral alternado (0), unilateral preferencial (0), bilateral simultânea (1) ou unilateral crônico (2). No fechamento labial observou-se e pontuou-se: sistemático (0), assistemático (1) ou ausente (2). Quanto à velocidade da mastigação, observou-se e pontuou- 
se: se adequada (0), aumentada (1) ou diminuída (1). Observou-se a ausência (0) ou presença (0) de ruídos e ausência (0) ou presença (1) de contrações musculares atípicas. Ao paciente questionou-se o lado preferencial para a mastigação e a pontuação seguiu-se os critérios: direito e esquerdo (0), direito (1), esquerdo (1) ou não soube responder (0). Ao paciente questionou-se: ausência (0) ou presença (1) de dor ao mastigar e ausência (0) ou presença (1) de ruído na articulação temporomandibular.

$\mathrm{Na}$ avaliação da deglutição, realizou-se duas provas. Na primeira prova, ofereceu-se bolacha ao paciente e observou-se o momento da deglutição: fechamento labial adequado (0), parcial (1) ou ausente (2). Observou-se e pontuou-se a postura da língua durante a deglutição: atrás dos dentes (0), contra os dentes (1) ou entre os dentes (2). Observou-se a postura do lábio inferior e pontuada: em contato com o superior (0) ou atrás dos dentes incisivos superiores (1). A contenção do alimento classificou-se e pontuou-se se adequada (0), parcial (1) ou inadequada (2). Observou-se a contração do músculo orbicular da boca, se adequada (0), pouca (1) ou acentuada (2). Observou-se a contração do músculo mentual, se ausente (0), pouca (1) ou acentuada (2). Observou-se a contração da musculatura cervical, se ausente (0), pouca (1) ou acentuada (2). Observou-se ainda: ausência (0) ou presença (1) de movimento de cabeça, ausência (0) ou presença (1) de ruídos durante a deglutição, coordenação adequada (0), presença de engasgo (1) ou tosse (1).

Após deglutir, observou-se a ausência (0) ou presença (1) de resíduos.

$\mathrm{Na}$ segunda prova, ofereceu-se água para o paciente. Observou-se e pontuou-se os mesmos critérios da primeira prova. Posteriormente questionou-se sobre ausência (0) ou presença (1) de dificuldades para deglutir e posição da língua durante a deglutição: atrás dos dentes superiores (0), atrás dos dentes inferiores (1), entre os dentes (2) ou não sabe (0).

A pontuação varia entre 0 e 61 .

Observou e descreveu-se as alterações de voz e fala.

O resultado da avaliação varia entre (entre 0 e 255).

\subsubsection{Avaliação fonoaudiológica específica para AOS}

Os itens considerados mais importantes na avaliação foram escolhidos de acordo com a musculatura específica trabalhada na AOS e ronco criando subpontuação deste protocolo. Os itens foram: classificação de Friedman para língua, mobilidade de véu palatino, contração de úvula, tônus da musculatura orofacial e ativação da musculatura da língua, esta sub pontuação varia entre 0 e 20. 


\subsection{Nasofibrolaringoscopia}

Os pacientes realizaram o exame de nasofibrolaringoscopia de acordo com os critérios de exclusão do protocolo de pesquisa.

\subsection{Polissonografia}

Os sujeitos realizaram uma PSG basal durante a noite (Alice 5, Philips Respironics, Murrysville, PA). A monitorização incluiu eletroencefalograma, eletrocardiograma, eletromiograma submentoniana e tibial, oximetria de pulso, medições de fluxo de ar (termístor oronasal e cânula de pressão) e movimentação da caixa torácica e abdominal através de cintas. Apneia foi definida como a redução de $90 \%$ do fluxo de ar por pelo menos 10 segundos. Hipopneia foi definida como uma redução significativa (>30\%) do fluxo por pelo menos 10 segundos associada à dessaturação de oxigênio de pelo menos 3\% ou despertar. O IAH foi calculado como o número total de eventos respiratórios (apneias mais hipopneias) por hora de sono. ${ }^{[74]}$

O ronco primário foi definido como presença de ronco e $\mathrm{IAH}<5$ eventos/hora de sono, AOS leve IAH $\geq 5$ e $<15$ eventos por hora de sono e AOS moderada IAH $\geq 15$ e $<30$ eventos por hora de sono, e a AOS grave por IAH $\geq 30$ eventos/hora de sono. ${ }^{[8]}$

A montagem da polissonografia foi realizada e monitorada durante toda a noite no Laboratório do Sono, por um técnico especializado. Os exames de polissonografia foram laudados sempre pelo mesmo pesquisador, cego para a identificação do grupo e momento.

\subsection{Ressonância magnética (RM) da via aérea superior}

\subsubsection{Aquisição das imagens}

Após adequado estabelecimento da coleta das imagens de ressonância magnética da VAS, todos foram realizados de modo idêntico. Antes foram realizadas coletas incompletas conforme será relatado nos resultados.

Os sujeitos foram posicionados de acordo com o plano de Frankfort (retas paralelas entre reta na orbita dos olhos e trágus da orelha), perpendicular ao scanner da mesa. Foi utilizada uma bobina neurovascular e almofadas de espuma foram colocadas entre a cabeça e a bobina e um trigger para verificar a respiração.

Antes e durante o exame os pacientes foram orientados a manter a boca fechada e língua na posição habitual, respirar normalmente pelo nariz e não movimentar a cabeça. Além disso foram orientados a engolir antes de iniciar a coleta e abster-se da deglutição durante todo o 
ruído intenso e após o ruído orientados que já poderiam engolir. As coletas foram realizadas com os pacientes acordados, conversando com os pacientes após cada sequência.

Os exames de imagem foram obtidos no aparelho General Eletric Medical - Milwaukee, WI -1,5 Tesla. Foram obtidas imagens axiais e sagitais.

\subsubsection{Medidas e análise}

As análises das imagens foram realizadas pela equipe do grupo do Dr Richard Schwab de forma cega. Os exames foram enviados via Dropbox apenas com as iniciais de cada paciente.

As imagens foram obtidas em ponderação T1 na sequência eco spin nos planos axiais e sagitais antes e depois da terapia e foram manualmente analisadas utilizando o software Amira 5.4.3 (Visage Imaging, San Diego CA), no Pulmonary Sleep Imaging Center (University of Pennsylvania).

O objetivo principal foi a identificação das modificações volumétricas da RM nos tecidos moles. As imagens de RM foram divididas em dois domínios: análise volumétrica dos tecidos moles e quantificação da gordura intramuscular da língua.

As análises volumétricas do tecido mole foram obtidas utilizando um pacote de software designado especificamente para análise da VAS. A equipe do Dr Richard Schwab utilizou o software Amira em estudos anteriores examinando a anatomia da VAS e foi anteriormente descrita e validada. Os volumes das estruturas moles da VAS foram obtidos utilizando algoritmos de reconstrução computacional. O primeiro passo nesse processo é utilizar um programa de segmentação bidimensional que permite o operador selecionar tecidos em cada fatia do contingente de dados das MRI. A cada tecido que é segmentado o módulo das duas dimensões de segmentação modificam o valor da cor de cada pixel nas estruturas do tecido com um operador específico de cor. Ao finalizar o operador segmenta apropriadamente as estruturas de tecido mole da região cranial até a região mais caudal, permitindo a criação de uma representação tridimensional de cada tecido da estrutura ao longo de todo o intervalo da VAS. Depois de cada tecido da estrutura ser segmentado o operador utiliza um algoritmo de quantificação com gama de cores para computar o volume ocupado em milímetros por cada estrutura ao longo de todo o intervalo do conjunto de dados.

$\mathrm{O}$ volume das seguintes estruturas foi obtido por meio das imagens axiais e sagitais: via aérea segmentada em três regiões como via aérea retropalatal (atrás do palato mole), via aérea entre palato mole e epiglote (entre final do palato mole e epiglote), via aérea retroglossal (posterior a epiglote); palato mole; língua (genioglosso, longitudinal superior e inferior, vertical, transverso e músculo geniohioideo); outras partes da língua (músculos hioglosso, 
milohioideo, estiloglosso e digástrico); paredes laterais da faringe retropalatal e retroglossal; e músculo pterigoideo medial.(Figura 7)
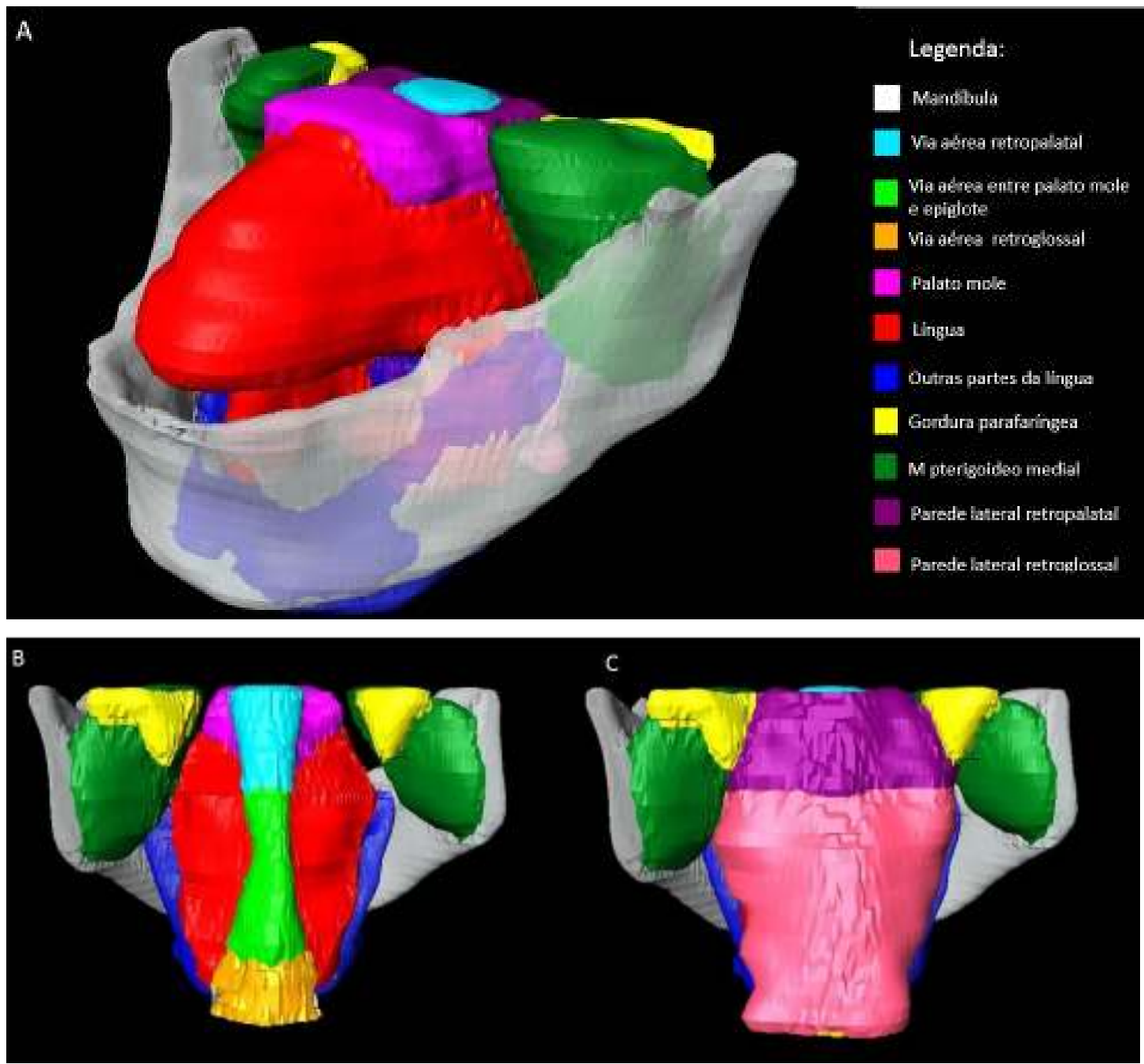

FONTE: Pulmonary Sleep Imaging Center -University of Pennsylvania

Figura 7: Reconstrução volumétrica da VAS; A: VAS com estruturas visão em 3D; B: VAS com estruturas visão posterior; C: VAS com estruturas visão mais posterior

-Total das estruturais retropalatais dentro da mandíbula (terp M) que é o volume incluindo todas as estruturas iniciando do primeiro corte que aparecia o palato mole ou a úvula até o corte em que a o palato mole afunilava/desaparecia dentro da mandíbula.

-Via aérea retropalatal (varp M) que é o volume que a via aérea ocupa dentro do terp M.

-Língua retropalatal (língua rp M) que é o volume que a língua ocupa dentro do terp M.

-Parede lateral retropalatal (plrp M) que é o volume que as paredes laterais ocupam dentro do terp M.

-Palato mole retropalatal (pmrp M) que é o volume que o palato mole ocupa dentro do terp M. 
-Gordura parafaríngea retropalatal (gpfrp M) que é o volume que a gordura parafaríngea ocupa dentro do terp $\mathrm{M}$.

-Total das estruturais retroglossais dentro da mandíbula (terg M): volume incluindo todas as estruturas iniciando do primeiro corte que aparecia a epiglote até o corte antes do palato mole dentro da mandíbula.

-Via aérea retroglossal (varg M) que é volume que a via aérea ocupa dentro do terg M.

-Língua retroglossal (língua rg M) que é o volume que a língua ocupa dentro do terg $\mathrm{M}$.

-Paredes laterais retroglossais (plrg M) que é o volume que as paredes laterais ocupam dentro do terg $\mathrm{M}$.

-Total das estruturais retropalatais dentro da mandíbula até plano anterior as pregas vocais (terp MV): volume incluindo todas as estruturas iniciando do primeiro corte que aparecia o palato mole ou a úvula até o corte em que a o palato mole afunilava/desaparecia dentro da mandíbula até as pregas vocais.

-Via aérea retropalatal (varp MV) que é volume que a via aérea ocupa dentro do terp MV.

-Língua retropalatal (língua rp MV) que é o volume que a língua ocupa dentro do terp MV.

-Paredes laterais retropalatal (plrp MV) que é o volume que as paredes laterais ocupam dentro do terp MV.

-Palato mole retropalatal (pmrp MV) que é o volume que o palato mole ocupa dentro do terp MV.

-Gordura parafaríngea retropalatal (gpfrp MV) que é o volume que a gordura parafaríngea ocupa dentro do terp MV.

-Total das estruturais retroglossais dentro da mandíbula até pregas vocais (terg MV): volume incluindo todas as estruturas iniciando do primeiro corte que aparecia a epiglote até o corte antes do palato mole dentro da mandíbula.

-Via aérea retroglossal (varg MV) que é volume que a via aérea ocupa dentro do terg MV.

-Língua retroglossal (língua rg MV) que é o volume que a língua ocupa dentro do terg MV.

-Parede lateral retroglossais (plrg MV) que é o volume que as paredes laterais ocupam dentro do terg MV.

De acordo com figura que se segue. (Figura 8) 


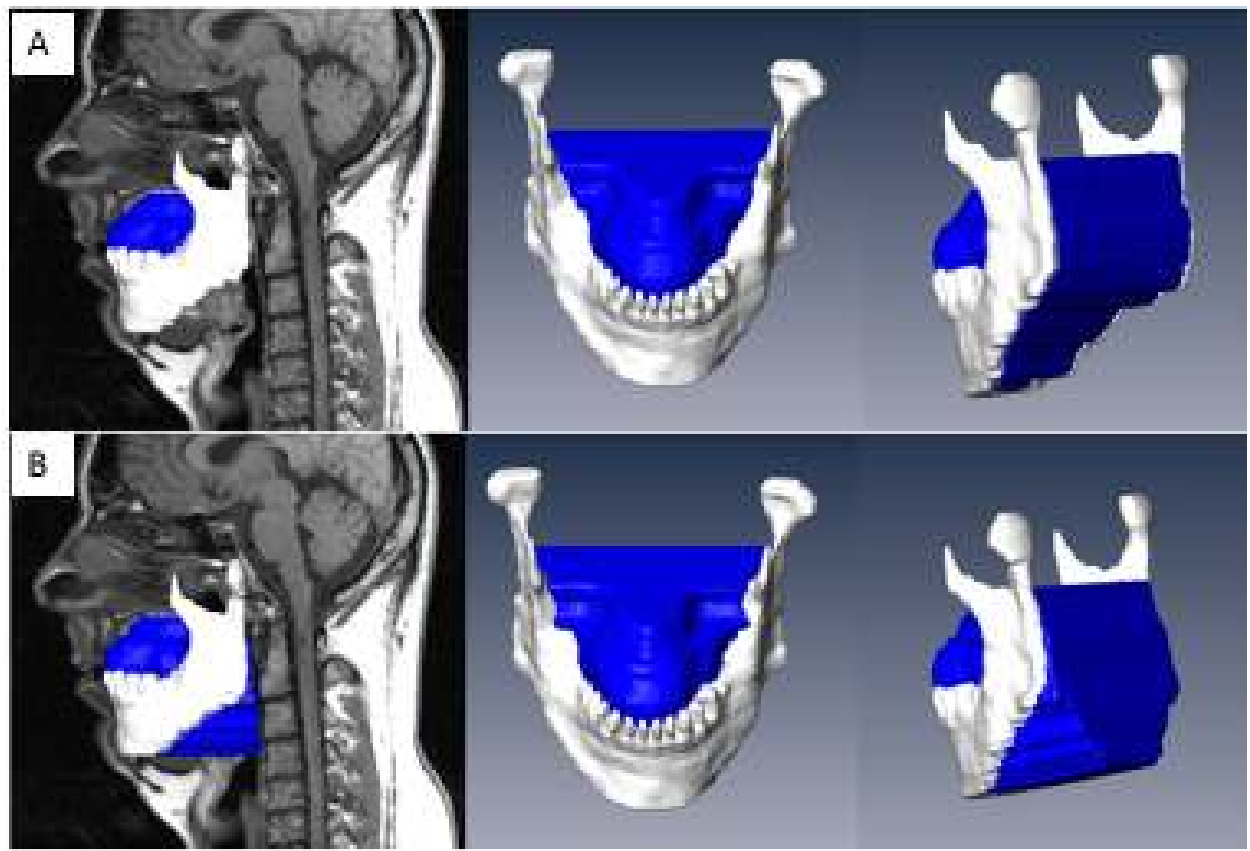

FONTE: Pulmonary Sleep Imaging Center -University of Pennsylvania

Figura 8: Reconstrução volumétrica da VAS; A: volume das estruturas contidas dentro da mandíbula; B: volume das estruturas contidas dentro mandíbula até as pregas vocais

Para análise da gordura da língua inicialmente foram realizadas as segmentações dos limites da língua determinadas por meio das imagens na sequência eco spin com sobrepostas às imagens do Dixon para apropriada visualização dos tecidos. Pois as imagens ponderadas de gordura geram uma indicação clara do tecido adiposo, mas os limites dos tecidos moles não são tão claros em comparação com as imagens de eco spin padrão. Em seguida, a gordura intramuscular é determinada utilizando um método de limar para identificar a gordura do resto da língua.

\subsection{Força e fadiga de língua}

A força e fadiga da língua foram avaliadas pelo desempenho do instrumento IOPI (Iowa Oral Performance Instrument - IOPI; Blaise Medical Inc., Hendersonville, Tennessee, EUA) que registra pressões da língua contra o palato através de um único bulbo de compressão de ar de aproximadamente $2 \mathrm{~cm} \times 1 \mathrm{~cm} \times 0,5 \mathrm{~cm}$. Este se conecta a um dispositivo que mostra as pressões registradas em quilopascal (KPa) em um display de LCD numérico. O bulbo é mantido na boca em posição anterior. O sujeito é orientado a pressionar com a ponta da língua o bulbo contra o palato duro. (Figura 9) 


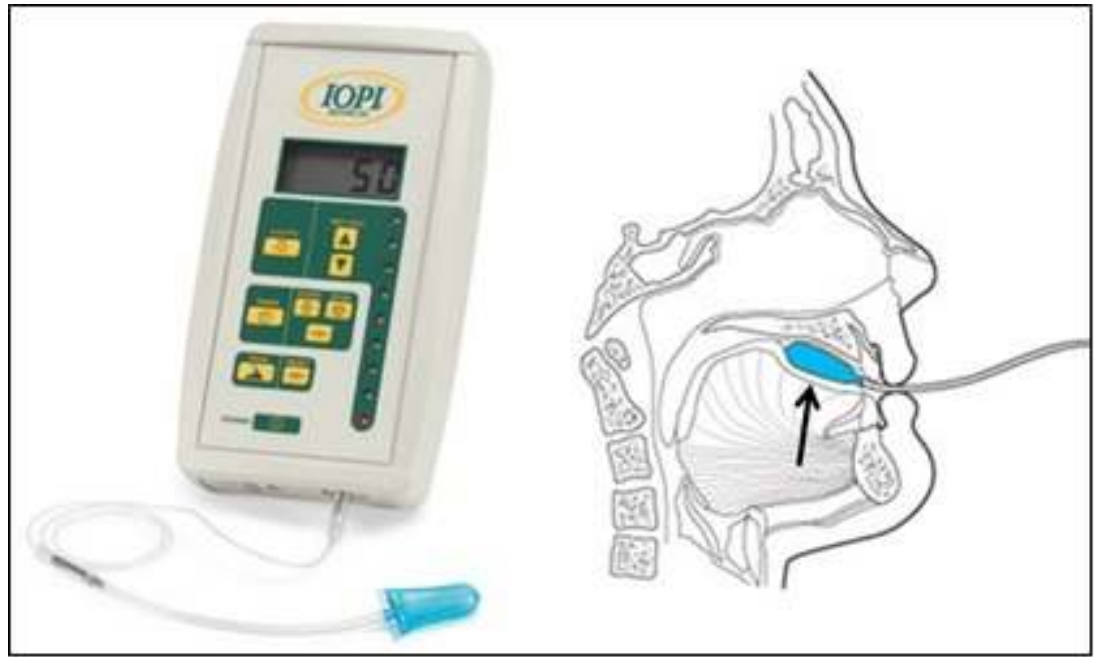

FONTE: http://www.iopimedical.com/

Figura 9: Equipamento do IOPI conectado com bulbo lingual e modelo com bulbo na posição correta com indicação de seta preta do movimento de pressão que deve ser exercido pela língua

Primeiramente foi realizado o teste de força de língua para medir a força máxima. $\mathrm{O}$ sujeito foi instruído a empurrar o bulbo com a máxima força possível. Foram realizados 4 testes com intervalo de 2 minutos entre eles. A máxima força foi selecionada. (Figura 10)

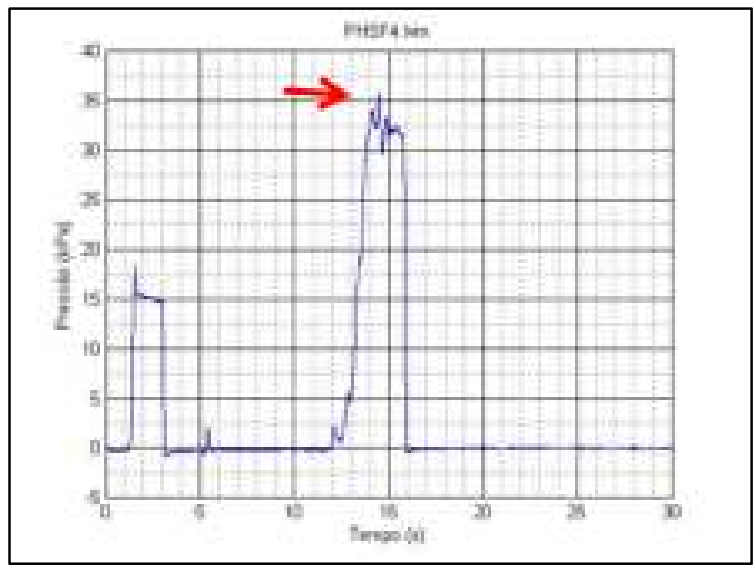

FONTE: Laboratório do Sono- Incor

Figura 10: Imagem (print screen) da tela demonstrando o Pico de Força

O teste de fadiga de língua foi realizado após 5 minutos de intervalo. $\mathrm{O}$ sujeito foi instruído a pressionar o bulbo contra o palato duro sustentando $50 \%$ do valor do máximo de força pelo máximo tempo possível. O tempo de fadiga foi considerado a partir do momento que o paciente alcançasse $50 \%$ pico de força até o momento que a pressão no bulbo caia $40 \%$ por pelo menos $0,5 \mathrm{seg}$ (fadiga) De acordo com em literatura. ${ }^{[75]}$ (Figura 11) 


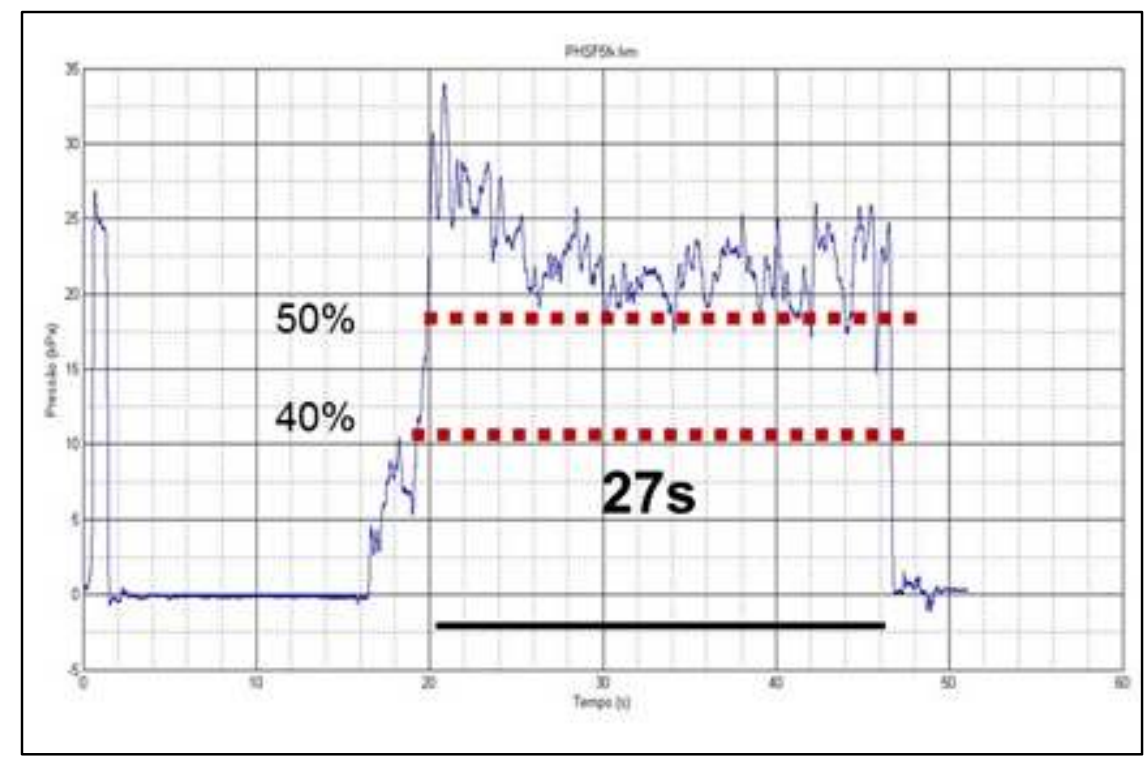

FONTE: Laboratório do Sono- Incor

Figura 11: Imagem (print screen) da tela demonstrando o tempo de fadiga considerado a partir do momento 27 segundo até o momento 47 segundos, com fadiga de 27 segundos, neste caso.

O aparelho tem um output que possibilita o envio do registro do sinal para análise em outros sistemas. Um sistema de aquisição de dados baseado em Instrumentação Virtual (LabVIEW, National Instruments, EUA) foi implementado em cooperação com o Professor Henrique Takachi Moriya do Laboratório de Engenharia Biomédica da Poli-USP. Este sistema de aquisição de dados permite a captação e armazenamento do sinal com uma frequência de amostragem de até $1 \mathrm{kHz}$ (quilohertz), o que permite a realização das análises do sinal no domínio do tempo e da frequência. (Figura 12). Foi desenvolvido um programa para a análise dos dados no MATLAB permitindo a análise do tempo de fadiga.

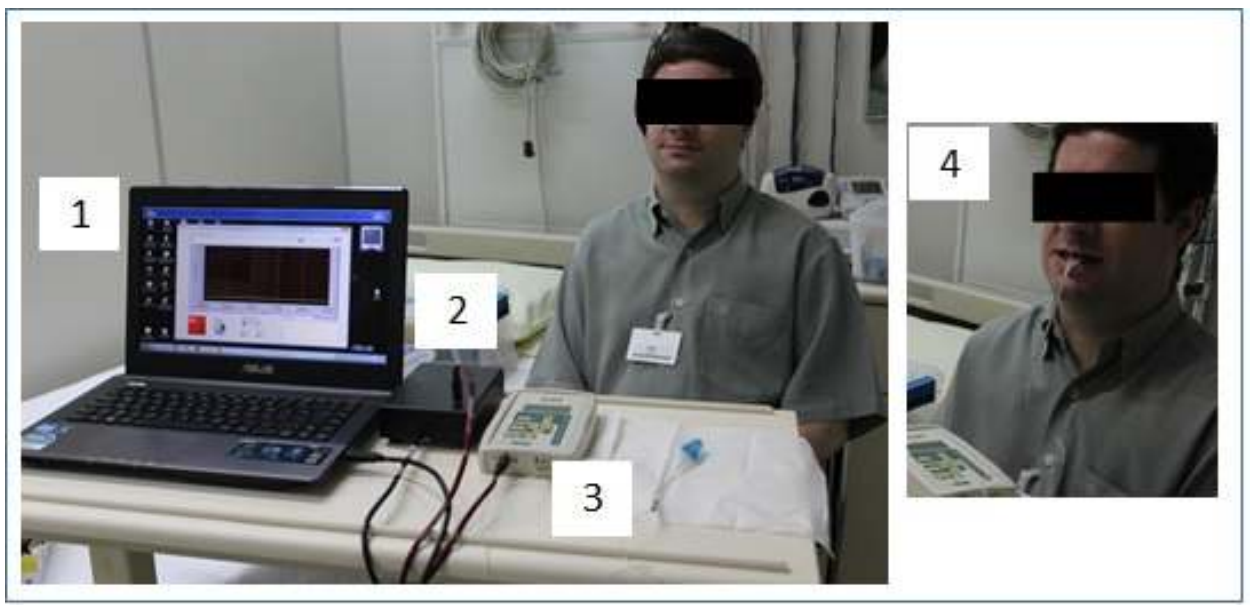

FONTE: Laboratório do Sono- Incor

Figura 12: Foto demonstrando: 1; Computador; 2: Sistema de aquisição de dados; 3: IOPI; 4: paciente com bulbo posicionado dentro da boca 


\subsection{Pressão crítica de fechamento (Pcrit)}

A indução do sono foi realizada no Laboratório do Sono, no período da manhã com duração aproximada de 4 horas. Os canais de PSG foram utilizados, com exceção das medições de fluxo de ar (termístor oronasal e cânula de pressão). O Midazolam foi diluído em uma solução salina com concentração de $1 \mathrm{mg} / 10 \mathrm{ml}$ e infundido em uma veia periférica gota a gota até ser observado o início do sono pela PSG. Caso o paciente acordasse e não fosse capaz de adormecer novamente após 10 minutos, a infusão de Midazolam era iniciada novamente.

As medidas da Pcrit foram realizadas em decúbito dorsal, mantendo a cabeça em posição neutra com apoio de dois travesseiros presos lateralmente por uma faixa com velcro, para que não fosse difícil movimentá-la.

Os pacientes utilizaram uma máscara nasal conectada a um pneumotacógrafo aquecido (modelo 3700A, Hans Rudolf, Kansas City, MO) e um transdutor de pressão diferencial (Validyne, Northbridge, CA) para a medição do fluxo inspiratório. A pressão da máscara foi medida continuamente e simultaneamente gravada em um canal separado do equipamento de PSG para o estadiamento do sono durante as quedas de pressão necessárias.

A pressão da máscara e o fluxo foram gravados em um computador pessoal usando um conversor analógico-digital (National Instruments, Austin, TX) e um software de aquisição de dados (LabView, National Instruments, Austin, TX). Um dispositivo de CPAP modificado (Philips Respironics, Murrysville, PA) capaz de gerar pressões positivas e negativas foi conectado à máscara. (Figura 13)

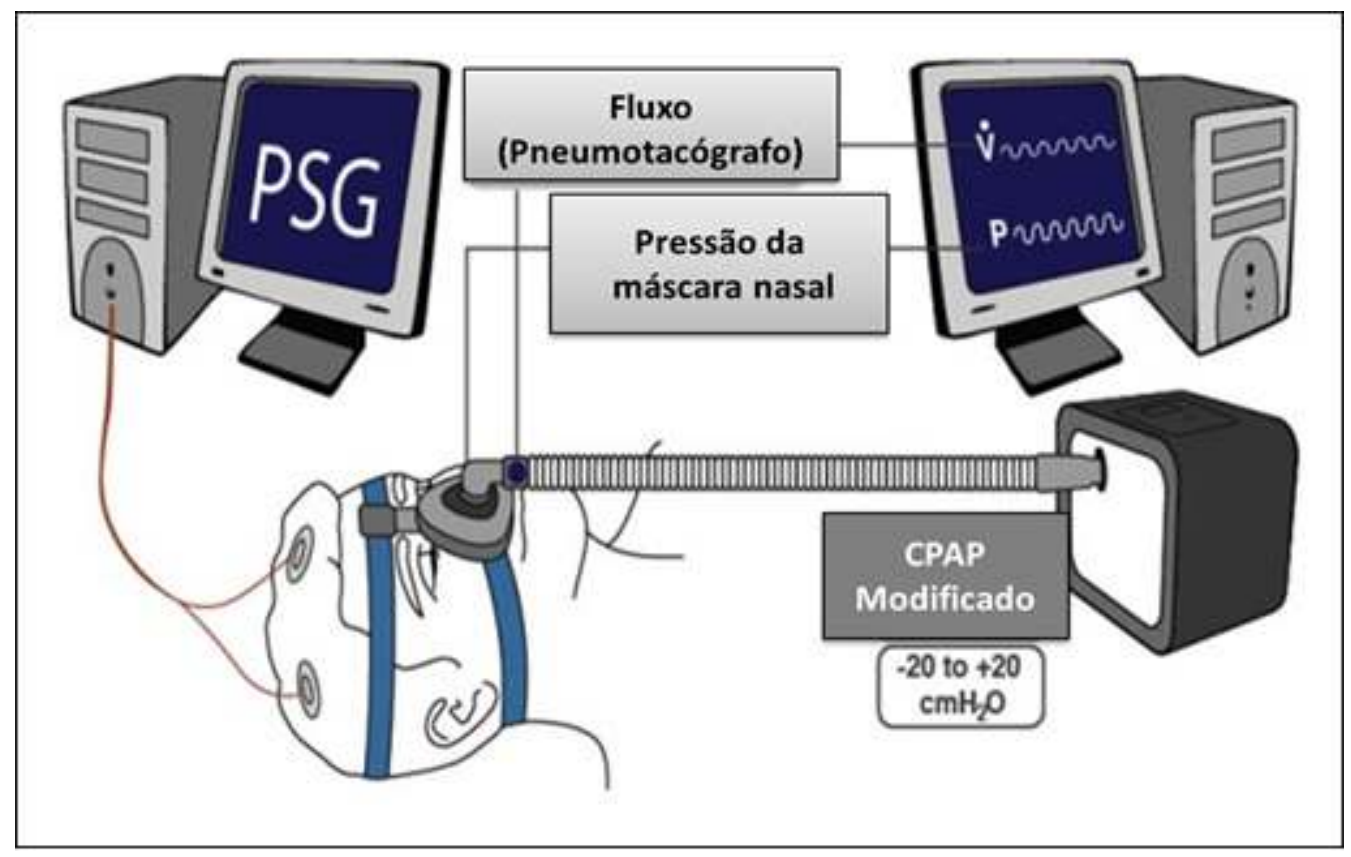

FONTE: Laboratório do Sono- Incor

Figura 13: Desenho da demonstração da realização do exame de Pcrit 
Após o início do sono, a pressão do CPAP foi aumentada a fim de suprimir a limitação de fluxo aéreo para cada paciente, denominada pressão de manutenção (holding pressure). Uma vez que pelo menos 2 minutos dos estágios 2 ou 3 fossem alcançados, a pressão de CPAP foi abruptamente reduzida em 1-2 $\mathrm{cmH}_{2} \mathrm{O}$ durante a expiração, por cinco respirações. A pressão do CPAP era então retornada à pressão de manutenção por um minuto antes de ser reduzida em mais 1-2 $\mathrm{cmH}_{2} \mathrm{O}$, por mais cinco respirações. Este processo de queda progressiva da pressão do CPAP prosseguia até que uma apneia obstrutiva ocorresse. Se houvesse despertar durante a queda de pressão, o CPAP era retornado à pressão de manutenção até que o paciente voltasse a atingir os estágios 2 ou 3. (Figura 14) Todo o processo de queda progressiva de CPAP até que ocorresse obstrução foi repetido 2-3 vezes em cada paciente.

Os dados foram analisados usando um software escrito em Matlab (The MathWorks, Inc., Natick, MA). O software foi desenvolvido para protocolo anterior, pelo engenheiro Henrique Takachi Moriya com a colaboração do Departamento de Bioengenharia da Escola Politécnica da Universidade de São Paulo.

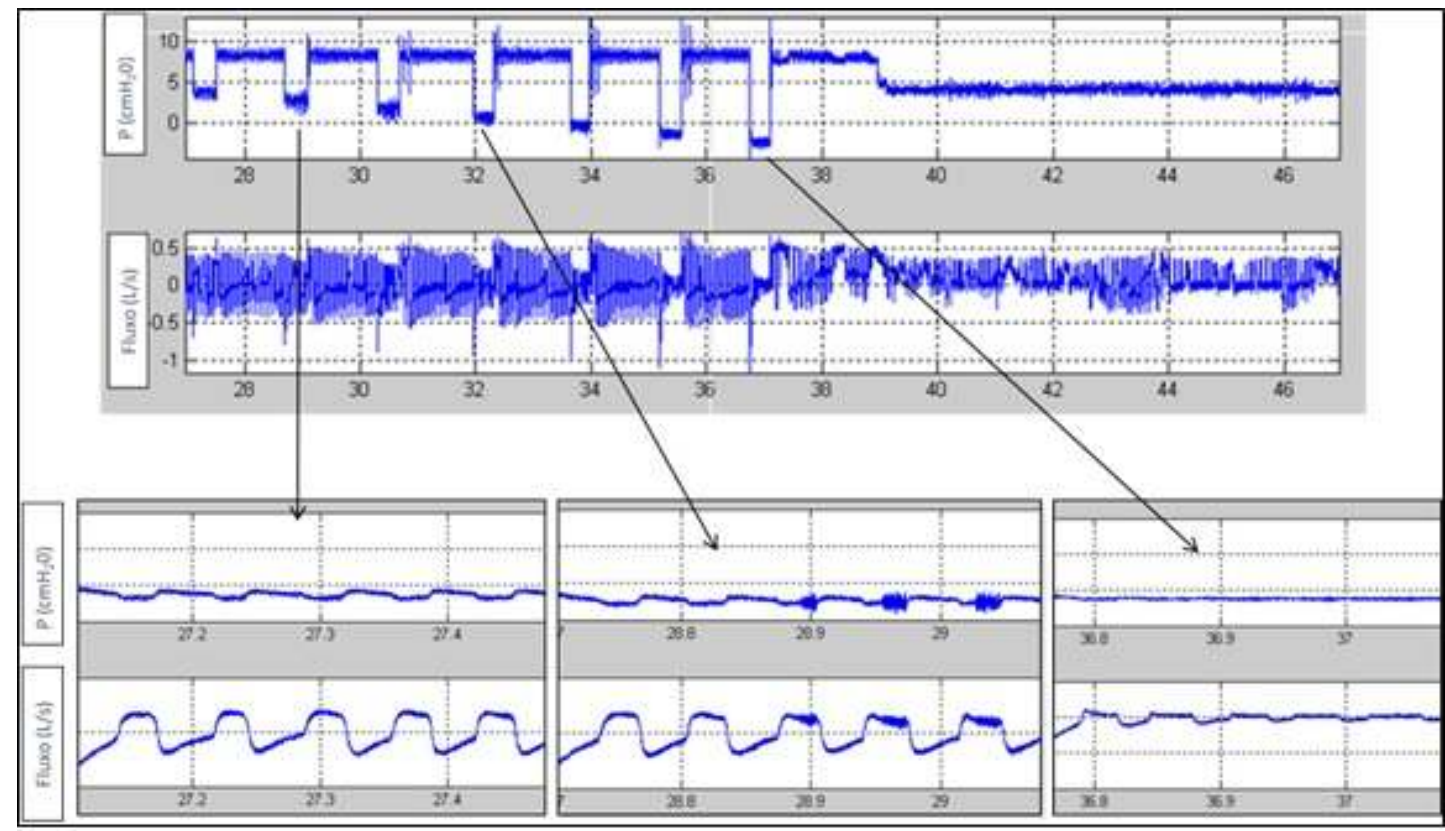

FONTE: Laboratório do Sono- Incor

Figura 14: Imagem (print screen) das telas demonstrando as reduções na pressão e consequentes restrições de fluxo

Para análise dos dados da Pcrit foi realizada a dispersão dos dados do pico de fluxo inspiratório (Vimax) da $3^{\mathrm{a}}, 4^{\mathrm{a}}$ e $5^{\mathrm{a}}$ respiração e gerado pontos para uma reta de regressão linear. A Pcrit foi determinada pela extrapolação da reta ao fluxo zero. (Figura 15) 


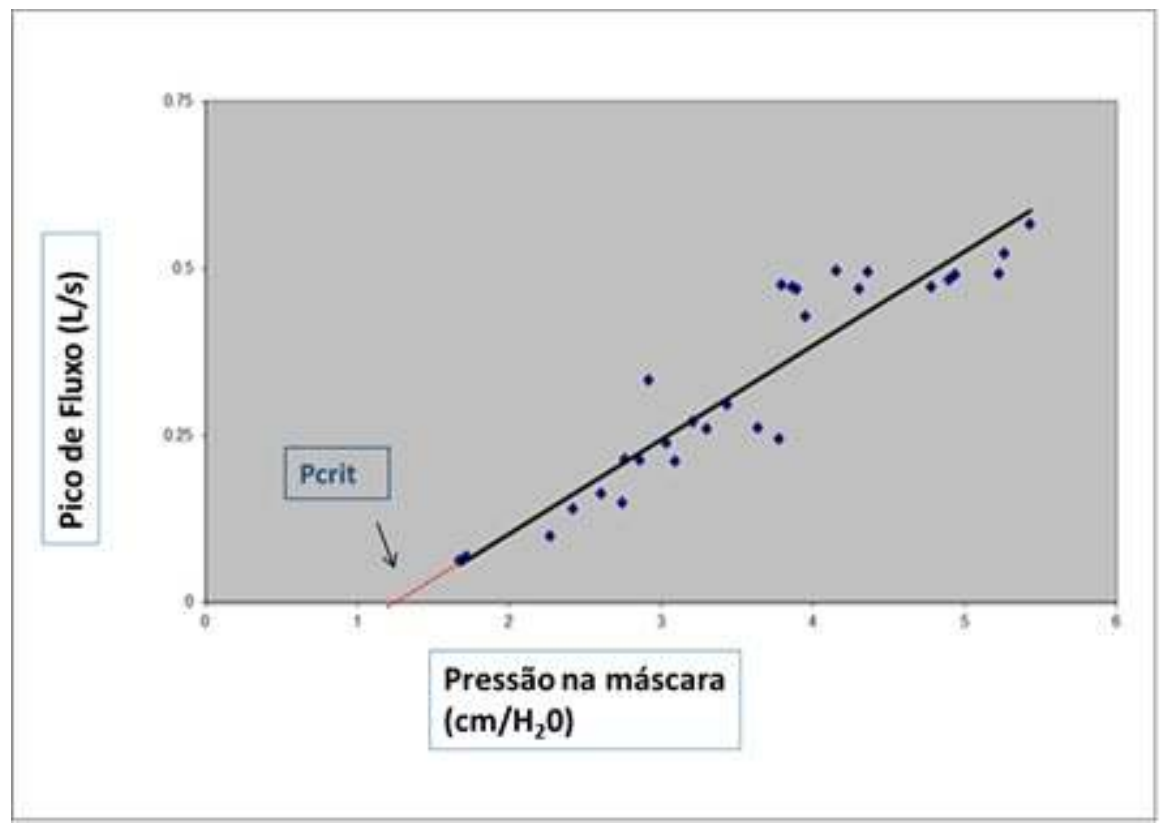

FONTE: Laboratório do Sono- Incor

Figura 15: Imagem (pcrint screen) da tela de determinação da Pcrit utilizando a regressão linear com extrapolação para o fluxo zero

\subsection{Análise estatística}

O cálculo da amostra partiu da pressuposição baseada na expectativa de uma redução de aproximadamente $1,5 \mathrm{cmH}_{2} \mathrm{O}$ na Pcrit com prévio conhecimento de queda de aproximadamente $40 \%$ no IAH no grupo Terapia e redução de 5\% no grupo Controle em estudo anterior. ${ }^{[22]}$

Calculamos um número total de 34 pacientes, considerando valor de significância $\mathrm{p}=0,05$ e desvio padrão de 1.3 e poder de $90 \%$. Considerando possíveis desistências e outros eventos o número total de 40 pacientes.

Os dados foram armazenados em uma planilha Excel e posteriormente importados para o programa SPSS versão 18 para análise.

As características de linha base dos pacientes de acordo com o grupo designado foram comparados por teste não paramétrico de distribuição de igualdade por meio do teste não paramétrico (Kolmogorov-Smirnov).

Para comparar diferenças basais entre os grupos foi realizado teste $\mathrm{T}$ (IndependentSamples ou Two-Independend-Sample/Mann-Whitney U) para variável com distribuição normal e não-normal respectivamente e descritas em média e desvio padrão ou mediana, mínimo e máximo, respectivamente. 
Além disso, foi utilizada teste de análise de variância paramétrica ANOVA dois caminhos para medidas repetidas (GLM) ou ANOVA não paramétrica. Assim, foi possível comparar os dois grupos (Controle e TMO) entre os dois instantes para as variáveis determinadas.

Nas características de base e após 3 meses de terapia paramétricas de acordo com o grupo designado (intra grupo) realizamos um teste T para medidas repetidas (Paired-Sample ou TwoRelated-Sample/Wilcoxom) para as mudanças para: questionários, Avaliação fonoaudiológica para AOS, Avaliação fonoaudiológica específica para AOS, volume das estruturas da RM, força e fadiga de língua, Pcrit, polissonográficas, e possíveis mudanças em variáveis explanatórias, incluindo IMC, circunferência cervical e circunferência abdominal.

Um valor de $\mathrm{p}<0,05$ foi considerado significante.

\subsection{Desenho Experimental}

Os pacientes incluídos no estudo foram randomizados de modo estratificado (ronco primário, apneia leve, apneia moderada e apneia grave) em Grupo Controle e Grupo TMO. Os sujeitos foram avaliados ao início e final (após três meses) do estudo por questionários, anamnese e avaliação fonoaudiológica, RM, força e fadiga da língua e Pcrit.

Todos pacientes foram orientados a realizar lavagem com $10 \mathrm{ml}$ de soro fisiológico nas duas narinas três vezes ao dia e realizaram 12 sessões semanais ( 3 meses) com duração aproximada de 30 minutos.

Ao final do estudo solicitamos o retorno de todos os pacientes para informar os resultados dos exames. O mesmo tratamento foi oferecido ao grupo Controle. Todos os pacientes foram incentivados a continuar os exercícios após o término do protocolo.

\subsubsection{Grupo Controle}

Os pacientes receberam orientação do uso de dilatador nasal, o qual foi utilizado todas as noites durante o sono e nos retornos semanais era feita a contagem de dilatadores para controlar o uso. Além de exercícios respiratórios, $3 \mathrm{x}$ ao dia, aumentando o tempo de inspiração $\mathrm{e}$ expiração no decorrer das sessões com o uso de expansão diafragmática.

\subsubsection{Grupo de tratamento miofuncional orofacial (TMO)}

Os exercícios da TMO foram realizados $3 \mathrm{x}$ ao dia associados às atividades de vida diárias. 
O protocolo de exercícios foi baseado em pesquisa anterior, a musculatura envolvida a ser trabalhado teve enfoque principal para a musculatura e quantidade suficiente que acreditamos ser necessário para AOS.

Exercícios específicos para musculatura relacionada a AOS e ronco permaneceram, porém, alguns menos relacionados com a musculatura relacionada a AOS e ronco foram excluídos. Entre os exercícios excluídos, 4 exercícios faciais foram retirados (exercícios de pressionar o músculo orbicular da boca, realizar movimento de sucção contraindo o músculo bucinador, realizar a elevação do ângulo da boca e realizar movimento de lateralização da mandíbula) e apenas 1 foi mantido. Entre os exercícios excluídos para musculatura da língua foi excluído o exercício de escovação da língua;

Os exercícios envolviam contração isotônica e posteriormente isométrica, de acordo com a evolução do paciente. A adequação das funções miofuncionais orofaciais também foram abordadas com o objetivo de manter a melhora da musculatura.

\subsubsection{Língua}

$1^{\text {o }}$ varrer: ponta da língua colocada na papila incisiva e deslizar no sentido anteroposterior, contra o palato duro. Inicialmente sem pressionamento lingual (isotônico) e depois com pressionamento lingual (isométrico), sem apertar os dentes, 20x. Musculatura alvo: musculatura genioglosso e hioglosso. Caso não fosse possível realizar este exercício o paciente era orientado a realizar o exercício de empurrar o palato duro: apertar o terço anterior da língua contra a região alveolar do palato duro mantendo o vedamento labial e sem apertamento dentário, 5 segundos, 20x. Musculatura alvo: supra hióideos (milohioideo, gêniohioideo e digástrico ventre anterior).

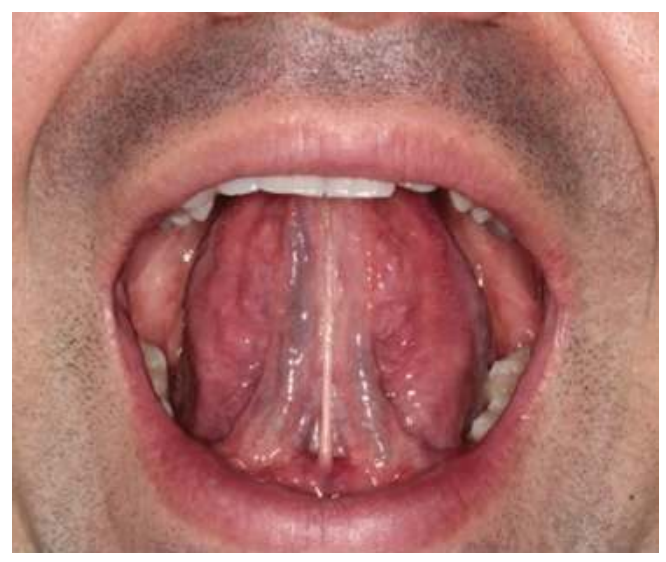

FONTE: Laboratório do Sono - Incor

Figura 2: Foto do exercício de varrer 
$2^{\circ}$ acoplamento: inicialmente estalos de língua isotônicos, 20 vezes. Depois grudar a língua contra o palato isometricamente mantendo o acoplamento lingual durante 5 segundos, 20x. Musculatura alvo: genioglosso, palatoglosso, hioglosso e suprahioideos (milohioideo, genioioideo e digástrico ventre anterior).

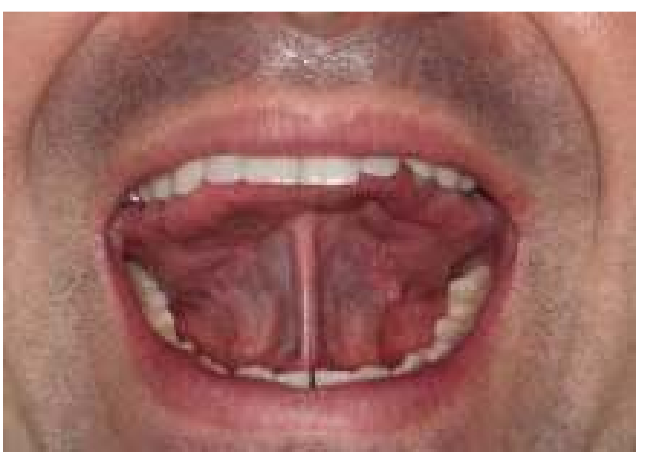

FONTE: Laboratório do Sono - Incor

Figura 3: Foto do exercício de acoplamento

$3^{\circ}$ abaixar o dorso da língua: com o auxílio de uma espátula ou dedo, estimular o reflexo de abaixamento do dorso lingual através de 5 toques rápidos na região do dorso da língua, 20x. Após percepção da musculatura necessária para realizar o abaixamento, é pedido para abaixar e relaxar o dorso lingual isotonicamente 20x; posteriormente manter o dorso lingual baixo, isometricamente por 5 segundos, 20x. Musculatura alvo: hioglosso e supra hióideos.

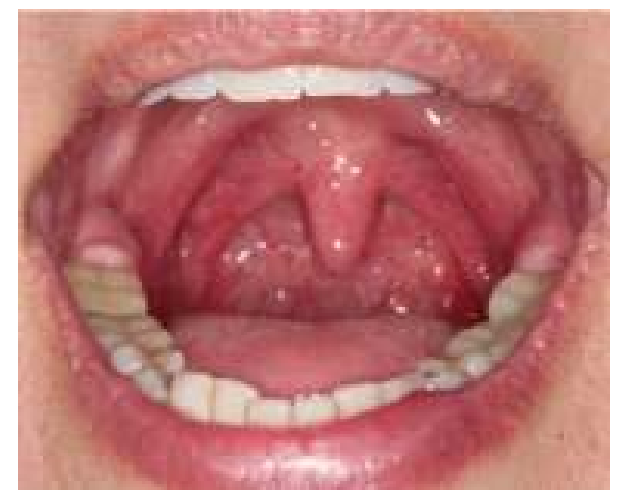

FONTE: Laboratório do Sono - Incor

Figura 4: Foto do exercício de abaixar o dorso da língua

4.10.2.2. Músculos elevador do palato, tensor do palato e músculo da úvula

$4^{\circ}$ Elevação do palato mole e úvula: produção da vogal "A" intermitente (exercícios isotônicos) 10x, por uma a duas semanas. Após percepção do paciente do movimento da musculatura, retira-se a vogal "A”, realizando somente a elevação da musculatura do palato intermitente, 20x. Após o ganho de controle e coordenação do movimento, a contração da musculatura foi mantida (exercício isométrico), recrutando inclusive o músculo da úvula na 
fase final, 5 segundos, 20x. Musculatura alvo: palatoglosso, palatofaríngeo, tensor do palato, elevador do palato e úvula.

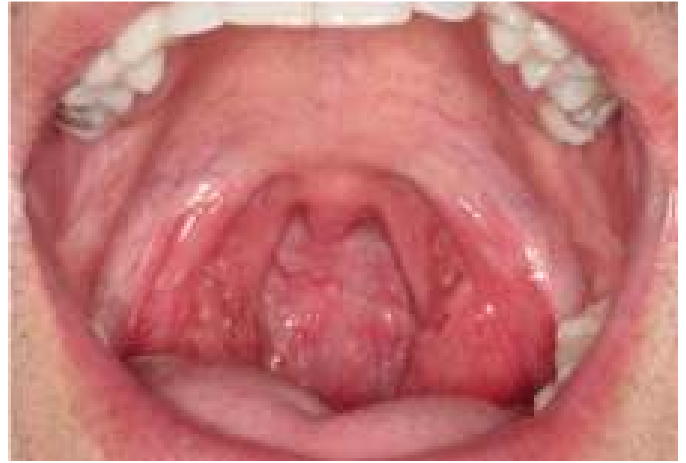

FONTE: Laboratório do Sono - Incor

Figura 6: Foto do exercício de elevação do palato mole e úvula

Em etapa final, o exercício de elevação do palato mole, tensor do palato e músculo da úvula é realizado exercício para o dorso da língua, isto é, apoiar o ápice da língua nos incisivos inferiores e abaixar o dorso lingual enquanto realiza a elevação do palato mole e úvula. 5 segundos, 20x. Musculatura alvo: palatoglosso, palatofaríngeo, tensor do palato, elevador do palato e úvula. E na última etapa, também musculatura de hioglosso e supra hióideos.

\subsubsection{Músculos bucinadores e orbiculares da boca}

$5^{\circ}$ Dedo na bochecha: dedo na mucosa interna da bochecha, paralelo a oclusão dentária. O paciente deve apertar o dedo com a bochecha contra os dentes. Inicialmente realizando exercícios isotônico, 10x cada lado. Posteriormente são realizados exercícios isométricos 10 segundos e 10x cada lado. Musculatura alvo: trabalhar principalmente cinta horizontal (bucinador principalmente e orbicular da boca).

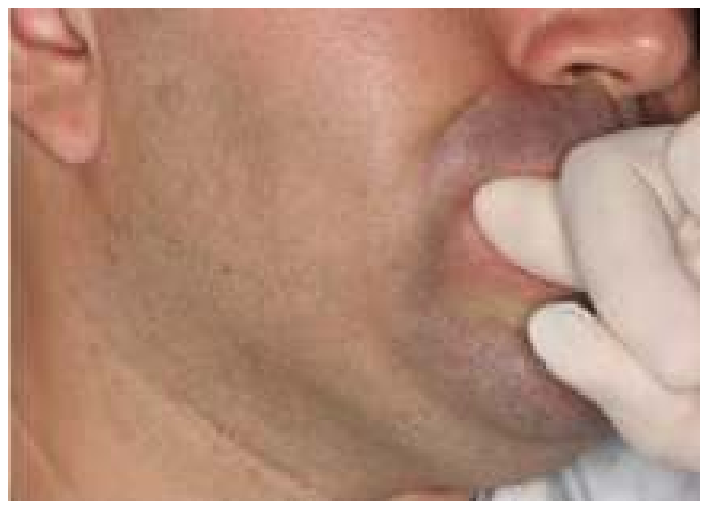

FONTE: Laboratório do Sono - Incor

Figura 5: Foto do exercício de dedo na bochecha 
$6^{\text {o }}$ Funções de mastigação e deglutição. Mastigação bilateral alternada e deglutição com a língua no palato duro sem contração oral, para manutenção dos músculos da língua e face.

Não foram observados eventos adversos da TMO.

\subsubsection{Adesão ao tratamento}

A adesão ao tratamento foi controlada por meio de uma tabela de simples visualização (Anexo D e E) que foi explicada e entregue ao paciente no início do tratamento a fim de que fosse possível realizar marcações do treino efetuado em casa e a frequência pudesse ser controlada pelo fonoaudiólogo responsável. 


\section{Resultados}




\subsection{Polissonografia}

Foram incluídos 60 sujeitos e randomizados 30 para os grupos Controle e $30 \mathrm{TMO}$, dois desistiram do protocolo (2 Controle) (Figura 16).

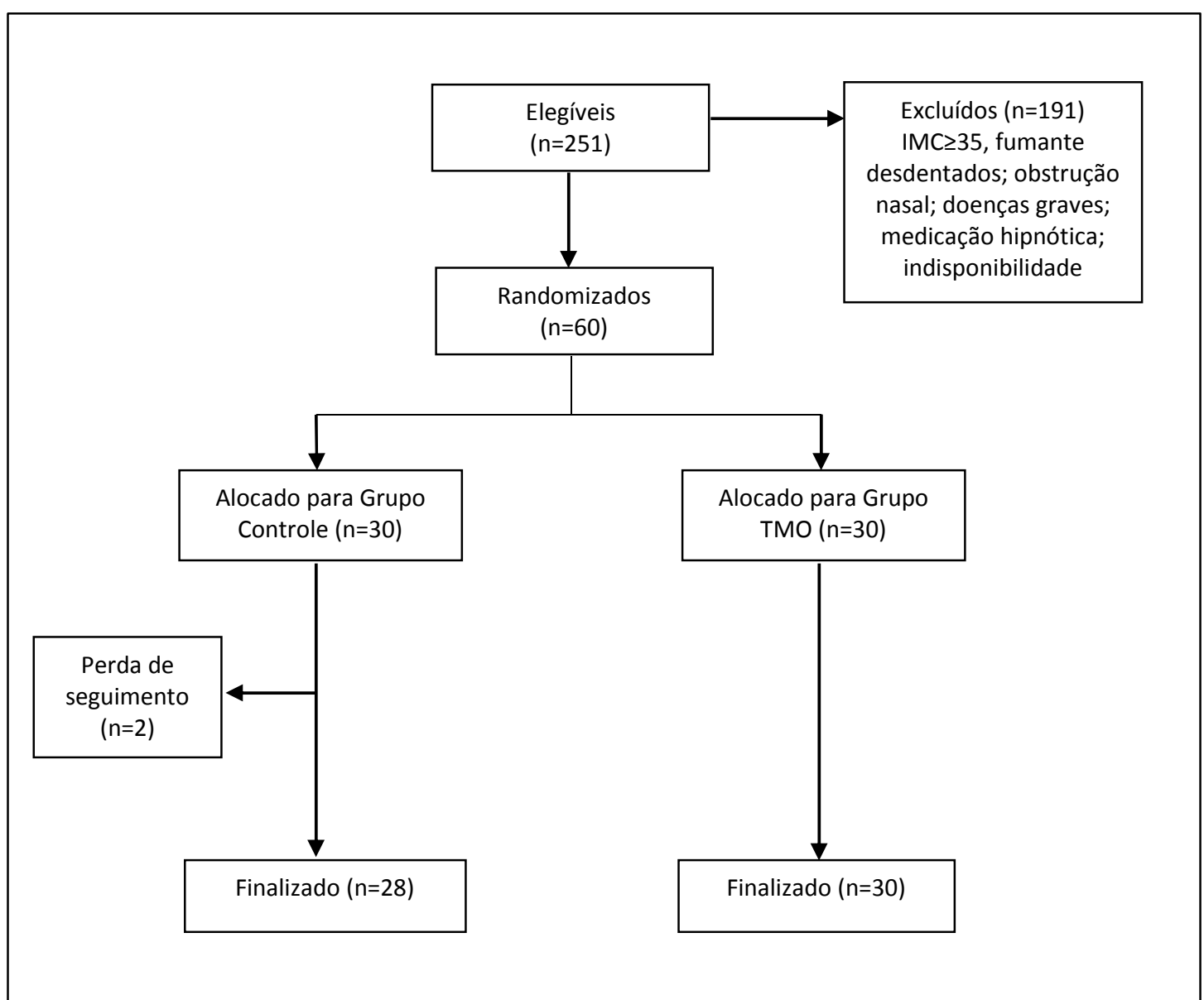

Figura 16: Fluxograma dos sujeitos randomizados, alocados para grupo, perda de seguimento e finalizados nos grupos Controle e TMO

A tabela 1, abaixo representa as características demográficas, antropométricas e clínicas dos sujeitos incluídos nos grupos Controle e TMO no basal.

Os sujeitos randomizados para os grupos Controle e TMO não apresentam diferença estatisticamente significante entre as médias para as características demográficas (gênero e idade), antropométricas (IMC, CC e CA) e características clínicas (qualidade de sono (Pittsburgh) e sonolência excessiva (Epworth)) e polissonográficas. 
Tabela 1 - Características demográficas, antropométricas, clínicas e polissonográficas dos sujeitos incluídos nos grupos Controle e TMO no basal

\begin{tabular}{|c|c|c|c|}
\hline & $\begin{array}{c}\text { Controle } \\
(n=28)\end{array}$ & $\begin{array}{c}\text { TMO } \\
(n=30)\end{array}$ & $\mathbf{p}$ \\
\hline Gênero masculino (n, \%) & $15(53,6 \%)$ & $19(63,3 \%)$ & 0,455 \\
\hline Idade (anos) & $45,5 \pm 11,7$ & $46,3 \pm 12,8$ & 0,814 \\
\hline $\mathrm{IMC}\left(\mathrm{kg} / \mathrm{m}^{2}\right)$ & $28,7 \pm 3,4$ & $28,9 \pm 3,5$ & 0,873 \\
\hline Circunferência cervical (cm) & $38 \pm 3,1$ & $8,8 \pm 3,3$ & 0,351 \\
\hline Circunferência abdominal (cm) & $95,3 \pm 8,7$ & $95,7 \pm 7$ & 0,729 \\
\hline Qualidade de sono Pittsburgh & $6[4,5-10]$ & $6,3 \pm 3,5$ & 0,192 \\
\hline Sonolência excessiva Epworth & $10,3 \pm 5,2$ & $9 \pm 5$ & 0,543 \\
\hline \multicolumn{4}{|l|}{ Polissonografia } \\
\hline TTS (min) & $381,5 \pm 36,6$ & $373 \pm 49,7$ & 0,473 \\
\hline Eficiência do sono (\%) & $85,2 \pm 6,4$ & $90,3[81,6-93,4]$ & 0,191 \\
\hline Índice de despertares (events/h) & $18,2 \pm 7,9$ & $21,3 \pm 10,9$ & 0,225 \\
\hline IAH (events/h) & $17,2 \pm 10,9$ & $19,5 \pm 14,2$ & 0,494 \\
\hline SpO2 mín (\%) & $84,3 \pm 6$ & $85,1 \pm 6,8$ & 0,619 \\
\hline Índice de dessaturação (events/h) & $12,9 \pm 8$ & $13,5 \pm 13,3$ & 0,858 \\
\hline Ronco primário $(n=6)$ & $3,3 \pm 0,9(3)$ & $3,2 \pm 2,3(3)$ & 0,916 \\
\hline Apneia leve $(n=21)$ & $9,9 \pm 3,2(10)$ & $10,5 \pm 3,2(11)$ & 0,640 \\
\hline Apneia moderada $(n=23)$ & $20,9 \pm 5,4(11)$ & $23,8 \pm 5,2(12)$ & 0,202 \\
\hline Apneia grave $(n=8)$ & $36,2 \pm 6,2(4)$ & $43,9 \pm 19,5(4)$ & 0,478 \\
\hline
\end{tabular}

A tabela 2 abaixo apresenta os resultados no basal e após 3 meses de randomização das características antropométricas, clínicas e polissonográficas nos sujeitos dos grupos Controle e TMO com os resultados do teste ANOVA para duas vias. Observando-se p significativo para redução da: circunferência cervical (CC); índice de despetares (Idesp); IAH; avaliação fonoaudiológica para AOS e avaliação fonoaudiológica específica para AOS, na TMO em relação ao Controle, conforme esperado.

Além disso, são apresentados os resultados do teste T paramétrico para o Controle que demonstrou diferença estatisticamente significante entre as médias basal e após 3 meses para redução da sonolência excessiva (Epworth), não esperado.

A TMO apresentou diferença estatisticamente significante entre as médias basal e após 3 meses para: redução na CC, no índice de despertar (Idesp), no IAH, no índice de dessaturação (Idess), na qualidade de sono de (Pittsburgh), na avaliação fonoaudiológica para AOS, na avaliação fonoaudiológica específica para AOS, no IAH para AOS moderada e no IAH para 
AOS grave, conforme esperado. E redução do tempo total de sono em supino (TTS sup), não esperado.

Tabela 2 - Características antropométricas e clínicas dos sujeitos incluídos nos grupos Controle e TMO no basal e após 3 meses de randomização

\begin{tabular}{|c|c|c|c|c|c|c|c|}
\hline \multirow[b]{2}{*}{$\mathrm{IMC}\left(\mathrm{kg} / \mathrm{m}^{2}\right)$} & \multicolumn{2}{|c|}{$\begin{array}{c}\text { Controle } \\
(n=28)\end{array}$} & \multirow{2}{*}{$\begin{array}{c}\mathbf{p} \\
\text { Valor } \\
0,734\end{array}$} & \multicolumn{2}{|c|}{$\begin{array}{l}\text { TMO } \\
(n=30)\end{array}$} & \multirow{2}{*}{$\begin{array}{c}\mathbf{p} \\
\text { valor }\end{array}$} & \multirow{2}{*}{$\begin{array}{c}\begin{array}{c}\mathbf{p} \\
\text { valor }\end{array} \\
0,693\end{array}$} \\
\hline & $28,7 \pm 3,4$ & $28,8 \pm 3,5$ & & $28,9 \pm 3,5$ & $28,8 \pm 3,4$ & & \\
\hline $\mathrm{CC}(\mathrm{cm})$ & $38 \pm 3,1$ & $37,9 \pm 3,1$ & 0,499 & $38,8 \pm 3,3$ & $38,4 \pm 4$ & $0,000 *$ & $0,047^{*}$ \\
\hline $\mathrm{CA}(\mathrm{cm})$ & $95,3 \pm 8,7$ & $95,7 \pm 8,9$ & 0,365 & $96 \pm 7,8$ & $95,7 \pm 7$ & 0,477 & 0,247 \\
\hline \multicolumn{8}{|l|}{ PSG } \\
\hline TTS (min) & $\begin{array}{l}381,5 \\
\pm 36,6\end{array}$ & $\begin{array}{l}371,7 \\
\pm 64,8\end{array}$ & 0,349 & $373 \pm 49,7$ & $\begin{array}{l}387,8 \\
\pm 65,3\end{array}$ & 0,186 & 0,108 \\
\hline $\begin{array}{l}\text { TTS sup } \\
\text { (min) }\end{array}$ & $\begin{array}{c}205 \\
1 \pm 122,6\end{array}$ & $208 \pm 182,1$ & 0,929 & $\begin{array}{c}242,4 \\
\pm 114,2\end{array}$ & $\begin{array}{c}187,9 \\
\pm 105,4\end{array}$ & $0,004^{*}$ & 0,118 \\
\hline Efic sono (\%) & $85,2 \pm 6,4$ & $84,6 \pm 10,7$ & 0,551 & $\begin{array}{c}90.3 \text { [56.3- } \\
97.9]\end{array}$ & $87,1 \pm 9,3$ & 0,358 & 0,291 \\
\hline $\begin{array}{c}\text { Idesp } \\
\text { (events/h) }\end{array}$ & $18,2 \pm 7,9$ & $19,9 \pm 8,2$ & 0,184 & $21,3 \pm 10,9$ & $16,9 \pm 7,9$ & $0,008^{*}$ & $0,003^{*}$ \\
\hline $\begin{array}{c}\mathrm{IAH} \\
\text { (events/h) }\end{array}$ & $17,2 \pm 10,9$ & $18,8 \pm 10,1$ & 0,302 & $19,5 \pm 14,2$ & $15 \pm 10,3$ & $0,006^{*}$ & $0,006^{*}$ \\
\hline $\begin{array}{c}\mathrm{SpO}_{2} \min \\
(\%)\end{array}$ & $84,3 \pm 6$ & $83,6 \pm 7,1$ & 0,487 & $85,1 \pm 6,8$ & $83,8 \pm 8,4$ & 0,134 & 0,612 \\
\hline $\begin{array}{c}\text { Idess } \\
\text { (dess/h) }\end{array}$ & $12,9 \pm 8$ & $13 \pm 7,3$ & 0,892 & $13,5 \pm 13,3$ & $10,3 \pm 9,6$ & $0,015^{*}$ & 0,055 \\
\hline Pittsburgh & $6,9 \pm 3,3$ & $6 \pm 3,3$ & 0,304 & $6,3 \pm 3,5$ & $4,3 \pm 2,5$ & $0,001 *$ & 0,114 \\
\hline Epworth & $10,3 \pm 5,2$ & $8,7 \pm 5,8$ & $0,003^{*}$ & $9,9 \pm 5$ & $8,9 \pm 4,4$ & 0,056 & 0,376 \\
\hline \multicolumn{8}{|l|}{ Av Fono } \\
\hline Av fono & $36,1 \pm 9$ & $35 \pm 11,6$ & 0,280 & $34,1 \pm 10,9$ & $18,5 \pm 8,4$ & $\begin{array}{c}<0,000 \\
*\end{array}$ & $\begin{array}{l}<0,000 \\
\quad *\end{array}$ \\
\hline $\begin{array}{l}\text { Av. fono. } \\
\text { específica }\end{array}$ & $10,5 \pm 3$ & $10,3 \pm 3,2$ & 0,748 & $9,3 \pm 2,9$ & $3,6 \pm 2,4$ & $\begin{array}{c}<0,000 \\
*\end{array}$ & $\begin{array}{c}<0,000 \\
\quad * \\
\end{array}$ \\
\hline \multicolumn{8}{|l|}{ PSG estrat } \\
\hline $\begin{array}{c}\text { Ronco } \\
\text { primário }\end{array}$ & $3,3 \pm 0,9$ & $7,5 \pm 2,5$ & 0,107 & $3,2 \pm 2,3$ & $3 \pm 0,7$ & 0,927 & 0,120 \\
\hline AOS leve & $9,9 \pm 3,2$ & $12,2 \pm 6,5$ & 0,200 & $10,5 \pm 3,2$ & $12 \pm 6$ & 0,370 & 0,717 \\
\hline $\begin{array}{c}\text { AOS } \\
\text { moderada }\end{array}$ & $20,9 \pm 5,4$ & $23,8 \pm 8,2$ & 0,361 & $23,8 \pm 5,2$ & $17,7 \pm 5,2$ & $0,001^{*}$ & $0,012^{*}$ \\
\hline AOS grave & $36,2 \pm 6,2$ & $30 \pm 5,6$ & 0,093 & $43,9 \pm 19,5$ & $24,7 \pm 21,4$ & $0,005^{*}$ & $0,011^{*}$ \\
\hline
\end{tabular}


Cada exame a seguir possui um número diferente de sujeitos, não foi possível incluir todos os sujeitos em todos os exames, caso a coleta de um dos exames não fosse possível o sujeito continuava a fazer parte de outros exames do Protocolo de pesquisa.

\subsection{Ressonância Magnética}

Inicialmente a coleta da RM ocorreu de forma insatisfatória, portanto dados foram perdidos, conforme será relatado. Posteriormente iniciou-se uma parceria com o pesquisador Richard J. Schwab do Centro para Sono e Neurobiologia Respiratória da Escola de Medicina da Pensilvânia - Filadelfia, Pensilvânia, Estados Unidos (Center for Sleep and Respiratory Neurobiology, University of Pennsylvania School of Medicine, Philadelphia, Pennsylvania). Várias reuniões foram realizadas, envolvendo os pesquisadores Geraldo Lorenzi-Filho, Fabiane Kayamori (eu), Pedro Rodrigues Genta do Laboratório do Sono da Disciplina de Pneumologia do Instituto do Coração do Hospital das Clínicas da Faculdade de Medicina da Universidade de São Paulo (InCor-FMUSP) que no momento estava na Harvard University, Eloisa Maria Mello Santiago Gebrim do Instituto de Radiologia da Faculdade de Medicina da Universidade de São Paulo (INRAD-FMUSP), o Professor Richard Schwab e equipe (Christopher Kim e Beverly Shin) todos do Center for Sleep and Respiratory Neurobiology University of Pennsylvania School of Medicine.

A primeira conferência ocorreu no dia 22/06/2012 com o intuito de expor os objetivos do trabalho e discutir os procedimentos necessários para a realização do exame de RM. Recebemos um protocolo que detalhava a forma adequada de aquisição das imagens e algumas dúvidas foram resolvidas por e-mail. Tivemos alguns problemas no envio das imagens que foram sanadas ao longo de aproximadamente um mês. Após o estabelecimento das rotinas de envio de imagens, nova reunião geral foi feita 13/11/2012. Nesta reunião, algumas dúvidas foram sanadas, principalmente em relação à coleta do exame. No período entre dezembro de 2011 e dezembro de 2012, alguns pacientes foram submetidos aos exames de RM. O método utilizado para aquisição das imagens foi sendo modificado no decorrer dos exames, porém ainda era considerado incompleto pelo grupo do Dr. Schwab. Nova reunião foi realizada no dia 06/02/2013 e foram mostradas as análises das coletas dos exames anteriores, porém ainda com importantes déficits. Foram identificados problemas em relação à posição da língua durante o exame, presença de artefatos metálicos e baixa resolução das imagens.

O grupo do Dr. Schwab nos sugeriu possíveis soluções. Em 19/04/2013 discutimos como poderíamos realizar a aquisição para análise da gordura da língua, análise que parecia ser importante para o protocolo. Tentamos repetir os parâmetros do Dixon (utilizado no equipamento dos EUA) na sequência Ideal (utilizada no equipamento do Brasil), o que exigiu 
novos testes. Conseguimos adequar a coleta das aquisições de RM ao padrão dos EUA, aumentando o tempo do exame para obter os dados para análise da gordura da língua, conforme sugerido pelo grupo do Dr Schwab.

Novos exames foram realizados e enviados para análise. Em 11/06/2013 fomos informados de que as coletas das imagens de RM estariam adequadas inclusive para análise da gordura de língua.

Durante os momentos de modificação das coletas não realizamos a RM em todos os sujeitos, visto que é um exame caro e possuímos verba da FAPESP para 40 sujeitos. Seis sujeitos inicialmente realizaram os exames de RM de forma incompleta (2 Controle e 4 TMO), em 4 sujeitos (1 Controle e 3 TMO) não foi possível realizar a análise das estruturas e apenas 2 (1 Controle e $1 \mathrm{TMO}$ ) realizadas as análises de forma razoável, porém sem dados de gordura de língua. Além disso 2 sujeitos Controle desistiram do protocolo e 1 sujeito TMO não conseguiu realizar o exame de RM. E outro sujeito Controle não foi possível analisar a gordura da língua, devido à artefatos na língua gerados pelos dentes com algum tipo de metal (Figura 17).

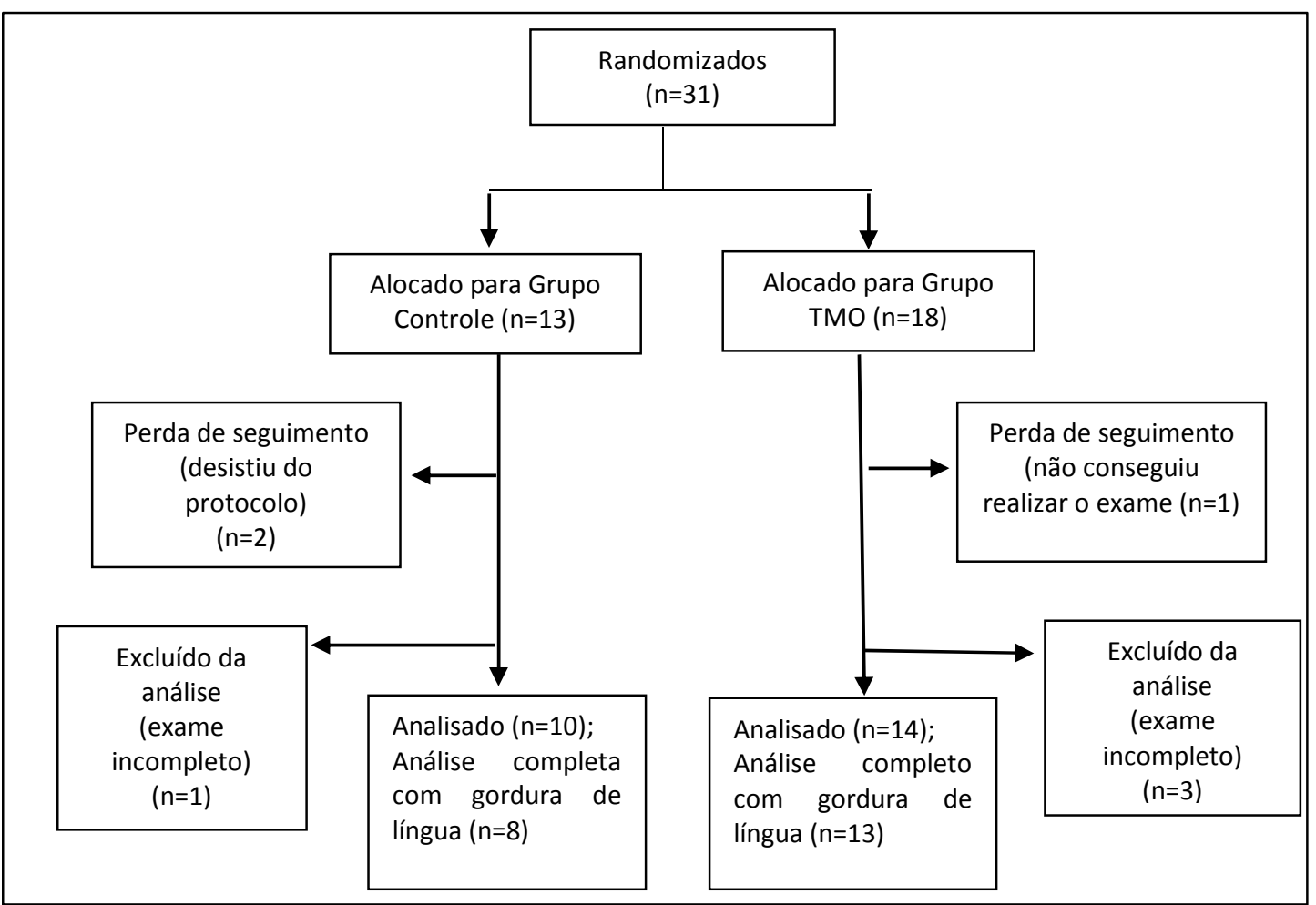

Figura 17: Fluxograma dos sujeitos randomizados, alocados para grupo, perda de seguimento e analisados nos grupos Controle e TMO, de acordo com dados do exame de RM de via aérea superior 
A tabela 3, abaixo representa as características demográficas, antropométricas e clínicas dos sujeitos incluídos nos grupos Controle e TMO no basal no exame de RM da via aérea superior.

Os sujeitos randomizados para grupos Controle e TMO não apresentam diferença estatisticamente significante entre as médias para as características demográficas (gênero e idade), antropométricas (IMC, CC e CA) e características clínicas (qualidade de sono, sonolência excessiva, intensidade de ronco, frequência de ronco, avaliação fonoaudiológica para AOS e avaliação fonoaudiológica específica para AOS).

Tabela 3 - Características demográficas, antropométricas e clínicas dos sujeitos incluídos nos grupos Controle e TMO no basal no exame de RM da via aérea superior

\begin{tabular}{cccc}
\hline & Controle $(\mathbf{n}=\mathbf{1 0})$ & TMO $(\mathbf{n}=\mathbf{1 4})$ & $\mathbf{P}$ \\
\hline Gênero masculino $(\mathrm{n}, \%)$ & $7(70 \%)$ & $12(85,7 \%)$ & 0,360 \\
Idade (anos) & $44,4 \pm 9,7$ & $42,3 \pm 12,7$ & 0,662 \\
IMC (kg/m²) & $30,1 \pm 3,6$ & $28,9 \pm 4,3$ & 0,478 \\
Circunferência cervical (cm) & $39,5 \pm 2,7$ & $40,6 \pm 3$ & 0,370 \\
Circunferência abdominal (cm) & $98 \pm 5,3$ & $96,8 \pm 9,8$ & 0,698 \\
Qualidade de sono, Pittsburgh & $7,9 \pm 3,3$ & $6,6 \pm 3,1$ & 0,370 \\
Sonolência excessiva, Epworth & $11 \pm 6,5$ & $12,1 \pm 4,8$ & 0,625 \\
Intensidade do ronco, questionário & $2,2 \pm 1$ & $2 \pm 1,4$ & 0,807 \\
Frequência do ronco, questionário & $3,1 \pm 1,1$ & $2,7 \pm 1,4$ & 0,473 \\
Av. fono. & $27,8 \pm 8,9$ & $32 \pm 9$ & 0,266 \\
Av. fono. espec. & $9,9 \pm 3,8$ & $9,9 \pm 3,6$ & 0,978 \\
\hline
\end{tabular}

IMC: índice de massa corpórea; Av. fono: avaliação fonoaudiológica para AOS; Av. fono. espec.: Avaliação fonoaudiológica especifica para AOS. Dados expressos em valor absoluto ou média \pm desvio padrão para as variáveis com distribuição normal.

A tabela 4, abaixo representa as características polissonográficas dos sujeitos incluídos nos grupos Controle e TMO no basal.

Os sujeitos randomizados para grupos Controle e TMO não apresentam diferença estatisticamente significante entre as médias para as características polissonográficas. 
Tabela 4 - Características polissonográficas dos sujeitos incluídos nos grupos Controle e TMO no basal no exame de RM das vias aéreas superiores

\begin{tabular}{cccc}
\hline & $\begin{array}{c}\text { Controle } \\
(\mathbf{n}=\mathbf{1 0})\end{array}$ & $\begin{array}{c}\text { TMO } \\
(\mathbf{n}=\mathbf{1 4})\end{array}$ & p valor \\
\hline Polissonografia & & & \\
\hline TTS (min) & $389,8 \pm 42,3$ & $381 \pm 61,2$ & 0,702 \\
TTS sup (min) & $209,1 \pm 112,2$ & $261,1 \pm 106,6$ & 0,320 \\
Eficiência do sono (\%) & $85,5 \pm 5,7$ & $85,3 \pm 13,6$ & 0,972 \\
Índice de despertares (desp/h) & $24,3 \pm 8,9$ & $24,1 \pm 11,8$ & 0,968 \\
IAH (events/h) & $23,8 \pm 11,5$ & $24,8 \pm 16,4$ & 0,876 \\
IAH NREM (events/h) & $19.4 \pm 8,9$ & $22,7 \pm 16,9$ & 0,583 \\
IAH REM (events/h) & $42,1 \pm 23,2$ & $32 \pm 21,7$ & 0,283 \\
IAH sup (events/h) & $33,1 \pm 10,3$ & $32,2 \pm 18,6$ & 0,888 \\
IA obstrutiva (events/h) & $1 \pm 1,5$ & $1[0-62,7]$ & 0,133 \\
IH (events/h) & $22 \pm 10,2$ & $17,3 \pm 8,9$ & 0,238 \\
SpO mín (\%) & $82,1 \pm 6,8$ & $83,9 \pm 5,6$ & 0,496 \\
Índice de dessaturação (events/hs) & $16,2 \pm 6,9$ & $17 \pm 16,8$ & 0,879 \\
\hline TTS: Tenpo
\end{tabular}

TTS: Tempo total de sono; sup: posição supina; IAH: índice de apneia e hipopneia; NREM: sono não REM; REM: sono REM; IA obstrutiva: índice de apneias obstrutivas; IH: índice de hipopneias; $\mathrm{SpO}_{2}$ mín: saturação mínima. Dados expressos em valor absoluto ou média \pm desvio padrão para as variáveis com distribuição normal.

A tabela 5 abaixo representa os dados da análise volumétrica da via aérea superior dos sujeitos incluídos nos grupos Controle e TMO no basal.

Os sujeitos randomizados para grupos Controle e TMO não apresentam diferença estatisticamente significante entre as médias para a análise volumétrica da via aérea superior. 
Tabela 5 - Análise volumétrica dos sujeitos incluídos nos grupos Controle e TMO no basal no exame de RM das vias aéreas superiores

\begin{tabular}{|c|c|c|c|}
\hline Variáveis & Controle & TMO & p valor \\
\hline & Pré $(n=10)$ & Pré (n=14) & $\mathbf{p}$ \\
\hline va retropalatal $\mathrm{mm}^{3}$ & $3171 \pm 1210$ & $3542 \pm 1789$ & 0,576 \\
\hline va palato mole epiglote $\mathrm{mm}^{3}$ & $2936 \pm 1257$ & $3363 \pm 2354$ & 0,609 \\
\hline va retroglossal & $3493 \pm 1547$ & $4702 \pm 2602$ & 0,170 \\
\hline palato mole $\mathrm{mm}^{3}$ & $9481 \pm 2292$ & $11237 \pm 2281$ & 0,077 \\
\hline língua mm³ & $86597 \pm 12650$ & $95691 \pm 15062$ & 0,134 \\
\hline epiglote $\mathrm{mm}^{3}$ & $1246 \pm 328$ & $1700 \pm 824$ & 0,079 \\
\hline g parafaríngea $\mathrm{mm}^{3}$ & $4884 \pm 2858$ & $4586 \pm 1902$ & 0,761 \\
\hline op língua $\mathrm{mm}^{3}$ & $25130 \pm 6297$ & $28852 \pm 6562$ & 0,178 \\
\hline $\mathrm{m}$ pterigoideo $\mathrm{mm}^{3}$ & $17524 \pm 4779$ & $18167 \pm 2547$ & 0,705 \\
\hline $\mathrm{pl}$ retropalatal $\mathrm{mm}^{3}$ & $12061 \pm 3482$ & $15089 \pm 3747$ & 0,057 \\
\hline $\mathrm{pl}$ retroepiglote $\mathrm{mm}^{3}$ & $11429 \pm 3740$ & $12887 \pm 3925$ & 0,371 \\
\hline $\mathrm{g}$ língua $\mathrm{mm}^{3}$ & $23612 \pm 8224$ & $27375 \pm 9394$ & 0,363 \\
\hline $\operatorname{terp}(\mathrm{M}) \mathrm{mm}^{3}$ & $103560 \pm 26919$ & $118817 \pm 22840$ & 0,148 \\
\hline $\operatorname{varp}(\mathrm{M}) \mathrm{mm}^{3}$ & $2716 \pm 1006$ & $3030 \pm 1283$ & 0,527 \\
\hline língua $\mathrm{rp} \mathrm{M} \mathrm{mm^{3 }}$ & $42253 \pm 12107$ & $49499 \pm 11215$ & 0,145 \\
\hline plrp $\mathrm{M} \mathrm{mm}^{3}$ & $10033 \pm 3198$ & $12842 \pm 3473$ & 0,056 \\
\hline pmrp $\mathrm{M} \mathrm{mm}^{3}$ & $9366 \pm 2233$ & $11193 \pm 2196$ & 0,059 \\
\hline gpfrp $\mathrm{M} \mathrm{mm^{3 }}$ & $3690 \pm 2168$ & $3696 \pm 1359$ & 0,933 \\
\hline terg $\mathrm{M} \mathrm{mm}^{3}$ & $62223 \pm 29502$ & $56003 \pm 26193$ & 0,592 \\
\hline $\operatorname{varg} \mathrm{M} \mathrm{mm}^{3}$ & $1124 \pm 924$ & $980 \pm 1288$ & 0,948 \\
\hline língua $\mathrm{rg} \mathrm{M} \mathrm{mm}^{3}$ & $29570 \pm 15620$ & $28082 \pm 9875$ & 0,794 \\
\hline plrg $\mathrm{M} \mathrm{mm}^{3}$ & $3079 \pm 2989$ & $2552 \pm 2719$ & 0,657 \\
\hline terp $\mathrm{MV} \mathrm{mm}^{3}$ & $114254 \pm 29988$ & $127985 \pm 24119$ & 0,227 \\
\hline varp $\mathrm{MV} \mathrm{mm}^{3}$ & $3171 \pm 1210$ & $3542 \pm 1789$ & 0,576 \\
\hline língua rp $\mathrm{MV} \mathrm{mm}^{3}$ & $41736 \pm 11268$ & $49499 \pm 11215$ & 0,109 \\
\hline plrp MV mm ${ }^{3}$ & $12061 \pm 3482$ & $14994 \pm 3715$ & 0,063 \\
\hline pmrp MV mm $m^{3}$ & $9411 \pm 2272$ & $11232 \pm 2240$ & 0,064 \\
\hline gpfrp MV mm ${ }^{3}$ & $4746 \pm 2862$ & $4092 \pm 1650$ & 0,485 \\
\hline terg $\mathrm{MV} \mathrm{mm}^{3}$ & $131153 \pm 38539$ & $127037 \pm 36532$ & 0,793 \\
\hline $\operatorname{varg} \mathrm{MV} \mathrm{mm}^{3}$ & $5681 \pm 1971$ & $6988 \pm 3399$ & 0,289 \\
\hline língua $\mathrm{rg} \mathrm{MV} \mathrm{mm}^{3}$ & $43841 \pm 13652$ & $44415 \pm 11055$ & 0,911 \\
\hline plrg $\mathrm{MV} \mathrm{mm^{3 }}$ & $10903 \pm 3622$ & $39028 \pm 8193$ & 0,706 \\
\hline
\end{tabular}

Legenda: va retropalatal: via aérea retropalatal; va palato mole epiglote: via aérea entre palato mole e epiglote; va retroglossal: via aérea retroglossal; g parafaríngea: gordura parafaríngea; op língua: outras partes da língua; $m$ pterigoideo: músculo pterigoideo; pl retropalatal: parede lateral retropalatal; pl retroepiglote: parede lateral 
retroepiglote; g língua: gordura da língua; terp $\mathrm{M}$ : total das estruturas retropalatais dentro da mandíbula; varp M: via aérea retropalatal dentro da mandíbula; língua rp: língua retropalatal dentro da mandíbula; plrp M: parede lateral retropalatal dentro da mandíbula; pmrp M: palato mole retropalatal dentro da mandíbula; gpfrp M: gordura parafaríngea retropalatal dentro da mandíbula; terg $\mathrm{M}$ : total das estruturas retroglossal dentro da mandíbula; varg M: via aérea retroglossal dentro da mandíbula; língua rg: língua retroglossall dentro da mandíbula; plrg M: parede lateral retroglossal dentro da mandíbula; terp MV: total das estruturas retropalatais dentro da mandíbula até as pregas vocais; varp MV: via aérea retropalatal dentro da mandíbula até as pregas vocais; língua rp MV: língua retropalatal dentro da mandíbula até as pregas vocais; plrp MV: parede lateral retropalatal dentro da mandíbula até as pregas vocais; pmrp MV: palato mole retropalatal dentro da mandíbula até as pregas vocais; gpfrp MV: gordura parafaríngea retropalatal dentro da mandíbula até as pregas vocais; terg MV: total das estruturas retroglossal dentro da mandíbula até as pregas vocais; varg MV: via aérea retroglossal dentro da mandíbula até as pregas vocais; língua rg MV: língua retroglossal dentro da mandíbula até as pregas vocais; plrg MV: parede lateral retroglossal dentro da mandíbula até as pregas vocais Dados expressos em valor absoluto ou média \pm desvio padrão para as variáveis com distribuição normal

A tabela 6 abaixo apresenta os resultados no basal e após 3 meses de randomização das características antropométricas e clínicas dos sujeitos dos grupos Controle e TMO com os resultados do teste ANOVA para duas vias. Observando-se p significativo para: redução da circunferência cervical (CC), avaliação fonoaudiológica para AOS e avaliação fonoaudiológica específica para AOS, no TMO em relação ao Controle, conforme esperado.

Além disso, são apresentados os resultados do teste T paramétrico para o Controle que demonstrou: diferença estatisticamente significante entre as médias basal e após 3 meses para redução da Sonolência excessiva (Epworth) e avaliação fonoaudiológica para AOS, não esperado.

O TMO apresentou diferença estatisticamente significante entre as médias basal e após 3 meses para: redução da circunferência cervical, sonolência excessiva (Epworth), avaliação fonoaudiológica para AOS e avaliação fonoaudiológica específica para AOS, conforme esperado. 
Tabela 6 - Características antropométricas e clínicas dos sujeitos incluídos nos grupos Controle e TMO no basal e após 3 meses de randomização no exame de RM das vias aéreas superiores

\begin{tabular}{|c|c|c|c|c|c|c|c|}
\hline & \multicolumn{2}{|c|}{$\begin{array}{c}\text { Controle } \\
(n=10)\end{array}$} & \multirow{2}{*}{$\begin{array}{c}\begin{array}{c}\mathbf{p} \\
\text { valor }\end{array} \\
0,110\end{array}$} & \multicolumn{2}{|c|}{$\begin{array}{c}\text { TMO } \\
(n=14)\end{array}$} & \multirow{2}{*}{$\begin{array}{c}\begin{array}{c}\mathbf{p} \\
\text { valor }\end{array} \\
0,430\end{array}$} & \multirow{2}{*}{$\begin{array}{c}\mathbf{p} \\
\text { valor } \\
0,099\end{array}$} \\
\hline $\begin{array}{c}\mathrm{IMC} \\
\left(\mathrm{Kg} / \mathrm{m}^{2}\right)\end{array}$ & $30,1 \pm 3,6$ & $30,4 \pm 3,4$ & & $28,9 \pm 4,3$ & $28,8 \pm 3,9$ & & \\
\hline $\mathrm{CC}(\mathrm{cm})$ & $39,5 \pm 2,7$ & $39,7 \pm 2,8$ & 0,099 & $40,6 \pm 3$ & $40,2 \pm 2,9$ & $0,005^{*}$ & $0,002^{*}$ \\
\hline $\mathrm{CA}(\mathrm{cm})$ & $98 \pm 5,3$ & $99 \pm 4,6$ & 0,060 & $96,8 \pm 9,8$ & $96,3 \pm 9,3$ & 0,536 & 0,145 \\
\hline Pittsburgh & $7,9 \pm 3,3$ & $7,4 \pm 3,2$ & 0,551 & $6,6 \pm 3,1$ & $4,9 \pm 2,5$ & 0,393 & 0,177 \\
\hline Epworth & $11 \pm 6,5$ & $9,8 \pm 6,3$ & $0,018^{*}$ & $12,1 \pm 4,8$ & $11,4 \pm 3,5$ & $0,005^{*}$ & 0,640 \\
\hline $\begin{array}{l}\text { Intensidade } \\
\text { do ronco }\end{array}$ & $2,2 \pm 1$ & $2 \pm 1,2$ & 0,168 & $2 \pm 1,4$ & $1,5 \pm 1$ & 0,088 & 0,345 \\
\hline $\begin{array}{l}\text { Frequência } \\
\text { do ronco }\end{array}$ & $3,1 \pm 1,1$ & $2,9 \pm 1$ & 0,555 & $2,7 \pm 1,4$ & $2,6 \pm 1,3$ & 0,612 & 0,895 \\
\hline Aval.fono & $27,8 \pm 8,9$ & $25,2 \pm 9,2$ & $0,014^{*}$ & $32 \pm 9$ & $18,6 \pm 8,5$ & $0,000 *$ & $<0,000$ \\
\hline Aval.espec. & $9,9 \pm 3,8$ & $9,1 \pm 3,9$ & 0,428 & $9,9 \pm 3,6$ & $4,4 \pm 2,7$ & $0,000 *$ & 0,002 \\
\hline
\end{tabular}

A tabela 7, abaixo apresenta os resultados no basal e após 3 meses de randomização das características polissonográficas dos grupos Controle e TMO com os resultados do teste ANOVA para duas vias. Observando-se p significativo para redução do índice de despertar (Idesp), IAH NREM, no TMO em relação ao Controle, conforme esperado.

Além disso, são apresentados os resultados do teste T paramétrico para o TMO que demonstrou diferença estatisticamente significante entre as médias basal e após 3 meses para: redução no índice de despertares, no IAH NREM (não REM) e no índice de dessaturação, conforme esperado e no tempo total de sono (TTS supino), não esperado.

O Controle não apresentou diferença estatisticamente significante entre as médias basal e após 3 meses para os dados polissonográficos. 
Tabela 7 - Características polissonográficas dos sujeitos incluídos nos grupos Controle e TMO no basal e após 3 meses de randomização no exame de RM das vias aéreas superiores

\begin{tabular}{|c|c|c|c|c|c|c|c|}
\hline & \multicolumn{2}{|c|}{ Controle $(n=10)$} & \multirow{2}{*}{$\begin{array}{c}\mathbf{P} \\
\text { valor }\end{array}$} & \multicolumn{2}{|c|}{ TMO (n=14) } & \multirow[t]{2}{*}{ P valor } & \multirow{2}{*}{$\begin{array}{c}\mathbf{P} \\
\text { Valor }\end{array}$} \\
\hline PSG & & & & & & & \\
\hline TTS (min) & $\begin{array}{l}389,8 \\
\pm 42,3\end{array}$ & $\begin{array}{l}356,3 \\
\pm 80,7\end{array}$ & 0,069 & $381 \pm 61,2$ & $\begin{array}{l}386,9 \\
\pm 76,1\end{array}$ & 0,759 & 0,145 \\
\hline TTS sup (min) & $\begin{array}{c}209,2 \\
\pm 112,2\end{array}$ & $\begin{array}{l}153,8 \\
\pm 93,4\end{array}$ & 0,025 & $261,1 \pm 106,6$ & $184,1 \pm 109$ & $0,010^{*}$ & 0,541 \\
\hline Efic sono(\%) & $85,5 \pm 5,7$ & $80,2 \pm 11,9$ & 0,077 & $85,3 \pm 13,6$ & $88 \pm 10,2$ & 0,102 & 0,011 \\
\hline $\begin{array}{c}\text { Idesp } \\
\text { (events/h) }\end{array}$ & $24,3 \pm 8,9$ & $25,9 \pm 9,9$ & 0,527 & $24,1 \pm 11,8$ & $18,5 \pm 10,3$ & $0,034^{*}$ & $0,049 *$ \\
\hline IAH (events/h) & $23,8 \pm 11,5$ & $27,2 \pm 8,2$ & 0,342 & $24,8 \pm 16,4$ & $19,3 \pm 12$ & 0,082 & 0,060 \\
\hline $\begin{array}{l}\text { IAH NREM } \\
\text { (events/h) }\end{array}$ & $19,4 \pm 8,9$ & $23,7 \pm 7,2$ & 0,194 & $22,7 \pm 16,9$ & $16,5 \pm 12,6$ & $0,058 * *$ & $0,026^{*}$ \\
\hline $\begin{array}{l}\text { IAH REM } \\
\text { (events/h) }\end{array}$ & $42,1 \pm 23,2$ & $41,7 \pm 20,9$ & 0,955 & $32 \pm 21,7$ & $23,8 \pm 17$ & 0,245 & 0,439 \\
\hline IAH supino & $33,1 \pm 10,3$ & $33,7 \pm 18$ & 0,911 & $32,2 \pm 18,6$ & $31,7 \pm 19,6$ & 0,933 & 0,896 \\
\hline IA obstrutiva & $1 \pm 1,5$ & $1,4 \pm 2,4$ & 0,173 & $1[0-62,7]$ & $5,8 \pm 13,6$ & 0,387 & 0,141 \\
\hline $\mathrm{IH}$ & $22 \pm 10,2$ & $25,4 \pm 8,2$ & 0,341 & $17,3 \pm 8,9$ & $13 \pm 6$ & 0,113 & 0,076 \\
\hline $\mathrm{SpO}_{2}$ mín & $82,1 \pm 6,8$ & $82,5 \pm 6,6$ & 0,774 & $83,9 \pm 5,6$ & $83,1 \pm 7,1$ & 0,600 & 0,572 \\
\hline Idess (dess./h) & $16,2 \pm 6,9$ & $17,4 \pm 7,7$ & 0,455 & $17 \pm 16,8$ & $12 \pm 12,2$ & $0,025^{*}$ & 0,030 \\
\hline
\end{tabular}

TTS: Tempo total de sono; sup: posição supina; Efic sono: eficiência do sono; Idesp. : índice de despertares; IAH: índice de apneia e hipopneia; NREM: sono não REM; REM: sono REM; IA obstrutiva: índice de apneias obstrutivas; $\mathrm{IH}$ : índice de hipopneias; $\mathrm{SpO}_{2}$ mín: saturação mínima; Idess.: índice de dessaturação. Dados expressos em valor absoluto ou média \pm desvio padrão para as variáveis com distribuição normal, medianas [intervalo interquartil] para variáveis sem distribuição normal e* $p<0,005$.

A tabela 8, abaixo, apresenta os resultados no basal e após 3 meses de randomização da análise volumétrica do exame de RM dos grupos Controle e TMO, os resultados do teste ANOVA para duas vias, não observou p significativo para nenhum dos dados.

Além disso, são apresentados os resultados do teste T paramétrico para TMO observou diferença estatisticamente significante entre as médias basal e após 3 meses para redução do volume da língua $(\mathrm{p}=0,031)$, da gordura da língua $(\mathrm{p}=0,008)$. (Figura 18)

O Controle não apresentou diferença estatisticamente significante entre as médias basal e após 3 meses. 
Tabela 8 - Análise volumétrica dos sujeitos incluídos nos grupos Controle e TMO no basal e após 3 meses de randomização no exame de RM das vias aéreas superiores

\begin{tabular}{|c|c|c|c|c|c|c|c|}
\hline \multirow[t]{2}{*}{ Variáveis } & \multicolumn{2}{|c|}{ Controle } & \multirow{2}{*}{$\begin{array}{c}\mathbf{p} \\
\text { valor }\end{array}$} & \multicolumn{2}{|c|}{ TMO } & \multirow{2}{*}{$\begin{array}{c}\mathbf{p} \\
\text { valor }\end{array}$} & \multirow{2}{*}{$\begin{array}{c}\mathbf{P} \\
\text { valor }\end{array}$} \\
\hline & Pré $(n=10)$ & Pós (n=10) & & Pré (n=14) & Pós ( $n=14)$ & & \\
\hline $\begin{array}{c}\text { va } \\
\text { retropalatal } \\
\mathrm{mm}^{3}\end{array}$ & $\begin{array}{c}3171 \\
\pm 1210\end{array}$ & $\begin{array}{c}3405 \\
\pm 1414\end{array}$ & 0,480 & $3542 \pm 1789$ & $3258 \pm 1162$ & 0,433 & 0,307 \\
\hline $\begin{array}{c}\text { va palato } \\
\text { mole epiglote } \\
\mathrm{mm}^{3}\end{array}$ & $\begin{array}{c}2936 \\
\pm 1257\end{array}$ & $2837 \pm 714$ & 0,767 & $3363 \pm 2354$ & $3051 \pm 2197$ & 0,512 & 0,733 \\
\hline $\begin{array}{c}\text { va } \\
\text { retroglossal }\end{array}$ & $\begin{array}{c}3493 \\
\pm 1547\end{array}$ & $\begin{array}{c}3400 \\
\pm 1402\end{array}$ & 0,837 & $4702 \pm 2602$ & $5000 \pm 2076$ & 0,440 & 0,506 \\
\hline $\begin{array}{l}\text { palato mole } \\
\mathrm{mm}^{3}\end{array}$ & $\begin{array}{c}9481 \\
\pm 2292\end{array}$ & $\begin{array}{c}9625 \\
\pm 1922\end{array}$ & 0,863 & $11237 \pm 2281$ & $10749 \pm 2727$ & 0,373 & 0,503 \\
\hline língua $\mathrm{mm}^{3}$ & $\begin{array}{c}86597 \\
\pm 12650\end{array}$ & $\begin{array}{c}86412 \\
\pm 10554\end{array}$ & 0,940 & $\begin{array}{c}95691 \\
\pm 15062\end{array}$ & $\begin{array}{c}90232 \\
\pm 15548\end{array}$ & $\begin{array}{l}0,031 \\
*\end{array}$ & 0,130 \\
\hline epiglote $\mathrm{mm}^{3}$ & $1246 \pm 328$ & $1280 \pm 628$ & 0,882 & $1700 \pm 824$ & $1777 \pm 877$ & 0,613 & 0,866 \\
\hline $\begin{array}{l}\text { g parafaríngea } \\
\mathrm{mm}^{3}\end{array}$ & $\begin{array}{c}4884 \\
\pm 2858\end{array}$ & $\begin{array}{c}5098 \\
\pm 2023\end{array}$ & 0,684 & $4586 \pm 1902$ & $4230 \pm 1724$ & 0,313 & 0,342 \\
\hline $\begin{array}{c}\text { op língua } \\
\mathrm{mm}^{3}\end{array}$ & $\begin{array}{l}25130 \\
\pm 6297\end{array}$ & $\begin{array}{l}26124 \\
\pm 7441\end{array}$ & 0,302 & $\begin{array}{c}28852 \pm \\
6562\end{array}$ & $30559 \pm 6215$ & 0,076 & 0,589 \\
\hline $\begin{array}{c}\mathrm{m} \text { pterigoideo } \\
\mathrm{mm}^{3}\end{array}$ & $\begin{array}{c}17524 \pm 477 \\
9\end{array}$ & $\begin{array}{c}17887 \pm 405 \\
4\end{array}$ & 0,671 & $18167 \pm 2547$ & $17498 \pm 3382$ & 0,358 & 0,352 \\
\hline $\begin{array}{c}\text { pl retropalatal } \\
\mathrm{mm}^{3}\end{array}$ & $\begin{array}{c}12061 \pm 348 \\
2\end{array}$ & $\begin{array}{c}12437 \pm 408 \\
0\end{array}$ & 0,590 & $15089 \pm 3747$ & $14108 \pm 3682$ & 0,272 & 0,259 \\
\hline $\begin{array}{c}\mathrm{pl} \\
\text { retroepiglote } \\
\mathrm{mm}^{3}\end{array}$ & $\begin{array}{c}11429 \pm \\
3740\end{array}$ & $\begin{array}{c}10664 \pm \\
3757\end{array}$ & 0,437 & $12887 \pm 3925$ & $13257 \pm 3920$ & 0,694 & 0,409 \\
\hline $\begin{array}{c}\text { g língua mm³ } \\
\text { (8 controle) } \\
\text { (13 terapia) }\end{array}$ & $\begin{array}{c}23612 \pm 822 \\
4\end{array}$ & $\begin{array}{c}19854 \pm 550 \\
7\end{array}$ & 0,169 & $27375 \pm 9394$ & $21639 \pm 7703$ & $\begin{array}{l}0,008 \\
*\end{array}$ & 0,515 \\
\hline terp $\mathrm{M} \mathrm{mm^{3 }}$ & $\begin{array}{l}103560 \\
\pm 26919\end{array}$ & $\begin{array}{l}104865 \\
\pm 21089\end{array}$ & 0,871 & $\begin{array}{l}118817 \\
\pm 22840\end{array}$ & $\begin{array}{l}115689 \\
\pm 21246\end{array}$ & 0,531 & 0,616 \\
\hline $\operatorname{varp} \mathrm{M} \mathrm{mm}^{3}$ & $\begin{array}{c}2716 \\
\pm 1006\end{array}$ & $2619 \pm 1044$ & 0,772 & $3030 \pm 1283$ & $2790 \pm 1005$ & 0,504 & 0,776 \\
\hline $\begin{array}{c}\text { língua rp M } \\
\mathrm{mm}^{3}\end{array}$ & $\begin{array}{c}42253 \\
\pm 12107\end{array}$ & $\begin{array}{l}43955 \\
\pm 7631\end{array}$ & 0,648 & $\begin{array}{r}49499 \\
\pm 11215\end{array}$ & $\begin{array}{c}48421 \\
\pm 11184\end{array}$ & 0,673 & 0,519 \\
\hline plrp $\mathrm{M} \mathrm{mm}^{3}$ & $\begin{array}{c}10033 \pm \\
3198\end{array}$ & $\begin{array}{c}10003 \pm \\
2348\end{array}$ & 0,953 & $\begin{array}{c}12842 \pm \\
3473\end{array}$ & $11825 \pm 3988$ & 0,132 & 0,124 \\
\hline pmrp $\mathrm{M} \mathrm{mm}^{3}$ & $\begin{array}{c}9366 \pm \\
2233\end{array}$ & $\begin{array}{c}9390 \\
\pm 1720\end{array}$ & 0,980 & $11193 \pm 2196$ & $10655 \pm 2575$ & 0,328 & 0,640 \\
\hline gpfrp $\mathrm{M} \mathrm{mm}$ & $\begin{array}{c}3690 \\
\pm 2168\end{array}$ & $\begin{array}{c}3314 \\
\pm 1373\end{array}$ & 0,563 & $3696 \pm 1359$ & $3264 \pm 1174$ & 0,181 & 0,931 \\
\hline terg $\mathrm{M} \mathrm{mm}^{3}$ & $\begin{array}{c}62223 \\
\pm 29502\end{array}$ & $\begin{array}{c}60411 \pm \\
3017 t\end{array}$ & 0,698 & $\begin{array}{c}56003 \\
\pm 26193\end{array}$ & $\begin{array}{c}56614 \\
\pm 23121\end{array}$ & 0,884 & 0,698 \\
\hline
\end{tabular}




\begin{tabular}{|c|c|c|c|c|c|c|c|}
\hline $\operatorname{varg} \mathrm{M} \mathrm{mm}^{3}$ & $1124 \pm 924$ & $1020 \pm 1120$ & 0,699 & $980 \pm 1288$ & $862 \pm 930$ & 0,423 & 0,909 \\
\hline $\begin{array}{c}\text { língua rg } M \\
\mathrm{~mm}^{3}\end{array}$ & $\begin{array}{c}29570 \pm \\
15620\end{array}$ & $\begin{array}{c}28183 \pm 144 \\
39\end{array}$ & 0,588 & $28082 \pm 9875$ & $25109 \pm 8084$ & 0,261 & 0,668 \\
\hline plrg $\mathrm{M} \mathrm{mm}^{3}$ & $\begin{array}{c}3079 \\
\pm 2989\end{array}$ & $2370 \pm 2313$ & 0,260 & $2552 \pm 2719$ & $2315 \pm 1937$ & 0,645 & 0,549 \\
\hline terp MV mm $\mathrm{mm}^{3}$ & $\begin{array}{l}114254 \\
\pm 29988\end{array}$ & $\begin{array}{c}117581 \pm 20 \\
398\end{array}$ & 0,685 & $\begin{array}{l}127985 \\
\pm 24119\end{array}$ & $\begin{array}{l}125543 \\
\pm 25483\end{array}$ & 0,663 & 0,542 \\
\hline $\operatorname{varp} \mathrm{MV} \mathrm{mm}^{3}$ & $3171 \pm 1210$ & $3059 \pm 1093$ & 0,755 & $3542 \pm 1789$ & $3248 \pm 1151$ & 0,410 & 0,720 \\
\hline $\begin{array}{c}\text { língua rp MV } \\
\mathrm{mm}^{3}\end{array}$ & $\begin{array}{c}41736 \\
\pm 11268\end{array}$ & $\begin{array}{c}44027 \pm 764 \\
2\end{array}$ & 0,525 & $\begin{array}{c}49499 \\
\pm 11215\end{array}$ & $\begin{array}{c}48699 \\
\pm 11867\end{array}$ & 0,761 & 0,472 \\
\hline plrp MV mm & $\begin{array}{l}12061 \\
\pm 3482\end{array}$ & $\begin{array}{c}11742 \pm \\
2325\end{array}$ & 0,583 & $14994 \pm 3715$ & $14042 \pm 3660$ & 0,276 & 0,480 \\
\hline $\begin{array}{c}\text { pmrp MV } \\
\mathrm{mm}^{3}\end{array}$ & $9411 \pm 2272$ & $\begin{array}{c}9315 \\
\pm 1734\end{array}$ & 0,922 & $11232 \pm 2240$ & $\begin{array}{l}10756 \\
\pm 2722\end{array}$ & 0,391 & 0,784 \\
\hline $\begin{array}{c}\text { gpfrp MV } \\
\mathrm{mm}^{3}\end{array}$ & $4746 \pm 2862$ & $\begin{array}{c}4117 \\
\pm 1610\end{array}$ & 0,362 & $4092 \pm 1650$ & $3817 \pm 1724$ & 0,343 & 0,587 \\
\hline terg $\mathrm{MV} \mathrm{mm^{3 }}$ & $\begin{array}{c}131153 \pm \\
38539\end{array}$ & $\begin{array}{c}131153 \pm 38 \\
539\end{array}$ & 0,954 & $\begin{array}{l}127037 \\
\pm 36532\end{array}$ & $\begin{array}{c}126879 \pm \\
39379\end{array}$ & 0,984 & 0,957 \\
\hline varg $\mathrm{MV} \mathrm{mm^{3 }}$ & $5681 \pm 1971$ & $\begin{array}{r}6080 \\
\pm 1705\end{array}$ & 0,540 & $6988 \pm 3399$ & $6664 \pm 3577$ & 0,619 & 0,441 \\
\hline $\begin{array}{c}\text { língua rg MV } \\
\mathrm{mm}^{3}\end{array}$ & $\begin{array}{c}43841 \pm 136 \\
52\end{array}$ & $\begin{array}{c}42747 \pm \\
13102\end{array}$ & 0,679 & $\begin{array}{c}44415 \\
\pm 11055\end{array}$ & $39028 \pm 8193$ & 0,055 & 0,262 \\
\hline plrg MV mm & $\begin{array}{l}10903 \\
\pm 3622\end{array}$ & $\begin{array}{l}10055 \\
\pm 3496\end{array}$ & 0,256 & $39028 \pm 8193$ & $11473 \pm 3572$ & 0,751 & 0,886 \\
\hline
\end{tabular}

Legenda: va retropalatal: via aérea retropalatal; va palato mole epiglote: via aérea entre palato mole e epiglote; va retroglossal: via aérea retroglossal; g parafaríngea: gordura parafaríngea; op língua: outras partes da língua; $m$ pterigoideo: músculo pterigoideo; pl retropalatal: parede lateral retropalatal; pl retroepiglote: parede lateral retroepiglote; g língua: gordura da língua; terp M: total das estruturas retropalatais dentro da mandíbula; varp M: via aérea retropalatal dentro da mandíbula; língua rp: língua retropalatal dentro da mandíbula; plrp M: parede lateral retropalatal dentro da mandíbula; pmrp M: palato mole retropalatal dentro da mandíbula; gpfrp M: gordura parafaríngea retropalatal dentro da mandíbula; terg $\mathrm{M}$ : total das estruturas retroglossal dentro da mandíbula; varg M: via aérea retroglossal dentro da mandíbula; língua rg: língua retroglossal dentro da mandíbula; plrg M: parede lateral retroglossal dentro da mandíbula; terp MV: total das estruturas retropalatais dentro da mandíbula até as pregas vocais; varp MV: via aérea retropalatal dentro da mandíbula até as pregas vocais; língua rp MV: língua retropalatal dentro da mandíbula até as pregas vocais; plrp MV: parede lateral retropalatal dentro da mandíbula até as pregas vocais; pmrp MV: palato mole retropalatal dentro da mandíbula até as pregas vocais; gpfrp MV: gordura parafaríngea retropalatal dentro da mandíbula até as pregas vocais; terg MV: total das estruturas retroglossal dentro da mandíbula até as pregas vocais; varg MV: via aérea retroglossal dentro da mandíbula até as pregas vocais; língua rg MV: língua retroglossal dentro da mandíbula até as pregas vocais; plrg MV: parede lateral retroglossal dentro da mandíbula até as pregas vocais. Dados expressos em valor absoluto ou média \pm desvio padrão para as variáveis com distribuição normal e* $p<0,005$. 


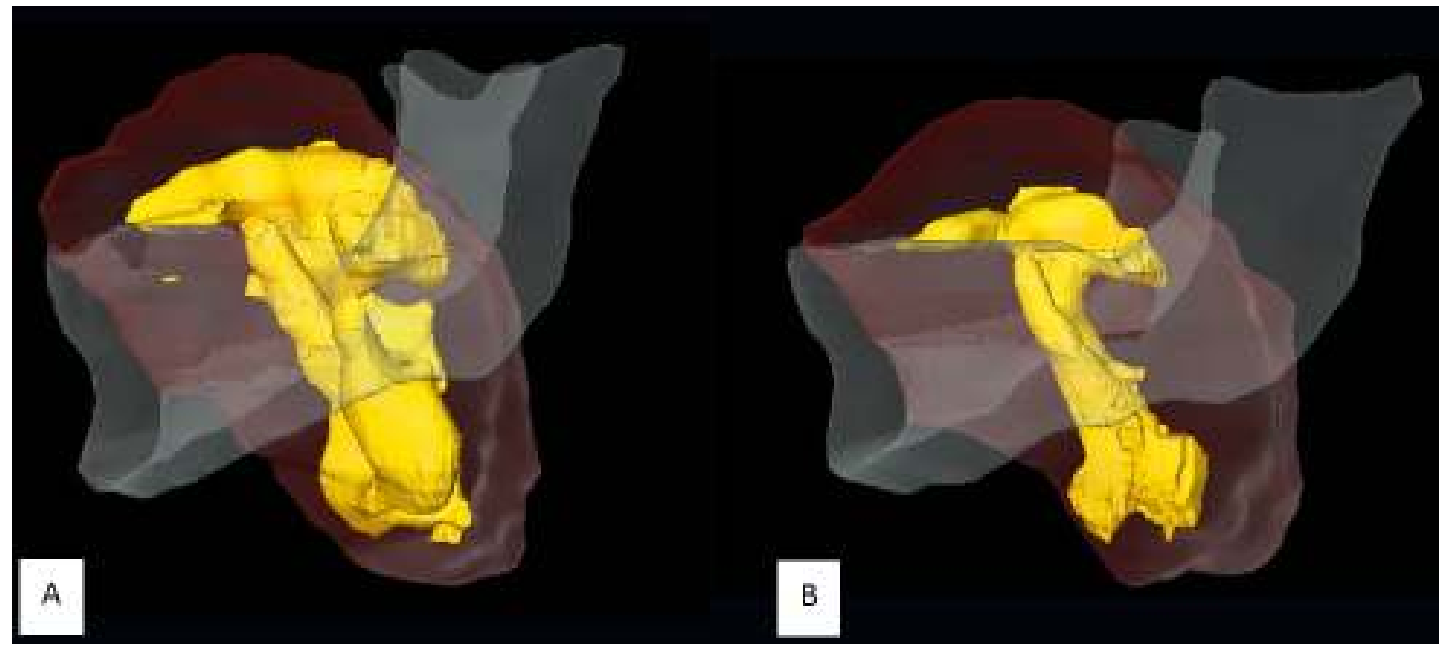

Figura: 18 Reconstrução volumétrica da língua e gordura da língua; A: no basal; B: após 3 meses de TMO

\subsection{Força e fadiga de língua}

Devido ao tempo para importação do equipamento e desenvolvimento do Software as coletas foram iniciadas posteriormente.

Quarenta sujeitos foram incluídos e randomizados para os grupos Controle (20) e TMO (20), 2 sujeitos desistiram (1 Controle e1 TMO). (Figura 19)

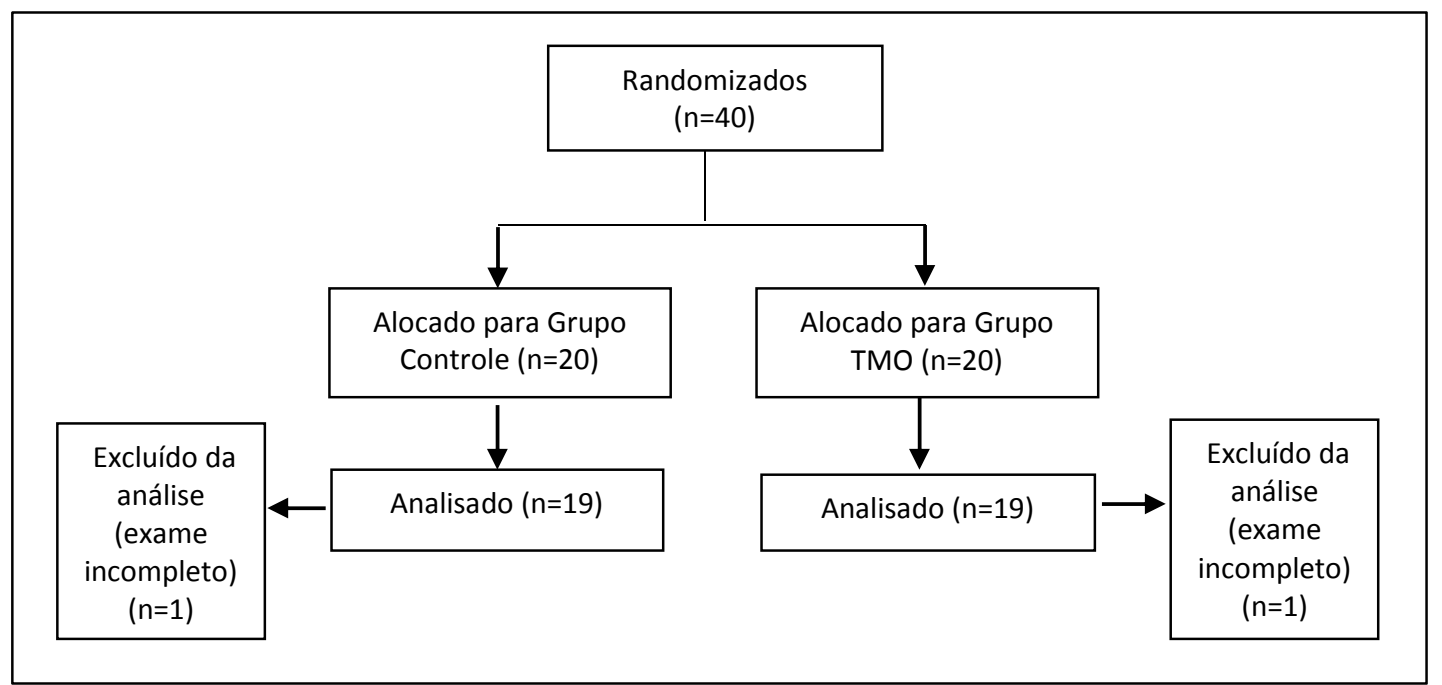

Figura:19 Fluxograma dos sujeitos randomizados, alocados para grupo, perda de seguimento e finalizados nos grupos Controle e TMO na força e fadiga de língua

A tabela 9, abaixo, representa as características demográficas, antropométricas e clínicas dos sujeitos incluídos nos grupos Controle e TMO no basal no exame de força e fadiga de língua.

Os sujeitos randomizados para os grupos Controle e TMO não apresentam diferença estatisticamente significante entre as médias para as características demográficas (gênero e 
idade), antropométricas (IMC, CC e CA) e características clínicas (qualidade de sono, sonolência excessiva, intensidade de ronco, frequência de ronco, avaliação fonoaudiológica para AOS e avaliação fonoaudiológica específica para AOS).

Tabela 9 - Características demográficas, antropométricas e clínicas dos sujeitos incluídos nos grupos Controle e TMO no basal no exame de força da língua e fadiga da língua

\begin{tabular}{cccc}
\hline & Controle (n=19) & TMO (n=19) & p valor \\
\hline Gênero masculino (n, \%) & $12(63,2 \%)$ & $15(78,9 \%)$ & 0,290 \\
Idade (anos) & $46,6 \pm 11,7$ & $42,5 \pm 12,8$ & 0,310 \\
IMC (kg/m²) & $28,4 \pm 3,8$ & $28,6 \pm 4$ & 0,891 \\
Circunferência cervical (cm) & $38,3 \pm 2,7$ & $39,6 \pm 3,2$ & 0,215 \\
Circunferência abdominal (cm) & $95,5 \pm 8,2$ & $96 \pm 8,8$ & 0,860 \\
Qualidade de sono, Pittsburgh & $6,8 \pm 3,4$ & $5,7 \pm 3,3$ & 0,295 \\
Sonolência excessiva, Epworth & $9,9 \pm 5,4$ & $11 \pm 5,2$ & 0,523 \\
Intensidade do ronco, questionário & $2,6 \pm 1$ & $2,1 \pm 1,2$ & 0,187 \\
Frequência do ronco, questionário & $4[1-4]$ & $2,9 \pm 1,3$ & 0,252 \\
Av. fono. Geral & $33,5 \pm 7,8$ & $32,5 \pm 10,2$ & 0,750 \\
Av. fono. espec. & $10,6 \pm 2,2$ & $9,6 \pm 3,2$ & 0,238 \\
\hline
\end{tabular}

IMC: índice de massa corpórea; Av. fono. geral: avaliação fonoaudiológica geral para AOS; Av. fono. espec.: Avaliação fonoaudiológica especifica para AOS. Dados expressos em valor absoluto ou média \pm desvio padrão para as variáveis com distribuição normal e medianas [intervalo interquartil] para variáveis sem distribuição normal e* $p<0,005$.

A tabela 10, abaixo apresenta as características polissonográficas e de força e fadiga da língua dos sujeitos incluídos nos grupos Controle e TMO no basal.

Os sujeitos randomizados para os grupos Controle e TMO não apresentam diferença estatisticamente significante entre as médias para as para as características polissonográficas e de força e fadiga da língua. 
Tabela 10 - Características polissonográficas dos sujeitos incluídos nos grupos Controle e TMO no basal no exame de força e fadiga da língua

\begin{tabular}{cccc}
\hline & $\begin{array}{c}\text { Controle } \\
(\mathbf{n}=\mathbf{1 9})\end{array}$ & $\begin{array}{c}\text { TMO } \\
\text { (n=19) }\end{array}$ & P \\
\hline Polissonografia & & & \\
TTS (min) & $378,8 \pm 41$ & $378,3 \pm 55,8$ & 0,976 \\
TTSsup (min) & $199,9 \pm 118,9$ & $248 \pm 111,2$ & 0,205 \\
Eficiência do sono (\%) & $84,9 \pm 5,6$ & $86,1 \pm 12,2$ & 0,692 \\
Índice de despertares (desp/h) & $19,2 \pm 8,7$ & $21,1 \pm 11,5$ & 0,552 \\
IAH (events/h) & $18 \pm 11,7$ & $20,8 \pm 16,5$ & 0,557 \\
IAH NREM (events/h) & $14,3 \pm 9,6$ & $18,7 \pm 16,3$ & 0,317 \\
IAH REM (events/h) & $32,7 \pm 24,3$ & $27,9 \pm 23$ & 0,538 \\
IAH supino (events/h) & $28 \pm 13,8$ & $26,8 \pm 19,2$ & 0,815 \\
IA obstrutiva (events/h) & $0,4[0-10,4]$ & $0,6[0-62,7]$ & 0,310 \\
IH (events/h) & $15,4 \pm 10,5$ & $14,9 \pm 9,6$ & 0,874 \\
SpO2 mín (\%) & $83,9 \pm 6,2$ & $85,2 \pm 5,7$ & 0,519 \\
IOPI & $13,9 \pm 8,7$ & $14 \pm 15,6$ & 0,980 \\
\hline Índice de dessaturação (events/h) & & & \\
\hline Força da língua (kPa) & $58,5 \pm 16,8$ & $52,6 \pm 10,1$ & 0,243 \\
Fadiga da língua (s) & $33,6 \pm 14$ & $30,4 \pm 11,8$ & 0,569 \\
\hline
\end{tabular}

TTS: Tempo total de sono; sup: supino; IAH: índice de apneia e hipopneia; NREM: sono não REM; REM: sono REM; IA obstrutiva: índice de apneias obstrutivas; IH: índice de hipopneias; SpO2 mín: saturação mínima. Dados expressos em valor absoluto ou média \pm desvio padrão para as variáveis com distribuição normal e medianas [intervalo interquartil] para variáveis sem distribuição normal.

A Tabela 11 abaixo apresenta os resultados no basal e após 3 meses de randomização das características antropométricas e clínicas dos sujeitos dos grupos Controle e TMO com os resultados do teste ANOVA paramétrico. Observando-se p significativo para Avaliação fonoaudiológica para AOS e Avaliação fonoaudiológica específica para AOS.

Além disso, são apresentados os resultados do teste $\mathrm{T}$ paramétrico para o Controle demonstrou: diferença estatisticamente significante entre as médias basal e após 3 meses para redução da Sonolência excessiva (Epworth) e frequência do ronco. O TMO observou diferença estatisticamente significante para redução da circunferência cervical, melhora da qualidade do sono (Pittsburgh), melhora da intensidade do ronco e redução da pontuação dos protocolos de Avaliação fonoaudiológica para AOS e Avaliação fonoaudiológica específica para AOS. 
Tabela 11 - Características antropométricas e clínicas dos pacientes incluídos nos grupos Controle e TMO no basal e após 3 meses de randomização no exame de força da língua e fadiga da língua

\begin{tabular}{|c|c|c|c|c|c|c|c|}
\hline \multirow[b]{2}{*}{$\mathrm{IMC}\left(\mathrm{kg} / \mathrm{m}^{2}\right)$} & \multicolumn{2}{|c|}{$\begin{array}{c}\text { Controle } \\
(n=19)\end{array}$} & \multirow{2}{*}{$\begin{array}{c}\mathbf{P} \\
\text { valor } \\
0,858\end{array}$} & \multicolumn{2}{|c|}{$\begin{array}{c}\text { TMO } \\
(n=19)\end{array}$} & \multirow{2}{*}{$\begin{array}{c}\mathbf{p} \\
\text { valor } \\
0,479\end{array}$} & \multirow{2}{*}{$\begin{array}{c}\mathbf{p} \\
\text { Valor } \\
0,545\end{array}$} \\
\hline & $28,4 \pm 3,8$ & $28,4 \pm 3,8$ & & $28,6 \pm 4$ & $28,5 \pm 3,8$ & & \\
\hline $\mathrm{CC}(\mathrm{cm})$ & $38,3 \pm 2,7$ & $38,2 \pm 2,8$ & 0,379 & $39,6 \pm 3,2$ & $39,2 \pm 3$ & $0,003^{*}$ & 0,262 \\
\hline $\mathrm{CA}(\mathrm{cm})$ & $95,5 \pm 8,2$ & $96,2 \pm 7,8$ & 0,127 & $96 \pm 8,8$ & $95 \pm 8,2$ & 0,607 & 0,169 \\
\hline Pittsburgh & $6,8 \pm 3,4$ & $6,2 \pm 3,4$ & 0,231 & $5,7 \pm 3,3$ & $4,3 \pm 2,7$ & $0,008^{*}$ & 0,318 \\
\hline Epworth & $9,9 \pm 5,4$ & $8,5 \pm 6,2$ & $0,023 *$ & $11 \pm 5,2$ & $10,4 \pm 4,2$ & 0,320 & 0,355 \\
\hline $\begin{array}{l}\text { Intensidade } \\
\text { do ronco }\end{array}$ & $2,6 \pm 1$ & $2,3 \pm 1,2$ & 0,235 & $2,1 \pm 1,2$ & $1[0-4]$ & $0,021^{*}$ & 0,154 \\
\hline $\begin{array}{c}\text { Frequência } \\
\text { do ronco }\end{array}$ & $4[1-4]$ & $2,7 \pm 1,2$ & 0,019* & $2,9 \pm 1,3$ & $2,7 \pm 1,2$ & 0,262 & 0,259 \\
\hline Aval.fono & $33,5 \pm 7,8$ & $31,1 \pm 9,5$ & 0,086 & $32,5 \pm 10,2$ & $17,5 \pm 8,5$ & $<0,000^{*}$ & $<0,000^{*}$ \\
\hline Aval.espec. & $10,6 \pm 2,2$ & $9,9 \pm 3,3$ & 0,380 & $9,6 \pm 3,2$ & $4 \pm 2,5$ & $<0,000^{*}$ & $<0,000^{*}$ \\
\hline
\end{tabular}

A Tabela 12 apresenta as características polissonográficas e de força e fadiga de língua dos pacientes incluídos no estudo no basal e após 3 meses de randomização do Controle e TMO com os resultados do teste ANOVA paramétrico. Observando-se p significativo para o índice de apneia hipopneia (IAH), índice de apneia hipopneia no sono NREM (IAH NREM) e índice de hipopneia (IH).

Além disso, são apresentados os resultados do teste T paramétrico para o TMO observou diferença estatisticamente significante entre as médias basal e após 3 meses para redução do tempo total de sono (TTS supino), índice de despertares, IAH NREM (não REM) e índice de dessaturação e aumento da força da língua.

Os resultados do teste $\mathrm{T}$ paramétrico para o Controle não apresentou diferença estatisticamente significante entre as médias basal e após 3 meses.

Tabela 12 - Características polissonográficas e do exame de força e fadiga de língua nos sujeitos incluídos nos grupos Controle e TMO no basal e após 3 meses de randomização no exame de força e fadiga de língua

\begin{tabular}{ccccc}
\hline $\begin{array}{c}\text { Controle } \\
(n=19)\end{array}$ & $\begin{array}{c}p \\
\text { valor }\end{array}$ & $\begin{array}{c}\text { TMO } \\
(n=19)\end{array}$ & $\begin{array}{c}p \\
\text { valor }\end{array}$ & P valor \\
\hline
\end{tabular}




\begin{tabular}{|c|c|c|c|c|c|c|c|}
\hline TTS (hs) & $378,8 \pm 41$ & $361,4 \pm 70,4$ & 0,184 & $378,3 \pm 55,8$ & $\begin{array}{l}388,8 \\
\pm 72,5\end{array}$ & 0,477 & 0,154 \\
\hline $\begin{array}{l}\text { TTS sup. } \\
\text { (hs) }\end{array}$ & $\begin{array}{r}199,9 \\
\pm 118,9\end{array}$ & $165,9 \pm 108,2$ & 0,139 & $248 \pm 111,2$ & $\begin{array}{c}188,5 \\
\pm 123,3\end{array}$ & $0,014^{*}$ & 0,414 \\
\hline $\begin{array}{c}\text { Efic.sono } \\
(\%)\end{array}$ & $84,9 \pm 5,6$ & $82 \pm 11,9$ & 0,165 & $86,1 \pm 12,2$ & $88 \pm 9,6$ & 0,151 & 0,051 \\
\hline Idesp. & $19,2 \pm 8,7$ & $18,8[65,-43,9]$ & 0,268 & $21,1 \pm 11,5$ & $16,7 \pm 9,5$ & $0,030^{*}$ & 0,748 \\
\hline $\mathrm{IAH}$ & $18 \pm 11,7$ & $20 \pm 11$ & 0,331 & $20,8 \pm 16,5$ & $16,2 \pm 11,7$ & 0,063 & 0,039* \\
\hline $\begin{array}{c}\text { IAH } \\
\text { NREM }\end{array}$ & $14,3 \pm 9,6$ & $22,4 \pm 23,3$ & 0,171 & $18,7 \pm 16,3$ & $13,8 \pm 11,8$ & $0,047^{*}$ & $0,041 *$ \\
\hline IAH REM & $32,7 \pm 24,3$ & $33,3 \pm 23$ & 0,903 & $27,9 \pm 23$ & $21,8 \pm 18$ & 0,239 & 0,357 \\
\hline IAH sup. & $28 \pm 13,8$ & $26,1 \pm 16,7$ & 0,565 & $26,8 \pm 19,2$ & $26,8 \pm 18,7$ & 0,989 & 0,723 \\
\hline IA obst. & $\begin{array}{c}0,4[0- \\
10,4]\end{array}$ & $1,8 \pm 2,4$ & 0,507 & $0,6[0-62,7]$ & $0,9[0-52]$ & 0,531 & 0,434 \\
\hline $\mathrm{IH}$ & $15,4 \pm 10,5$ & $17,9 \pm 10,5$ & 0,218 & $14,9 \pm 9,6$ & $11,4 \pm 6,2$ & 0,083 & $0,034^{*}$ \\
\hline $\begin{array}{l}\mathrm{SpO}_{2} \\
\text { mín. }\end{array}$ & $83,9 \pm 6,2$ & $84,7 \pm 5,9$ & 0,390 & $85,2 \pm 5,7$ & $83,7 \pm 7,6$ & 0,241 & 0,143 \\
\hline Idess. & $13,9 \pm 8,7$ & $12,7 \pm 8$ & 0,398 & $14 \pm 15,6$ & $10,6 \pm 11,2$ & $0,040 *$ & 0,313 \\
\hline \multicolumn{8}{|l|}{ IOPI } \\
\hline $\begin{array}{c}\text { Força da } \\
\text { língua } \\
(\mathrm{kPa})\end{array}$ & $58,5 \pm 16,8$ & $57,3 \pm 12,5$ & 0,685 & $52,6 \pm 10,1$ & $55,4 \pm 12,1$ & $0,046^{*}$ & 0,202 \\
\hline $\begin{array}{l}\text { Fadiga da } \\
\text { língua (s) }\end{array}$ & $33,6 \pm 14$ & $31,6 \pm 16,8$ & 0,544 & $30,4 \pm 11,8$ & $35,1 \pm 14,8$ & 0,198 & 0,169 \\
\hline \multicolumn{8}{|c|}{ TTS: Tempo total de sono; sup: na posição supina; Efic. sono: eficiência do sono; Idesp. : índice de despertares; } \\
\hline
\end{tabular}

\subsection{Pressão Crítica de Fechamento (Pcrit)}

No início do projeto tínhamos como objetivo incluir apenas homens e pacientes com AOS moderado. Devido ao conhecimento prévio de que mulheres apresentam menor colapsabilidade da VAS em relação aos homens na Pcrit ${ }^{[76]}$ e conhecimento clínico da pouca melhora em relação ao IAH de pacientes com apneia leve e ronco habitual devido ao efeito chão, além do conhecimento clínico de que os pacientes com AOS grave a melhora do IAH seria insatisfatória afim de que o paciente provavelmente ainda necessitasse de outro tratamento. Portanto tentamos arduamente concretizar os objetivos iniciais.

O exame de Pcrit com sono induzido é de extrema complexidade. Diversas foram as dificuldades técnicas, principalmente em relação à vazamentos pela boca nos quais não foi possível realizar as medidas. Nestes casos optava-se por: 1a apertar ainda mais a mentoneira colocada para evitar a abertura da boca; 2a limpeza da mucosa externa e colocação de uma fita 
adesiva; porém na maioria dos casos o paciente continuava com vazamento pela boca. Por este motivo 7 pacientes (Controle (2) e TMO (5)) foram excluídos deste protocolo por vazamento na máscara. Durante o protocolo é necessário que o paciente durma e permaneça no estágio 2 e/ou 3 do sono. Dois pacientes (Controle (1) e TMO (1)) não conseguiram aprofundar nos estágios de sono, portanto não foi realizada coleta dos dados suficiente para análise e foram excluídos deste protocolo por não conseguirem aprofundar o sono. Quatro pacientes desistiram do protocolo (Controle (3) e TMO (1)).

$\mathrm{Na}$ data de 25/04/2013, o equipamento que gera pressão negativa quebrou e passou a não fornecer pressões negativas necessárias para realização do exame. Foi realizado contato com o fornecedor do equipamento da Philips Respironics, pois o equipamento é exclusivo para protocolos de pesquisa e existem poucos exemplares desse equipamento. $\mathrm{O}$ equipamento foi enviado aos EUA no dia 17/05/2013 junto com a equipe do Laboratório do Sono do InCor que estava indo para o congresso da ATS (American Thoracic Society) e trocado por outro novo. Dr Geraldo Lorenzi-Filho que retornava para o Brasil no dia 22/05/2013 trouxe o novo equipamento para o laboratório do sono no dia 27/05/2013. O equipamento foi testado e estava funcionando bem.

Devido às grandes dificuldades técnicas apresentadas durante o decorrer do projeto e o tempo despendido em relação às coletas aproximadamente 4 horas, decidimos parar de incluir pacientes nesta parte do protocolo.

Os sujeitos incluídos foram 30 sujeitos, 17 finalizaram o estudo (7 Controle; 10 TMO). (Figura 20) 


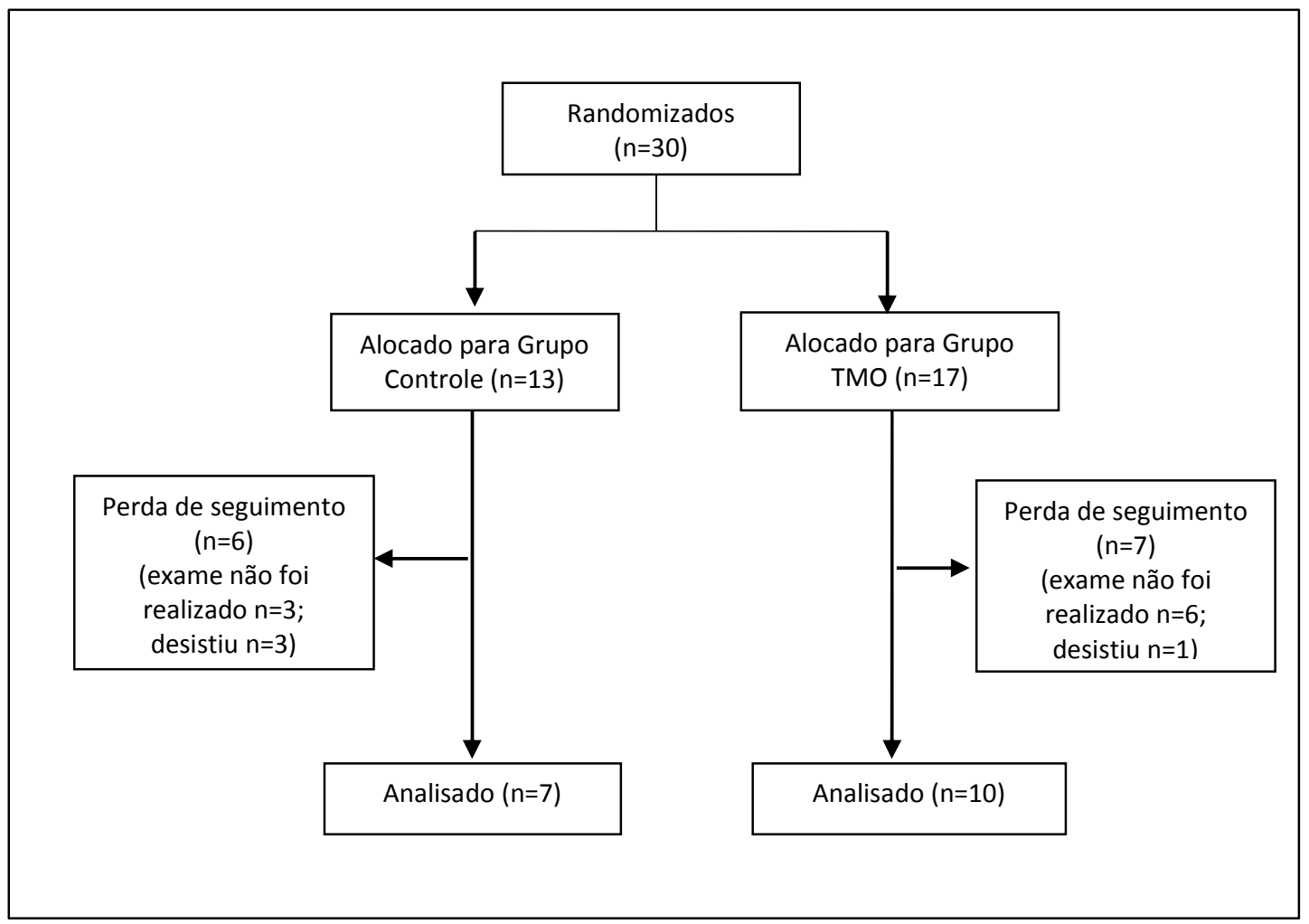

Figura 16: Fluxograma dos pacientes randomizados, alocados para grupo, perda de seguimento e finalizados nos grupos Controle e TMO exame de Pcrit

A tabela 13, abaixo representa as características demográficas, antropométricas, clínicas dos sujeitos incluídos nos grupos Controle e TMO no basal no exame de Pcrit.

Os sujeitos randomizados para grupos Controle e TMO não apresentam diferença estatisticamente significante entre as médias para as características demográficas (gênero e idade), antropométricas (IMC, CC e CA) e características clínicas (qualidade de sono, sonolência excessiva, intensidade de ronco, frequência de ronco, avaliação fonoaudiológica para AOS e avaliação fonoaudiológica específica para AOS). 
Tabela 13 - Características demográficas, antropométricas, clínicas e Pcrit dos sujeitos incluídos nos grupos Controle e TMO no basal no exame de Pcrit

\begin{tabular}{cccc}
\hline & $\begin{array}{c}\text { Controle } \\
(\mathbf{n = 7})\end{array}$ & $\begin{array}{c}\text { TMO } \\
(\mathbf{n = 1 0 )}\end{array}$ & p valor \\
\hline Gênero masculino (n\%) & $7(100 \%)$ & $9(90 \%)$ & 0,403 \\
Idade (anos) & $35,9 \pm 9,5$ & $43 \pm 15,7$ & 0,300 \\
IMC (Kg/m ${ }^{2}$ ) & $27,3 \pm 4,6$ & $28,3 \pm 3,5$ & 0,589 \\
Circunferência cervical (cm) & $38,6 \pm 3,4$ & $40,1 \pm 3,4$ & 0,379 \\
Circunferência abdominal (cm) & $92 \pm 9,8$ & $97,5 \pm 8,3$ & 0,231 \\
Qualidade de sono, Pittsburgh & $7 \pm 2,8$ & $5,6 \pm 3,2$ & 0,364 \\
Sonolência excessiva, Epworth & $13 \pm 5,5$ & $9,2 \pm 5,8$ & 0,196 \\
Intensidade do ronco, questionário & $2,4 \pm 0,9$ & $2,2 \pm 1$ & 0,653 \\
Frequência do ronco, questionário & $3,6 \pm 0,5$ & $2,8 \pm 1,3$ & 0,228 \\
Av. fono. geral & $34,1 \pm 12,2$ & $29,1 \pm 8,9$ & 0,340 \\
Av. fono. espec. & $9,1 \pm 1,7$ & $9,1 \pm 3,2$ & 0,975 \\
\hline
\end{tabular}

IMC: índice de massa corpórea; AOS: apneia obstrutiva do sono; Av. fono. geral: avaliação fonoaudiológica geral para AOS; Av. fono. espec.: Avaliação fonoaudiológica especifica para AOS. Dados expressos em valor absoluto ou média \pm desvio padrão para as variáveis com distribuição normal e * p<0,005.

A Tabela 14, abaixo representa as características polissonográficas e do exame de Pcrit dos sujeitos incluídos nos grupos Controle e TMO no basal no exame de Pcrit.

Os sujeitos randomizados para grupos Controle e TMO não apresentam diferença estatisticamente significante entre as médias para as características polissonográficas e de Pcrit. 
Tabela 14 - Características polissonográficas dos sujeitos incluídos nos grupos Controle e TMO no basal do exame de Pcrit

\begin{tabular}{|c|c|c|c|}
\hline & $\begin{array}{c}\text { Controle } \\
(n=7)\end{array}$ & $\begin{array}{c}\text { TMO } \\
(n=10)\end{array}$ & p valor \\
\hline \multicolumn{4}{|l|}{ Polissonografia } \\
\hline TTS (hs) & $396,7 \pm 38,2$ & $395,1 \pm 47$ & 0,101 \\
\hline TTSsup (hs) & $264,5 \pm 139$ & $248 \pm 87,5$ & 0,738 \\
\hline Eficiência do sono (\%) & $89,2 \pm 5$ & $84,2 \pm 12,5$ & 0,344 \\
\hline Índice de despertares & $16 \pm 7,6$ & $25,8 \pm 12,9$ & 0,095 \\
\hline $\mathrm{IAH}$ & $13 \pm 10,6$ & $22,9 \pm 19,6$ & 0,250 \\
\hline IAH NREM & $10,4 \pm 8,3$ & $22,1 \pm 19,3$ & 0,154 \\
\hline IAH REM & $23,2 \pm 20,1$ & $25 \pm 25,7$ & 0,880 \\
\hline IAH supino & $23,9 \pm 15,4$ & $30,7 \pm 19,6$ & 0,455 \\
\hline IA obstrutiva & $1,2 \pm 2,7$ & $8,3 \pm 19,2$ & 0,355 \\
\hline $\mathrm{IH}$ & $11,3 \pm 9,3$ & $14,1 \pm 7$ & 0,475 \\
\hline $\mathrm{SpO}_{2}$ mín & $85,8 \pm 5,3$ & $85,8 \pm 4,8$ & 0.982 \\
\hline Índice de dessaturação & $11,4 \pm 8,4$ & $16,4 \pm 19$ & 0,525 \\
\hline \multicolumn{4}{|l|}{ Pcrit } \\
\hline Pcrit $\left(\mathrm{cmH}_{2} \mathrm{O}\right)$ & $-1,44 \pm 2,3$ & $-2 \pm 3.3$ & 0,697 \\
\hline Slope & $0,101 \pm 0,56$ & $0,624 \pm 0,24$ & 0,065 \\
\hline Pmanut. $\left(\mathrm{cmH}_{2} \mathrm{O}\right)$ & $7,5 \pm 1,8$ & $8,6 \pm 1,5$ & 0,179 \\
\hline
\end{tabular}

TTS: Tempo total de sono; TTSsup: tempo total de sono na posição supina; IAH: índice de apneia e hipopneia; NREM: sono não REM; REM: sono REM; IA obstrutiva: índice de apneias obstrutivas; IH: índice de hipopneias; $\mathrm{SpO}_{2}$ mín: saturação mínima; Idess.: índice de dessaturação; Pcrit: pressão crítica de fechamento; Pmanut.:pressão de manutenção. Dados expressos em valor absoluto ou média \pm desvio padrão para as variáveis com distribuição normal

A Tabela 15 apresenta os resultados no basal e após 3 meses de randomização das características antropométricas e clínicas dos sujeitos.

As variáveis que demonstram significância estatística da interação grupo e período são: avaliação fonoaudiológica para AOS e avaliação fonoaudiológica específica para AOS.

As variáveis que demonstram significância estatística no TMO no teste $\mathrm{T}$ são: circunferência cervical (CC), qualidade de sono (Pittsburgh), intensidade de ronco e avaliação fonoaudiológica para AOS e avaliação fonoaudiológica específica para AOS.

O Controle não apresenta diferença estatisticamente significante no teste T para nenhuma das variáveis. 
Tabela 15 - Características antropométricas e clínicas dos sujeitos incluídos nos grupos Controle e TMO no basal e após 3 meses de randomização no exame de Pcrit

\begin{tabular}{|c|c|c|c|c|c|c|c|}
\hline \multirow[b]{2}{*}{ IMC $\left(\mathrm{Kg} / \mathrm{m}^{2}\right)$} & \multicolumn{2}{|c|}{$\begin{array}{c}\text { Controle } \\
(n=7)\end{array}$} & \multirow{2}{*}{$\begin{array}{c}\mathbf{p} \\
\text { valor }\end{array}$} & \multicolumn{2}{|c|}{$\begin{array}{c}\text { TMO } \\
(n=10)\end{array}$} & \multirow{2}{*}{$\begin{array}{c}\begin{array}{c}\mathbf{p} \\
\text { valor }\end{array} \\
0,882\end{array}$} & \multirow{2}{*}{$\begin{array}{c}\begin{array}{c}\mathbf{p} \\
\text { valor }\end{array} \\
0,806\end{array}$} \\
\hline & $27,3 \pm 4,6$ & $27,4 \pm 4,6$ & & $28,3 \pm 3,5$ & $28,4 \pm 3,6$ & & \\
\hline $\mathrm{CC}(\mathrm{cm})$ & $38,6 \pm 3,4$ & $38,6 \pm 3,5$ & 0,826 & $40,1 \pm 3,4$ & $39,6 \pm 3$ & $0,025^{*}$ & 0,118 \\
\hline $\mathrm{CA}(\mathrm{cm})$ & $92 \pm 9,8$ & $92,6 \pm 9,9$ & 0,536 & $97,5 \pm 8,3$ & $97,2 \pm 7,3$ & 0,710 & 0,481 \\
\hline Pittsburgh & $7 \pm 2,8$ & $5,9 \pm 2,7$ & 0,172 & $5,6 \pm 3,2$ & $3,8 \pm 2,9$ & $0,014^{*}$ & 0,495 \\
\hline Epworth & $13 \pm 5,5$ & $11,1 \pm 8,2$ & 0,229 & $9,2 \pm 5,8$ & $9,3 \pm 5,8$ & 0,891 & 0,190 \\
\hline $\begin{array}{l}\text { Intensidade } \\
\text { do ronco }\end{array}$ & $2,4 \pm 0,9$ & $2,1 \pm 0,9$ & 0,569 & $2,2 \pm 1$ & $1,5 \pm 1$ & $0,045^{*}$ & 0,449 \\
\hline $\begin{array}{c}\text { Frequência } \\
\text { do ronco }\end{array}$ & $3,6 \pm 0,5$ & $2,7 \pm 1,7$ & 0,225 & $2,8 \pm 1,3$ & $2,3 \pm 0,9$ & 0,244 & 0,623 \\
\hline Aval.fono & $34,1 \pm 12,2$ & $32,9 \pm 12,7$ & 0,623 & $29,1 \pm 8,9$ & $17,2 \pm 9$ & $0,002 *$ & $0,014^{*}$ \\
\hline Aval.espec. & $9,1 \pm 1,7$ & $9,9 \pm 4,2$ & 0,613 & $9,1 \pm 3,2$ & $3,5 \pm 2,5$ & $<0,000^{*}$ & $0,002 *$ \\
\hline
\end{tabular}

A Tabela 16 apresenta os resultados no basal e após 3 meses de randomização das características polissonográficas e de Pcrit dos sujeitos dos grupos Controle e TMO de acordo com os resultados do teste ANOVA dois caminhos.

As variáveis que demonstram significância estatística da interação grupo e período são: índice de despertar (Idesp) e saturação mínima $\left(\mathrm{SpO}_{2}\right)$.

As variáveis que demonstram significância estatística no TMO no teste T é o índice de despertar (Idesp).

O Controle não apresenta diferença estatisticamente significante no teste $\mathrm{T}$ para nenhuma das variáveis. 
Tabela 16 - Características polissonográficas e do exame de Pcrit dos sujeitos dos grupos Controle e TMO no basal e após 3 meses de randomização no exame de Pcrit

\begin{tabular}{|c|c|c|c|c|c|c|c|}
\hline & \multicolumn{2}{|c|}{ Controle $(n=7)$} & $\begin{array}{c}\mathbf{p} \\
\text { valor }\end{array}$ & \multicolumn{2}{|c|}{ TMO $(n=10)$} & $\begin{array}{c}p \\
\text { valor }\end{array}$ & $\begin{array}{c}\mathbf{p} \\
\text { valor }\end{array}$ \\
\hline TTS (min) & $396,7 \pm 38,2$ & $\begin{array}{l}412,3 \\
\pm 32,6\end{array}$ & 0,297 & $395,1 \pm 47$ & $380,3 \pm 79,8$ & 0,372 & 0,850 \\
\hline $\begin{array}{l}\text { TTS supino } \\
\text { (min) }\end{array}$ & $264,5 \pm 139$ & $\begin{array}{l}227,1 \\
\pm 162\end{array}$ & 0,407 & $248 \pm 87,5$ & $214,6 \pm 150$ & 0,224 & 0,994 \\
\hline Efic.sono(\%) & $89,2 \pm 5$ & $91,1 \pm 1,9$ & 0,290 & $84,2 \pm 12,5$ & $86,3 \pm 9,7$ & 0,342 & 0,962 \\
\hline Idesp.(desp/h) & $16 \pm 7,6$ & $17,4 \pm 6,4$ & 0,589 & $25,8 \pm 12,9$ & $18,1 . \pm 12,1$ & $0,028^{*}$ & $0,042^{*}$ \\
\hline IAH (events/h) & $13 \pm 10,6$ & $13 \pm 9$ & 0,954 & $22,9 \pm 19,6$ & $19,2 \pm 14,5$ & 0,214 & 0,336 \\
\hline $\begin{array}{l}\text { IAH NREM } \\
\text { (events/h) }\end{array}$ & $10,4 \pm 8,3$ & $10,6 \pm 8$ & 0,915 & $22,1 \pm 19,3$ & $17,1 \pm 14,9$ & 0,118 & 0,195 \\
\hline $\begin{array}{l}\text { IAH REM } \\
\text { (events/h) }\end{array}$ & $23,2 \pm 20,1$ & $23 \pm 15,8$ & 0,938 & $25 \pm 25,7$ & $21,5 \pm 19,7$ & 0,672 & 0,738 \\
\hline $\begin{array}{l}\text { IAH supino } \\
\text { (events/h) }\end{array}$ & $23,9 \pm 15,4$ & $16,8 \pm 10,3$ & 0,501 & $30,7 \pm 19,6$ & $32,6 \pm 22,2$ & 0,755 & 0,531 \\
\hline $\begin{array}{l}\text { IA obstrutiva } \\
\text { (events/h) }\end{array}$ & $1,2 \pm 2,7$ & $0,9 \pm 1,5$ & 0,518 & $8,3 \pm 19,2$ & $7,2 \pm 15,9$ & 0,392 & 0,630 \\
\hline IH (events/h) & $11,3 \pm 9,3$ & $11,6 \pm 8,6$ & 0,830 & $14,1 \pm 7$ & $11,6 \pm 5,9$ & 0,178 & 0,248 \\
\hline $\begin{array}{c}\mathrm{SpO}_{2} \text { mínima } \\
(\%)\end{array}$ & $85,8 \pm 5,3$ & $87,3 \pm 3,5$ & 0,276 & $85,8 \pm 4,9$ & $81,5 \pm 8,4$ & 0,033 & $0,024^{*}$ \\
\hline Idess (dess/h) & $11,4 \pm 8,4$ & $9,2 \pm 6,5$ & 0,252 & $16,4 \pm 19$ & $14,4 \pm 13,8$ & 0,390 & 0,951 \\
\hline \multicolumn{8}{|l|}{ PCrit } \\
\hline PCrit $\left(\mathrm{cmH}_{2} \mathrm{O}\right)$ & $-1,44 \pm 2,3$ & $-2,29 \pm 3,1$ & 0,428 & $-2 \pm 3,3$ & $-2,9 \pm 2,5$ & 0,199 & 0,345 \\
\hline $\begin{array}{l}\text { Midazolam } \\
\text { (mg) }\end{array}$ & $2,6 \pm 1,3$ & $3,3 \pm 0,9$ & 0,106 & $3 \pm 1,3$ & $2,7 \pm 1,1$ & 0,534 & 0,479 \\
\hline $\begin{array}{l}\text { Pmanut. } \\
\left(\mathrm{cmH}_{2} \mathrm{O}\right)\end{array}$ & $7,5 \pm 1,8$ & $7,6 \pm 2,3$ & 0,711 & $8,6 \pm 1,5$ & $8 \pm 2,7$ & 0,259 & 0,094 \\
\hline
\end{tabular}

índice de despertares; IAH: índice de apneia e hipopneia; NREM: sono não REM; REM: sono REM; IA obstrutiva: índice de apneias obstrutivas; $\mathrm{IH}$ : índice de hipopneias; $\mathrm{SpO}_{2}$ mín: saturação mínima; Idess.: índice de dessaturação; Pmanut.:pressão de manutenção. Dados expressos em valor absoluto ou média \pm desvio padrão para as variáveis com distribuição normal e * $p<0,005$. 
6.Discussão 
O nosso estudo teve como objetivo principal testar a hipótese de que um programa reduzido de exercícios de TMO é capaz de reduzir a gravidade da AOS em pacientes com AOS. Observamos que a TMO realizada por 3 meses é capaz de produzir uma diminuição significativa da gravidade da AOS. No entanto, esses efeitos positivos são vistos somente em pacientes com AOS moderada e grave, não sendo significativo em pacientes com ronco primário e AOS leve. Os efeitos benéficos da TMO são acompanhados de uma melhora da avaliação fonoaudiológica para a AOS. Os efeitos fisiológicos da TMO foram menos evidentes, mas houve uma tendência na melhora na força da língua com diminuição do volume e da gordura da língua.

\subsection{Tipos de exercícios}

A revisão sistemática e a meta análise foram realizadas recentemente abordando o tema terapia miofuncional para tratamento da apneia obstrutiva do sono. ${ }^{[77]}$. Elas demonstraram que a TMO reduz o IAH nos adultos e pode servir como um complemento para outros tratamentos de AOS.

O estudo foi realizado com o instrumento de sopro australiano, conhecido como didgeridoo, para avaliar o efeito após treino com técnica de respiração circular na musculatura da VAS. Foram randomizados 25 pacientes (14 treino com respiração circular e 11 controle) para treinos com duração de 25 minutos, durante 6 dias na semana por 4 meses. ${ }^{[78]}$

Um estudo prévio do nosso laboratório avaliou o efeito de exercícios orofaríngeos, que foi tese da fonoaudióloga Katia Guimarães, randomizou 31 pacientes (15 Controle e $16 \mathrm{TMO}$ ) com AOS moderada. Foram realizados exercícios $(\mathrm{n}=10)$ diariamente por 30 minutos durante 3 meses. ${ }^{[22]}$

Outro estudo, avaliou a efetividade da terapia fonoaudiológica (TF) só ou como coadjuvante no tratamento com CPAP. Os pacientes foram randomizados para quatro grupos: $\mathrm{TF}(\mathrm{n}=27)$; TF em associação com o uso de CPAP $(n=22)$; terapia placebo $(n=24)$; apenas uso de CPAP $(n=27)$ e realizaram uma ampla gama de exercícios diários, com 20 minutos de duração que eram modificados no decorrer das 12 semanas.

Para o estudo de Vanessa Ieto, realizado em conjunto com este protocolo, foi criado um instrumento específico para medir o ronco nos pacientes com ronco primário e AOS leve e moderada. Ela avaliou a frequência e intensidade do ronco após 3 meses de TMO com os exercícios reduzidos. ${ }^{[25][79]}$ 


\subsubsection{Racional de redução dos exercícios}

Tivemos como objetivo incorporar o mínimo possível de exercícios orofaríngeos, permanecendo apenas os que acreditamos atuar especificamente os músculos da língua, supra hióideos, palato mole, elevador do palato, palatoglosso e palatofaríngeo, úvula, bucinadores e orbicular da boca, com enfoque para AOS, além de trabalhar as funções apenas de modo preventivo e de manutenção. Não priorizamos os exercícios da musculatura facial. Os exercícios selecionados foram: o exercício de varrer, o exercício de acoplamento e o exercício de abaixar o dorso da língua, o exercício de elevação do palato mole e músculo da úvula e o exercício de dedo na bochecha foi mantido.

$1^{\circ}$ : O varrer fortalece os músculos da língua e supra hióideos.

$2^{\circ}$ : O acoplamento da língua auxilia o seu reposicionamento, que é um fator importante. Este exercício gera uma pressão negativa que mantém a musculatura da língua grudada ao palato na região anterior e o palato mole permanece próximo à língua, que não é jogado para trás. ${ }^{[80]}$ (Figura 21

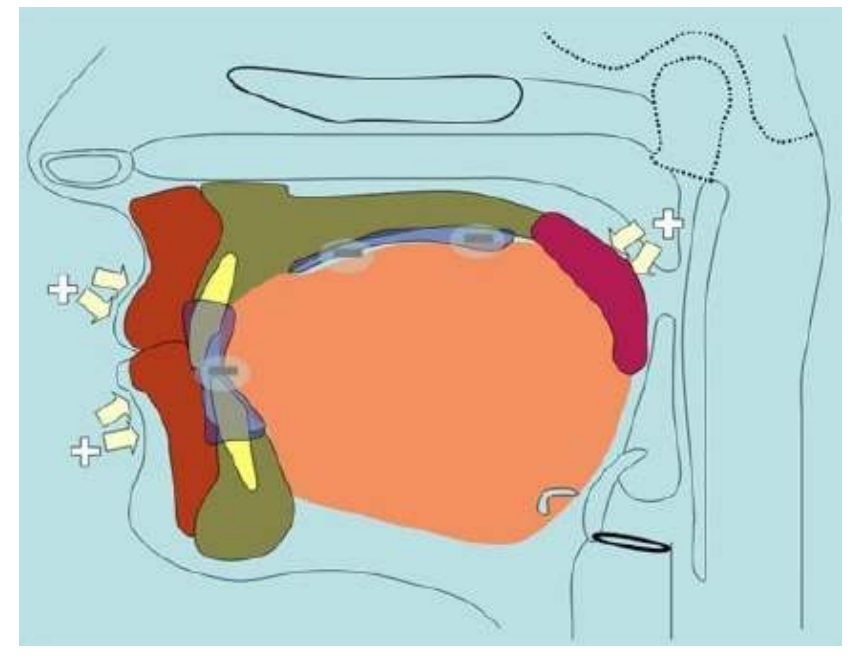

Fonte: Engelke W, 2011

Figura 21: Desenho demonstrando pressão negativa intraoral com posicionamento da língua estabilizada em palato e fechamento dos compartimentos

$3^{\circ}$ : A elevação do palato mole e úvula gera uma contração que fortalece essas estruturas (elevador do palato mole, tensor do palato, palatoglosso e palatofaríngeo e úvula) e reduzem suas movimentações e vibrações.

4: O exercício de abaixamento da língua permite uma maior expansão da VAS retroglossal, com equilíbrio na ativação do genioglosso por meio do relaxamento deste músculo (geralmente muito ativado) e principalmente pela contração do hioglosso. 
50: O exercício do dedo na bochecha auxilia a manter o vedamento labial pela cinta que o músculo bucinador forma com o músculo orbicular da boca. Isso consequentemente previne a respiração oral.

$6^{\text {o: }}$ A mastigação bilateral alternada auxilia na manutenção da musculatura intrínseca da língua, que durante a mastigação de cada lado se mantém contraída, mantendo a contração dos músculos transverso e vertical. Esta função também utiliza o mecanismo de bucinadores, o que fortalece a musculatura e auxilia o vedamento labial.

Não foram utilizados cinco exercícios da terapia da fonoaudióloga Kátia Guimarães ${ }^{[21]}$ :

A escovação da língua que atua na propriocepção da musculatura da língua. Consideramos este exercício desnecessário porque temos outro que além de estimular a propriocepção, estimula o reflexo de abaixamento do dorso da língua

Os quatro exercícios faciais foram retirados porque utilizamos outros que consideramos mais eficientes. São eles: contrair o músculo orbicular da boca, realizar movimento de sucção contraindo o bucinador, elevar alternada do canto da boca e lateralizar a mandíbula.

\subsection{Efeito nos diferentes trabalhos}

No nosso estudo avaliamos a efetividade da TMO com um número reduzido de exercícios orofaríngeos na diminuição da gravidade da AOS em pacientes com ronco primário, AOS leve, moderada e grave. Demonstrou-se um efeito significativo sobre o IAH geral, porém ao estratificar os dados o efeito significativo ocorreu no IAH de pacientes com AOS moderada e grave.

Possivelmente devido a um efeito chão, no ronco primário e AOS leve. Porém, comparando-se os estudos de forma estratificada e em porcentagem de melhora observa-se que a redução do IAH em estudo pioneiro ${ }^{[22]}$ foi maior. Observa-se que no atual estudo não houve redução na AOS leve. Questiona-se a pouca adesão ao estudo ou que a redução dos exercícios tenha comprometido a diminuição do IAH. 
Tabela 18 - Comparação dos dados do grupo terapia nos diversos estudos

\begin{tabular}{|c|c|c|c|c|c|}
\hline & Puhan $^{[78]}$ & Guimarães $^{[22]}$ & Diaferia $^{[23]}$ & leto[$^{[25]}$ & Presente estudo \\
\hline Tipo de estudo & randomizado & randomizado & randomizado & randomizdo & randomizado \\
\hline $\mathrm{N}$ & 14 & 16 & 27 & 19 & 30 \\
\hline Idade (anos) & 50 & 52 & 45 & 48 & 46 \\
\hline \multirow[t]{2}{*}{$\mathrm{IMC}\left(\mathrm{kg} / \mathrm{m}^{2}\right)$} & $25,8 \pm 4$ & $29,6 \pm 3,8$ & 25 & $27,5[26,6-$ & $28,9 \pm 3,5$ \\
\hline & & & & $30,9]$ & \\
\hline \multirow[t]{2}{*}{$\mathrm{CC}$} & ----- & 39,6 vs 38,5 & 41,6 vs 41,5 & 38 vs 37,5 & 38,8 vs 38,4 \\
\hline & & $p=0,01^{*}$ & NS & $p=0,038^{*}$ & $p=0,047^{*}$ \\
\hline \multicolumn{6}{|c|}{ Questionários } \\
\hline \multirow[t]{2}{*}{ Epworth } & $0,03 *$ & 14 vs 8 & 13,7 vs7,5 & NS & NS \\
\hline & & $p=0,006^{*}$ & $<0,001^{*}$ & & \\
\hline \multirow[t]{2}{*}{ Pittsburgh } & NS & 10 vs 7 & ------- & NS & NS \\
\hline & & $p=0,001^{*}$ & & & \\
\hline \multicolumn{6}{|c|}{ Exercícios tipo/quantidade } \\
\hline $\begin{array}{l}\text { Quantidade de } \\
\text { exercícios }\end{array}$ & 1 & 10 & $\begin{array}{c}\text { Ampla gama de } \\
\text { exercícios }\end{array}$ & 6 & 6 \\
\hline Tempo & 6 dias $/ 25$ & 7 dias $/ 30$ & 7dias/20 & 7 dias $/ 24$ & 7 dias $/ 24$ \\
\hline \multirow[t]{2}{*}{ praticado } & minutos $/ 4$ & minutos/3meses & minutos $/ 3$ & minutos $/ 3$ & minutos $/ 3$ meses \\
\hline & meses & & meses & meses & \\
\hline \multicolumn{6}{|c|}{ IAH estratificado } \\
\hline \multirow[t]{4}{*}{ IAH geral } & NS & $22,4 \pm 4,8$ vs 13,7 & 28 vs 13,9 & NS & $19,5 \pm 14,2$ vs \\
\hline & & $\pm 8,5$ & $<0,001^{*}$ & & $15 \pm 10,2$ \\
\hline & & $38,4 \%$ & & & $0,006 *$ \\
\hline & & & & & $23,1 \%$ \\
\hline \multirow[t]{2}{*}{ SpO2 } & ------- & 82,7 vs 83,6 & 83,7 vs 84,9 & 88 vs 86 & 85,1 vs 83,8 \\
\hline & & NS & $<0,001^{*}$ & NS & NS \\
\hline \multirow{2}{*}{$\begin{array}{l}\text { Índice de } \\
\text { despertares }\end{array}$} & ------- & ------- & 26,3 vs 21,3 & 19 vs 15,3 & 21,3 vs 16,9 \\
\hline & & & $<0,001^{*}$ & $0,039 *$ & $<0,003^{*}$ \\
\hline \multirow[t]{2}{*}{ AOS leve } & ------ & ------- & -------- & NS & $10,5 \pm 3,2$ vs $12 \pm 6$ \\
\hline & & & & & NS \\
\hline \multirow[t]{4}{*}{ AOS moderada } & $22,3 \pm 5$ vs ---- & $22,4 \pm 4,8$ vs 13,7 & --------- & 25,4 vs 18,1 & $23,8 \pm 5,2$ vs \\
\hline & ---- & $\pm 8,5$ & & $\mathrm{p}=0,017^{*}$ & $17,7 \pm 5,2$ \\
\hline & & $38,4 \%$ & & $(28,7 \%)$ & $p=0,012^{*}$ \\
\hline & & & & & $(25,6 \%)$ \\
\hline \multirow[t]{4}{*}{ AOS grave } & ------ & ----- & ------- & ----- & $43,9 \pm 19,5$ vs \\
\hline & & & & & $24,7 \pm 21,4$ \\
\hline & & & & & $p=0,012^{*}$ \\
\hline & & & & & $(43,7 \%)$ \\
\hline
\end{tabular}

${ }^{*} \mathrm{p}<0,05$. 
Em nosso trabalho não observamos o impacto da TMO nos questionários de qualidade de sono (questionário de Pittsburgh) e no grau de sonolência excessiva diurna (questionário Epworth). Esses dados diferem do trabalho de Guimarães, Puhan e Diaféria que observaram uma melhora na sonolência. Por outro lado, nossos dados estão em linha com os resultados recentes de Ieto, que também não observou melhora na sonolência. Em relação a qualidade de sono observada pelo questionário de Pittsburgh, os dados estão em acordo com Puhan e Ieto, mas diferem do estudo de Guimarães, que observou melhora na qualidade de sono.

Especulamos que essas diferenças sejam dependentes dos níveis basais de cada variável. O mesmo fenômeno acontece com o IAH em pacientes que não têm a variável alterada ou pouco alterada no momento basal. São casos que se modificam com o tratamento pois esses parâmetros já estavam próximos da normalidade na entrada do estudo.

Durante o atual estudo com TMO não foram observadas mudanças significativas no IMC. Os pacientes randomizados para TMO apresentaram uma diminuição significativa na CC $(38,8 \pm 3,3$ vs $38,4 \pm 4)$ de $0,4 \mathrm{~cm}$, assim como estudos prévios que também apontaram uma redução de $1,0 \mathrm{~cm}^{[22]}$ e $0,5 \mathrm{~cm}^{[25]}$. Outro estudo porém, não constatou modificação na $\mathrm{CC}^{[23]}$.

No estudo com TMO reduzida os dados polissonográficos, como o índice de despertar, apresentaram uma redução significativa no grupo terapia $(21,3 \pm 10,9$ vs $16,9 \pm 7,9$ despertares/h), semelhantes aos achados de Diaféria e Ieto, porém diferentemente de Guimarães. Já os dados de saturação mínima foram diferentes dos achados de Diaféria, no entanto, similares aos dados de Ieto e Guimarães, nos quais a saturação mínima não teve diferença estatisticamente significante.

\subsection{Efeitos em outras variáveis}

Os efeitos da TMO na avaliação fonoaudiológica miofuncional específica para AOS utilizada mostraram uma redução significativa na pontuação. Por meio da avaliação observouse uma melhora efetiva na musculatura orofaríngea, indicando o uso da avaliação na prática clínica, apesar de ainda ser considerada subjetiva. A avaliação não ocorreu de forma cega porque a foi a própria fonoaudióloga quem avaliou, acompanhou as terapias e reavaliou os pacientes.

Os efeitos da TMO na anatomia da via aérea superior (VAS), por meio da ressonância magnética, (RM) não demonstraram interação significativa no teste ANOVA de duas vias. Possivelmente isso não ocorreu nos dados da RM porque o número de pacientes era pequeno, 24 pacientes (10 do grupo controle e 14 do grupo terapia), o mesmo problema ocorreu na análise da quantidade de gordura da língua porque o número de pacientes era ainda menor. ( 8 do grupo controle e 13 do grupo terapia) provavelmente inviabilizando a interação. 
Os possíveis mecanismos de ação que devem reduzir o IAH são mostrados pelo teste $\mathrm{t}$ pareado em pacientes na TMO. A redução da quantidade da gordura intramuscular $(\mathrm{p}=0.008)$ ocasiona a diminuição do volume da língua $(\mathrm{p}=0.031)$.

No estudo anterior ${ }^{[22]}$ os pacientes eram mais velhos e com maior IMC, por isso, apresentavam possivelmente maior quantidade de gordura acumulada e consequentemente isso também deve ter ocorrido na língua. Portanto, ao realizarem os exercícios orofaríngeos, reduziriam mais a quantidade de gordura na língua e reduziriam mais o IAH.

Os efeitos da TMO na fisiologia avaliados por força e fadiga de língua em 38 pacientes (19 Controle e 19 TMO) não demonstraram interação significativa no teste ANOVA de duas vias. Observamos no teste $\mathrm{t}$ um aumento significativo da força da língua $(\mathrm{p}=0,046)$ no TMO. Este não era o objetivo principal, mas demonstrou um pequeno aumento no grupo TMO $(52,6 \pm 10,1$ vs $55,4 \pm 12,1)$. Estudos demonstram que a força de língua pode ser aumentada com exercícios de língua, ${ }^{[81]}{ }^{[82]}$ porém, com exercícios de treino de força, que exigem maior intensidade de força da língua em relação aos exercícios realizados pelo TMO.

Esperava-se modificações no tempo de fadiga da musculatura, porém, o estudo prévio não demonstrou modificações significativas para a fadiga após exercícios para a contração mantida, ${ }^{[81]}$ mesmo porque, para modificação na musculatura da língua são necessários treinos específicos de acordo com cada objetivo ${ }^{[83]}$, o que não foi realizado no TMO.

$\mathrm{Na}$ avaliação da fisiologia da VAS por meio da pressão crítica de fechamento (Pcrit) mostrou-se de difícil realização e foram incluídos 7 do grupo controle e 10 do grupo exercícios. Além disso, o número de sujeitos para demonstrar modificações na VAS de forma significativa pode ser grande, visto que as modificações em relação a pressão são mínimas. Atualmente sabe-se que a dificuldade na realização do exame deve-se ao escape de ar pela boca e ao fato da musculatura do palato mole fechar e não ser possível mensurar as pressões na máscara nasal. Portanto, em outros estudos deve-se planejar as possíveis perdas. Os dados foram insuficientes para possível conclusão.

A adesão ao tratamento é uma potencial limitação do estudo. Porém, com a redução da quantidade de exercícios, acredita-se que isto facilite a realização dos exercícios e a consequente adesão.

Os possíveis mecanismos de ação da terapia começam a ser esclarecidos, porém, ainda insuficientes para indicações precisas e satisfatórias. A terapia possui grandes restrições por ter limitações, trabalhando-se apenas na musculatura de tecido mole. Portanto, a indicação da TMO deve ser específica e pontual, mesmo porque a fisiopatologia exata da AOS permanece bastante controversa. 
7. Conclusão 
O programa reduzido de TMO para AOS

- É efetivo em reduzir a gravidade da AOS.

- É efetivo somente em pacientes com AOS moderada e grave.

- Resulta em melhora da avaliação fonoaudiológica para AOS.

- Resulta em uma tendência a diminuição da gordura e volume da língua.

- Resulta em uma tendência a aumentar a força da língua sem impacto significativo na fadiga da língua e não nos permite concluir alteração na Pcrit devido ao baixo poder da amostra. 
8. Anexos 


\section{Anexo A: Parecer do Comitê de Ética em pesquisa}

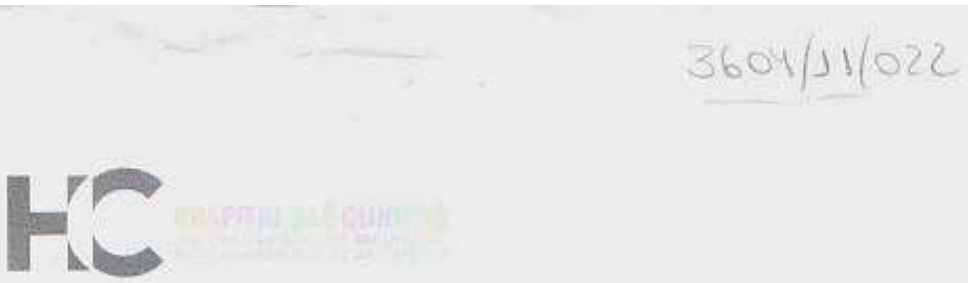

\section{APROVAÇÃO}

A Comissąo de Ética para Análise de Projetos de Pesquisa . CAPPesa da Diretoria Clinica do Hosplial das Clinicas da Faculdade de Medicina da Universidade de Sāo Paulo, em sessāo de 20/04/2013, APROVOU o Protocolo de Pesquisa $n^{\circ}$ 0140/11, intitulado: "EFEITOS DA TERAPIA MIOFUNCIONAL OROFACIAL EM PACIENTES COM RONCO PRIMÁRIO, APNEIA OBSTRUTIVA DO SONO LEVE E MODERADA SOBRE: 1. PRESSĀO CRÍtICA DE FECHAMENTO DA FARINGE, PRESSÃO EXPIRATÓRIA NEGATIVA E RESSONÂNCIA MAGNÉIICA; 2. RONCO E QUALIDADE DE SONO", apresentado pela COMISSĀO CIENTÍFICA DO INCOR, inclusive o Termo de Consentimento Livre e Esciarecido.

Cabe ao pesquisador elaborar e apresentar do CAPPesa, os relatórios parciais e final sobre a pesquisa /Resolução do Conselho Nacional de Saúde $n^{\circ}$ 196, de 10/10/1996, inciso IX.2, letra "c").

Pesquisador (a) Responsável: Dr. Geraldo Lorenzi-Filho

PROF, DR. EUCLIDES AYRES DE CASTILHO Coordenador

Comissāo de Ética para Análise de

Projetos de Pesquisa - CAPPesq

WUISSROO CIENTIFICA
RECEBIDO

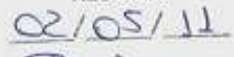

Bouine

Comissăo de Etica para Análise de Projetos de Pesquisa do HCFMUSP da Diretoria Clinica do Hospital das Clinicas da Faculdade de Medicina da Universidade de Sáo Paulo Rua Ovidio Pires de Campos, 225, 5 = andar - CEP 05403010 . Sso Paub - SP Fone' 01130696442 Fax 01130696492 e-mail cappesaghenet usp.br 
Anexo B: Termo de Consentimento Livre Esclarecido

\author{
HOSPITAL DAS CLÍNICAS DA FACULDADE DE MEDICINA DA \\ UNIVERSIDADE DE SÃO PAULO-HCFMUSP
}

TERMO DE CONSENTIMENTO LIVRE E ESCLARECIDO

\title{
DADOS DE IDENTIFICAÇÃO DO SUJEITO DA PESQUISA OU RESPONSÁVEL LEGAL
}

1.NOME:

DOCUMENTO DE IDENTIDADE No:

DATA NASCIMENTO: .......................

ENDEREÇO:

BAIRRO:

CEP: $\mathrm{N}^{\circ}$ SEXO: $M \square F \square$

2.RESPONSÁVEL LEGAL

NATUREZA (grau de parentesco, tutor, curador etc.)

DOCUMENTO DE IDENTIDADE:

DATA NASCIMENTO: ....................

ENDEREÇO:

BAIRRO:

CEP: .

TELEF

ELEFONE: DDD ( APTO:

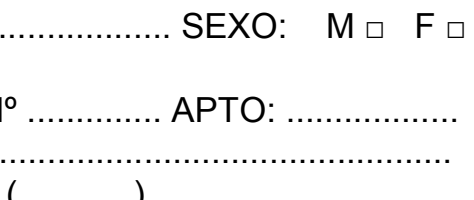

SEXO: $M \square F \square$

№ APTO: CIDADE: TELEFONE: DDD (.............

\section{DADOS SOBRE A PESQUISA}

1. TÍTULO DO PROTOCOLO DE PESQUISA: EFEITOS DA TERAPIA MIOFUNCIONAL OROFACIAL EM PACIENTES COM RONCO PRIMÁRIO, APNEIA OBSTRUTIVA DO SONO LEVE E MODERADA SOBRE: 1. Pressão crítica de fechamento da faringe, pressão expiratória negativa e ressonância magnética; 2. Ronco e qualidade de sono

PESQUISADOR PRINCIPAL: Geraldo Lorenzi-Filho

CARGO/FUNÇÃO: Diretor do Laboratório do Sono

UNIDADE DO HCFMUSP: Laboratório do Sono do InCor da Disciplina de Pneumologia PESQUISADOR EXECUTANTE: Fabiane Kayamori e Vanessa leto

CARGO/FUNÇÃO: Fonoaudiólogas INSCRIÇÃO CONSELHO REGIONAL № CRFa 16503/ NN CRFa 13183

UNIDADE DO HCFMUSP: Laboratório do Sono do InCor da Disciplina de Pneumologia

3. AVALIAÇÃO DO RISCO DA PESQUISA:

$$
\begin{array}{ll}
\text { RISCO MÍNIMO } x & \text { RISCO MÉDIO } \square \\
\text { RISCO BAIXO } \square & \text { RISCO MAIOR } \square
\end{array}
$$

4.DURAÇÃO DA PESQUISA: 4 anos 


\section{HOSPITAL DAS CLÍNICAS DA FACULDADE DE MEDICINA DA UNIVERSIDADE DE SÃO PAULO-HCFMUSP}

As informações a seguir estão sendo fornecidas para sua participação voluntária neste estudo cujo objetivo é avaliar tratamentos não convencionais para o ronco e para a apneia obstrutiva do sono. Você será sorteado para participar de um dos dois grupos: o primeiro grupo será orientado a realizar exercícios para a musculatura da garganta e o segundo realizará lavagem nasal com soro fisiológico e utilizará uma fita adesiva nasal durante o sono. Os dois grupos realizarão exames que nos mostrará como está a garganta, o sono e o som do ronco. Caso concorde em participar do estudo, o (a) senhor (a) deve estar disponível por nos próximos três meses durante trinta minutos por semana para retornos semanais no Hospital para acompanhamento.

O (a) senhor (a) fará os seguintes exames: 1.Polissonografia: avaliará seu sono associado a um instrumento que medirá o som do ronco. Para a avaliação do sono é necessário que sejam colados na cabeça adesivos ligados a fios que não causarão desconforto na cabeça, um pequeno cano nasal e cintas no tórax e abdômen. Para a realização deste exame é necessário dormir no Laboratório do Sono do InCor em duas noites: sendo uma anterior e outra posterior ao tratamento. Este exame é realizado em ambiente confortável e não prejudicará o seu sono. 2. Pressão Crítica de fechamento da faringe - será realizado no mesmo local e com equipamento parecido, mas você utilizará uma máscara ao redor do nariz para respirar. No início do exame, após você adormecer, será realizado um exame para medir com qual facilidade sua garganta fecha. Este exame simula o que ocorre durante uma pausa na respiração durante o sono. Este exame é específico para este estudo e, portanto, experimental. Pode haver pequeno desconforto, pois será reduzida a pressão em sua garganta, o que pode fazer com que você desperte. Se você despertar, poderá respirar normalmente, sem qualquer desconforto. O risco para sua saúde é mínimo porque o teste é curto, realizado com acompanhamento contínuo do seu coração, de sua respiração e da oxigenação do sangue. 3 - Espirometria: será pedido para que o paciente assopre algumas vezes em um tubo. 4 - Pressão expiratória negativa: será colocada uma máscara na boca ligada a um aparelho e será pedido que respire normalmente. No final da saída do ar será enviada uma quantidade de ar pelo aparelho e sua respiração será acompanhada. 5 Ressonância Magnética da garganta: o qual é feito deitado num aparelho de ressonância que dura aproximadamente 15 minutos. Este exame servirá para determinar as partes da garganta que podem estar relacionadas com o desenvolvimento das pausas na respiração durante o sono. Este exame não causará desconforto, sendo totalmente indolor.

Ao início e final do estudo o (a) senhor (a) deverá responder questionários sobre seu sono, problemas de saúde passados e/ou atuais, medicamentos que usa normalmente, sobre o risco de cochilar durante o dia, realizar medidas do pescoço, abdômen, altura e peso, avaliação fonoaudiológica (que avaliará as estruturas da boca e do pescoço, bem como a 


\section{HOSPITAL DAS CLÍNICAS DA FACULDADE DE MEDICINA DA UNIVERSIDADE DE SÃO PAULO-HCFMUSP}

mastigação e o modo de engolir) e fotos do rosto e da parte interna da boca. Além disso, se existir alguém que durma no mesmo quarto, esta pessoa deverá responder um questionário sobre seu ronco e a qualidade de sono dela.

Trata-se de estudo experimental testando a hipótese de que os exercícios poderão diminuir o som do ronco e melhorar a apneia obstrutiva do sono. Os tratamentos propostosnão trarão mal nenhum a saúde. Somente no final do estudo poderemos concluir a presença de algum benefício, os quais poderão incluir melhora nas pausas respiratórias, melhora do ronco, melhora da qualidade de sono do paciente e do parceiro de quarto.

Existem outras formas de tratamento para o seu problema e caso o senhor não se adapte ao tratamento proposto, o senhor será encaminhado no final do estudo para o ambulatório e nova avaliação do médico de sono.

Em qualquer etapa do estudo, você terá acesso aos profissionais responsáveis pela pesquisa para esclarecimento de eventuais dúvidas. O principal investigador é o Dr Geraldo Lorenzi-Filho que pode ser encontrado no endereço Av. Dr. Enéas de Carvalho Aguiar, $44-$ $7^{\circ}$. Andar (Laboratório do Sono). Telefone (s) 2661-5486. Se você tiver alguma consideração ou dúvida sobre a ética da pesquisa, entre em contato com o Comitê de Ética em Pesquisa (CEP) - Rua Ovídio Pires de Campos, 225 - $5^{\circ}$ andar - tel: 2661-6442 ramais 16, 17, 18 ou 20, FAX: 3069-6442 ramal 26 - E-mail: cappesq@hcnet.usp.br.

É garantida a liberdade da retirada de consentimento a qualquer momento e deixar de participar do estudo, sem qualquer prejuízo à continuidade de seu tratamento na Instituição.

As informações obtidas serão analisadas em conjunto com outros pacientes, não sendo divulgado a identificação de nenhum paciente.

O (a) senhor (a) tem o direito de ser mantido atualizado sobre os resultados parciais das pesquisas, quando em estudos abertos, ou de resultados que sejam do conhecimento dos pesquisadores.

Não há despesas pessoais para o participante em qualquer fase do estudo, incluindo exames e consultas. Também não há compensação financeira relacionada à sua participação. Se existir qualquer despesa adicional, ela será absorvida pelo orçamento da pesquisa.

É compromisso do pesquisador de utilizar os dados e o material coletado somente para esta pesquisa.

Acredito ter sido suficientemente informado a respeito das informações que li ou que foram lidas para mim, descrevendo o estudo "EFEITOS DA TERAPIA MIOFUNCIONAL OROFACIAL EM PACIENTES COM RONCO PRIMÁRIO, APNEIA OBSTRUTIVA DO SONO 


\section{HOSPITAL DAS CLÍNICAS DA FACULDADE DE MEDICINA DA UNIVERSIDADE DE SÃO PAULO-HCFMUSP}

LEVE E MODERADA SOBRE: 1. Pressão crítica de fechamento da faringe, pressão expiratória negativa e ressonância magnética; 2 . Ronco e qualidade de sono".

Eu discuti com o Dr. Geraldo Lorenzi-Filho sobre a minha decisão em participar nesse estudo. Ficaram claros para mim quais são os propósitos do estudo, os procedimentos a serem realizados, seus desconfortos e riscos, as garantias de confidencialidade e de esclarecimentos permanentes. Ficou claro também que minha participação é isenta de despesas e que tenho garantia do acesso a tratamento hospitalar quando necessário. Concordo voluntariamente em participar deste estudo e poderei retirar o meu consentimento a qualquer momento, antes ou durante o mesmo, sem penalidades ou prejuízo ou perda de qualquer benefício que eu possa ter adquirido, ou no meu atendimento neste Serviço.

Assinatura do paciente/representante legal Data $1 \quad 1$

Assinatura da testemunha

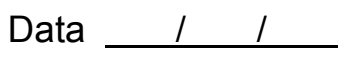

para casos de pacientes menores de 18 anos, analfabetos, semi analfabetos ou portadores de deficiência auditiva ou visual.

(Somente para o responsável do projeto)

Declaro que obtive de forma apropriada e voluntária o Consentimento Livre e Esclarecido deste paciente ou representante legal para a participação neste estudo. 


\section{Anexo C: Adendo}

Adendo - Carta de modificaçäo dos critérios de inclusäo

Projeto: EFEITOS DA TERAPIA MIOFUNCIONAL OROFACIAL EM PACIENTES COM RONCO PRIMÁRIO, APNEIA OBSTRUTIVA DO SONO LEVE E MODERADA SOBRE: 1. Pressão crítica de fechamento da faringe, pressão expiratória negativa e ressonância magnética; 2 . Ronco e qualidade de sono

Devido à dificuldade de inclusão de pacientes de acordo com a extensa lista de critérios de exclusão e a grande quantidade de pacientes com apneia grave aguardando a aquisição do CPAP, modificaremos os critérios de inclusão.

Página 19 - Inserido texto em itálico e sublinhado, que consta as modificações.

Consideraremos elegiveis pacientes de ambos os sexos, com idade entre 25 e 65 anos e diagnóstico clínico e polissonográfico recente de ronco primário, AOS leve, AOS moderada e $A O S$ grave, avaliados no Laboratóro do Sono da Disciplina de Pneumologia do Instituto do Coração do Hospital das Clinicas da Faculdade de Medicina da Universidade de São Paulo. $O$ ronco primário será definido como presença de ronco e IAH $<5$ eventos/hora de sono, AOS leve $\mathrm{IAH} \geq 5 \mathrm{e}<15$ eventos por hora de sono, AOS moderada será definido como presença de ronco e IAH $\geq 15$ e $<30$ eventos por hora de sono e $A O S$ grave definido como $\mid A H>30$, cujos pacientes se recusem a utilizar o CPAP. ou estejam aguardando a compra do CPAP elou não tenham condiçóes financeiras/acesso para compra do CPAP 


\section{Anexo D: Tabela de adesão ao tratamento grupo Terapia}

PROTOCOLO DE FONOAUDIOLOGIA

Orientações: Preencher a tabela abaixo de acordo com a realização dos exercícios. Se foram bem feitos (ok), se foram feitos mais ou menos (+ou-) ou se não foram feitos (não).

\begin{tabular}{|l|l|l|l|}
\hline Dia & manhã & tarde & noite \\
\hline & & & \\
\hline & & & \\
\hline & & & \\
\hline & & & \\
\hline & & & \\
\hline & & & \\
\hline & & & \\
\hline
\end{tabular}

\begin{tabular}{|l|l|}
\hline & \multicolumn{1}{|c|}{ EXERCÍCIOS A SEREM REALIZADAS 3 VEZES AO DIA } \\
\hline PONTA DE LÍNGUA & VARRER \\
& PAPINHO \\
\hline LÍNGUA INTEIRA & GRUDAR A LÍNGUA NO CÉU DA BOCA \\
\hline PARTE DE TRÁS DA LÍNGUA & ABAIXAR O FUNDO DA LÍNGUA \\
\hline PARTE DE TRÁS DO CÉU DA BOCA & ELEVAÇÃO DO PALATO MOLE E ÚVULA \\
\hline BOCHECHA & \\
\hline NARIZ & DEDO NA BOCHECHA \\
\hline Data do próximo atendimento: & \\
\hline
\end{tabular}
horário: 
Anexo E: Tabela de adesão ao tratamento grupo controle PROTOCOLO DE FONOAUDIOLOGIA

Orientações: Preencher a tabela abaixo de acordo com a realização dos exercícios. Se foram bem feitos (ok), se foram feitos mais ou menos (+ou-) ou se não foram feitos (não).

FAVOR TRAZER NA PRÓXIMA CONSULTA

\begin{tabular}{|l|l|l|l|}
\hline Dia & manhã & tarde & noite \\
\hline & & & \\
\hline & & & \\
\hline & & & \\
\hline & & & \\
\hline & & & \\
\hline & & & \\
\hline & & & \\
\hline
\end{tabular}

\begin{tabular}{|c|c|}
\hline EXERCÍCIO PROPOSTO & EXERCÍCIOS A SEREM REALIZADAS 3 VEZES AO DIA \\
\hline $\begin{array}{l}\text { RESPIRAÇÃO } \\
\text { DEITADO/SENTADO/EM } \\
\text { PÉ }\end{array}$ & $\begin{array}{l}\text { COLOCAR AS MÃOS APOIADAS NA REGIÃO DA BARRIGA. PUXAR O AR PELO NARIZ } \\
\text { INFLANDO A BARRIGA E SOLTAR ESVAZIANDO A BARRIGA. } \\
\text { REPETIR } 10 \text { VEZES }\end{array}$ \\
\hline $\begin{array}{l}\text { RESPIRAÇÃO } \quad \text { EM } \\
\text { TEMPOS }\end{array}$ & $\begin{array}{l}\text { COLOCAR AS MÃOS APOIADAS NA REGIÃO DA BARRIGA. PUXAR O AR PELO NARIZ } \\
\text { EM SEGUNDOS, INFLANDO A BARRIGA E SOLTAR EM } \\
\text { SEGUNDOS, ESVAZIANDO A BARRIGA. } \\
\text { REPETIR } 10 \text { VEZES }\end{array}$ \\
\hline $\begin{array}{l}\text { RESPIRAÇÃO COSTO- } \\
\text { DIAFRAGMÁTICA }\end{array}$ & $\begin{array}{l}\text { EM PÉ, APOIAR A MÃO NA REGIÃO DAS COSTELAS. PUXAR O AR PELO NARIZ } \\
\text { INFLANDO A BARRIGA E ELEVANDO O BRAÇO. SOLTAR ESVAZIANDO A BARRIGA } \\
\text { E ABAIXANDO O BRAÇO. } \\
\quad \text { REPETIR } 10 \text { VEZES }\end{array}$ \\
\hline $\begin{array}{l}\text { LAVAGEM COM SORO } \\
\text { FISIOLÓGICO }\end{array}$ & 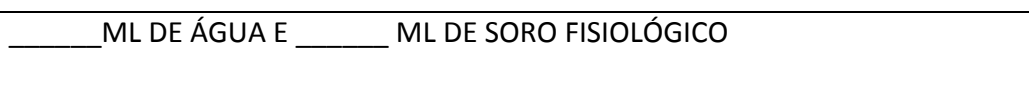 \\
\hline DILATADOR NASAL & $\begin{array}{l}\text { LIMPAR A PELE COM ÁGUA E SABÃO, SECAR E COLOCAR O DILATADOR } \\
\text { CONFORME ORIENTADO. }\end{array}$ \\
\hline
\end{tabular}
horário: 


\section{Anexo F: Questionário para ronco (parte do questionário de Berlim)}

1-Você ronca?

\begin{tabular}{|l|l|l|l|l|l|l|l|l|}
\hline Sim & Não & Não sabe & Esposa (o) & Sim & & Não \\
\hline
\end{tabular}

Intensidade do ronco:

\begin{tabular}{|l|l|}
\hline 1-Tão alto quanto a respiração & \\
\hline 2-Tão alto quanto falar & \\
\hline 3-Mais alto que falar & \\
\hline 4-Muito alto, houve-se do outro quarto & \\
\hline
\end{tabular}

Frequência do ronco:

\begin{tabular}{|l|l|}
\hline 0 - nunca ou quase nunca & \\
\hline 1 - 1 a 2 vezes por mês & \\
\hline 2 - 1 a 2 vezes por semena & \\
\hline 3 - 3 a 4 vezes por semana & \\
\hline 4 - quase todo dia & \\
\hline
\end{tabular}

O seu ronco incomoda outras pessoas?

\begin{tabular}{|l|l|l|}
\hline Sim & Não & \\
\hline
\end{tabular}

Resultados para a intensidade de 1 a 3 :

$1=$ tão alto quanto a respiração; $2=$ tão alto quanto falar; 3 = muito alto, ouve-se do outro quarto

Resultados para a frequência de 1 a 4 :

$0=$ nunca ou quase nunca;

$1=1$ a 2 vezes por mês;

$2=1$ a 2 vezes por semana;

$3=3$ a 4 vezes por semana

$4=$ quase todo dia 


\section{Anexo G: Questionário de sonolência: Escala de Sonolência de Epworth}

Quantifica grau de sonolência

0 - Nenhuma chance de cochilar; 1 - pequena chance de cochilar; 2 - moderada chance de cochilar; 3 - alta chance de cochilar

\begin{tabular}{|l|l|l|l|l|}
\hline \multicolumn{1}{|c|}{ SITUAÇÃO } & & & & \\
\hline Sentado e lendo & 0 & 1 & 2 & 3 \\
\hline Assistindo TV & 0 & 1 & 2 & 3 \\
\hline Sentado em lugar público (cinema, igreja, sala de espera) & 0 & 1 & 2 & 3 \\
\hline Como passageiro de trem, carro ou ônibus, andando uma hora sem parar & 0 & 1 & 2 & 3 \\
\hline Deitando-se para descansar à tarde, quando as circunstâncias permitem & 0 & 1 & 2 & 3 \\
\hline Sentado e conversando com alguém & 0 & 1 & 2 & 3 \\
\hline Sentado calmamente após o almoço (sem álcool) & 0 & 1 & 2 & 3 \\
\hline Dirigindo um carro, enquanto para por alguns minutos ao pegar um & 0 & 1 & 2 & 3 \\
trânsito intenso & & & & \\
\hline
\end{tabular}

Resultado: até $10=$ normal; $>10=$ sonolência excessiva diurna. 
Anexo H: Questionário da qualidade de sono - Questionário de qualidade de vida

\section{de Pittsburgh}

QUESTIONÁRIO DE QUALIDADE DE VIDA DE PITTSBURGH (questionário geral de qualidade de sono)

\section{Responda as questões a seguir de acordo com as características do seu sono apenas no último mês:}

1. Durante o mês passado, a que horas você foi se deitar à noite, na maioria das vezes?

2. Durante o mês passado, quanto tempo (em minutos) você demorou para pegar no sono, na maioria das vezes?

3. Durante o mês passado, a que horas você acordou de manhã, na maioria das vezes? cama)

4. Durante o mês passado, quantas horas de sono por noite você dormiu? (pode ser diferente do número de horas que você ficou na

5. Para cada uma das questões seguintes, escolha uma única resposta, que você ache mais correta. Por favor, responda a todas as questões. Durante o mês passado, quantas vezes você teve problemas para dormir por causa de:

a. Demorar mais de 30 minutos para pegar no sono:

( ) nenhuma vez; ( ) menos de uma vez por semana; ( ) uma ou duas vezes por semana; ( ) três vezes por semana ou mais

b. Acordar no meio da noite ou de manhã muito cedo:

( ) nenhuma vez; ( ) menos de uma vez por semana; ( ) uma ou duas vezes por semana; ( ) três vezes por semana ou mais

c. Levantar-se para ir ao banheiro:

( ) nenhuma vez; ( ) menos de uma vez por semana; ( ) uma ou duas vezes por semana; ( ) três vezes por semana ou mais

d. Ter dificuldade para respirar:

( ) nenhuma vez; ( ) menos de uma vez por semana; ( ) uma ou duas vezes por semana; ( ) três vezes por semana ou mais

e. Tossir ou roncar muito alto:

( ) nenhuma vez; ( ) menos de uma vez por semana; ( ) uma ou duas vezes por semana; ( ) três vezes por semana ou mais

f. Sentir muito frio

( ) nenhuma vez; ( ) menos de uma vez por semana; ( ) uma ou duas vezes por semana; ( ) três vezes por semana ou mais

g. Sentir muito calor

( ) nenhuma vez; ( ) menos de uma vez por semana; ( ) uma ou duas vezes por semana; ( ) três vezes por semana ou mais

h. Ter sonhos ruins ou pesadelos

( ) nenhuma vez; ( ) menos de uma vez por semana; ( ) uma ou duas vezes por semana; ( ) três vezes por semana ou mais

i. Sentir dores

( ) nenhuma vez; ( ) menos de uma vez por semana; ( ) uma ou duas vezes por semana; ( ) três vezes por semana ou mais

j. Outras razões (por favor descreva) Quantas vezes você teve problemas pra dormir por esta razão, durante o mês passado?

( ) nenhuma vez; ( ) menos de uma vez por semana; ( ) uma ou duas vezes por semana; ( ) três vezes por semana ou mais

6. Durante o mês passado, como você classificaria a qualidade do seu sono?

( ) Muito boa ( ) boa ( ) ruim ( ) muito ruim

7. Durante o mês passado, você tomou algum remédio para dormir, receitado pelo médico, ou indicado por outra pessoa (farmacêutico, amigo, familiar) ou mesmo por sua conta?

( ) nenhuma vez; ( ) menos de uma vez por semana; ( ) uma ou duas vezes por semana; ( ) três vezes por semana ou mais

8. Durante o mês passado, se você teve problemas para ficar acordado enquanto estava dirigindo, fazendo suas refeições ou participando de qualquer outra atividade social, quantas vezes isto aconteceu?

( ) nenhuma vez; ( ) menos de uma vez por semana; ( ) uma ou duas vezes por semana; ( ) três vezes por semana ou mais

9. Durante o mês passado, você sentiu indisposição ou falta de entusiasmo para realizar suas atividades diárias?

( ) nenhuma indisposição nem falta de entusiasmo; ( ) indisposição e falta de entusiasmos pequenas; ( ) indisposição e falta de entusiasmos moderadas; ( ) muita indisposição e falta de entusiasmo

10. Para você, o sono é ( ) um prazer ( ) uma necessidade Outro -qual?

11. Você cochila? ( ) sim （）não Caso sim - você cochila intencionalmente, ou seja, por que quer cochilar?（） sim（）não

12. Para você, cochilar é: ( ) um prazer ( ) uma necessidade Outro - qual?

Resultados: pontuação global superior a 5 (cinco) pontos é indicativa de sono de má qualidade 


\section{Anexo I: Anamnese}

\section{ANAMNESE - para Apneia Obstrutiva do Sono}

Data da Avaliação: I__ Informante:

Nome do paciente:

Idade: anos $\mathrm{DN}$ :

Endereço:

Bairro:

Tel casa:( $)$

Vizinho(a):

Profissão:

$\operatorname{IMC}\left(\mathrm{kg} / \mathrm{m}^{2}\right)$
1 Estado civil:

Melhores dias da semana e horário para terapia:

\section{Queixa:}

\section{Sintomas:}

\begin{tabular}{|l|l|l|l|}
\hline & não & sim & Frequência \\
\hline sonolência diurna excessiva & & & \\
\hline engasgos durante o sono & & & \\
\hline despertares recorrentes & & & \\
\hline sono não reparador & & & \\
\hline fadiga diurna & & & \\
\hline dificuldade de concentração & & & \\
\hline Ronco & & & \\
\hline
\end{tabular}

Problemas de saúde/medicamentos:

\section{Problemas respiratórios:}

\begin{tabular}{|l|l|l|l|l|l|}
\cline { 5 - 6 } \multicolumn{2}{l}{} & Frequência anual & Tratamento & Medicamentos \\
\hline resfriados frequentes & não & $\operatorname{sim}$ & & & \\
\hline problemas de garganta & não & $\operatorname{sim}$ & & & \\
\hline Amidalite & não & $\operatorname{sim}$ & & & \\
\hline Halitose & não & $\operatorname{sim}$ & & & \\
\hline Asma & não & $\operatorname{sim}$ & & & \\
\hline bronquite & não & $\operatorname{sim}$ & & & \\
\hline pneumonia & não & $\operatorname{sim}$ & & & \\
\hline Rinite & não & $\operatorname{sim}$ & & & \\
\hline Sinusite & não & $\operatorname{sim}$ & & & \\
\hline obstrução nasal & não & $\operatorname{sim}$ & & & \\
\hline prurido nasal & não & $\operatorname{sim}$ & & & \\
\hline Coriza & não & $\operatorname{sim}$ & & & \\
\hline espirros em salva & não & $\operatorname{sim}$ & & & \\
\hline
\end{tabular}


Sono:

\begin{tabular}{|c|c|c|c|c|}
\hline sialorreia & não & \multicolumn{2}{|l|}{$\operatorname{sim}$} & às vezes \\
\hline ingestão de água a noite & não & \multicolumn{2}{|l|}{ Sim } & às vezes \\
\hline boca aberta ao dormir & não & \multicolumn{2}{|l|}{$\operatorname{sim}$} & às vezes \\
\hline boca seca ao acordar & não & \multicolumn{2}{|l|}{$\operatorname{sim}$} & às vezes \\
\hline dores na face ao acordar & não & & às vezes \\
\hline postura & decúbito lateral & \multicolumn{2}{|l|}{ decúbito dorsal } & decúbito ventral \\
\hline mão apoiada sob o rosto & não & \begin{tabular}{l|l}
$\operatorname{sim}$ & $\mathrm{D}$ \\
\end{tabular} & $\mathrm{E}$ & às vezes \\
\hline
\end{tabular}

Outros problemas:

Tratamentos:

\begin{tabular}{|l|c|l|l|l|l|}
\hline \multicolumn{1}{|c|}{ Não } & realizado & Atual & motivo & profissional \\
\hline fonoaudiológico & & & & & \\
\hline Médico & & & & & \\
\hline Fisioterápico & & & & & \\
\hline Odontológico & & & & & \\
\hline Procedimento & Exodontia & prótese & implante & aparatologia fixa & aparatologia removível \\
\hline Cirúrgicos & Não & $\operatorname{sim}$ & qual & Quando \\
\hline
\end{tabular}

Outros tratamentos:

Alimentação atual:

\begin{tabular}{|c|l|l|l|}
\hline & sim & não & às vezes \\
\hline frutas & & & \\
\hline verduras & & & \\
\hline kegumes & & & \\
\hline cereais (arroz, macarrão, trigo) & & & \\
\hline grãos (feijão, lentilha, ervilha) & & & \\
\hline carnes & & & \\
\hline leite e derivados & & & \\
\hline açucares & & & \\
\hline
\end{tabular}

De maneira geral ingere predominantemente alimentos:

\begin{tabular}{|c|c|c|c|c|c|}
\hline Líquidos & sólidos & & & & \\
\hline \multicolumn{6}{|l|}{ Mastigação } \\
\hline ingestão de líquidos durante as refeições & não & \multicolumn{2}{|c|}{$\operatorname{sim}$} & \multicolumn{2}{|c|}{ às vezes } \\
\hline dor ou desconforto ao mastigar & não & $\operatorname{sim}$ & $\mathrm{D}$ & $\mathrm{E}$ & às vezes \\
\hline ruído articular & não & $\operatorname{sim}$ & $\mathrm{D}$ & $\mathrm{E}$ & às vezes \\
\hline dificuldade mastigatória & não & \multicolumn{4}{|c|}{ sim-qual: } \\
\hline escape de alimentos durante a mastigação & não & \multicolumn{4}{|c|}{$\operatorname{sim}$} \\
\hline
\end{tabular}

\section{Outros problemas:}

\section{Deglutição}

\begin{tabular}{|l|l|l|l|}
\hline Com dificuldade & Não & $\operatorname{sim}$ & às vezes \\
\hline Com ruído & Não & $\operatorname{sim}$ & às vezes \\
\hline Engasgos & Não & $\operatorname{sim}$ & às vezes \\
\hline Odinofagia (dor ao deglutir) & Não & $\operatorname{sim}$ & às vezes \\
\hline Refluxo nasal & Não & $\operatorname{sim}$ & às vezes \\
\hline Escape anterior & Não & $\operatorname{sim}$ & às vezes \\
\hline Pigarro & Não & $\operatorname{sim}$ & às vezes \\
\hline
\end{tabular}




\begin{tabular}{|l|l|l|l|}
\hline Tosse & Não & sim & às vezes \\
\hline Resíduos após a deglutição & Não & $\operatorname{sim}$ & às vezes \\
\hline
\end{tabular}

Outros problemas:

Hábitos Orais:

\begin{tabular}{|l|l|l|l|}
\hline Umidificar os lábios & não & $\operatorname{sim}$ & intensidade \\
\hline Tabagismo? o quê? & não & $\operatorname{sim}$ & quantidade/dia \\
\hline Etilismo & não & $\operatorname{sim}$ & quantidade/ dia \\
\hline
\end{tabular}

Outros hábitos:

Hábitos de Mordida

\begin{tabular}{|l|l|l|l|l|}
\hline Bruxismo (ranger dentes) & não & $\operatorname{sim}$ & \multicolumn{2}{|l|}{} \\
\hline Apertamento dentário & não & $\operatorname{sim}$ & \multicolumn{2}{|c|}{ Intensidade } \\
\hline Onicofagia (roer unhas) & não & $\operatorname{sim}$ & Intensidade \\
\hline Morder mucosa oral & não & $\operatorname{sim}$ & Intensidade & intensidade \\
\hline Morder objetos & não & $\operatorname{sim}$ & Qual & \\
\hline
\end{tabular}

Outros hábitos:

Hábitos de Postura

\begin{tabular}{|l|l|l|c|c|}
\hline Interpor lábio inferior & não & Sim & intensidade \\
\hline Protrair a mandíbula & não & Sim & & E \\
\hline Apoiar de mão na mandíbula & não & Sim & D & E \\
\hline Apoiar de mão na cabeça & não & Sim & D & \\
\hline
\end{tabular}

Outros hábitos: 
Anexo J: Avaliação fonoaudiológica para AOS

\section{Avaliação fonoaudiológica para AOS}

Nome:

№

Data do exame: Idade: anos e meses DN:

Peso:

kg Altura:

m IMC (kg/ m2):

Circunferência cervical: cm Circunferência abdominal: cm

1. POSTURA CORPORAL (Observar o paciente em pé e sem calçado)

Cabeça[ ]Somar todas as pontuações (melhor resultado $=0$ e pior $=4$ ) [flexão e extensão $=$ sim] [rotação $=$ não] [inclinação $=$ talvez]

\begin{tabular}{|llllll|}
\hline Frontal: & $(0)$ normal & $(1)$ rotação $D$ & $(1)$ rotação $E$ & $(1)$ inclinação $D$ & (1) inclinação $E$ \\
\hline Lateral: & $(0)$ normal & (1) anteriorizada & (1) flexão & (1) extensão & \\
\hline
\end{tabular}

Ombros [ ]Somar todas as pontuações (melhor resultado $=0$ e pior $=3$ )

\begin{tabular}{|llll|}
\hline Frontal: & $(0)$ normal & $(1)$ elevado $D$ & $(1)$ elevado $\mathrm{E}$ \\
\hline Lateral: & $(0)$ normal & $(1)$ rotação anteriorizado \\
\hline
\end{tabular}

\section{Observação:}

\section{MEDIDAS DA FACE, MOVIMENTO MANDIBULAR E OCLUSÃO}

Face(manter os lábios em contato, tomar cada medida 3 vezes com paquímetro e calcular a média)

\begin{tabular}{|l|c|c|c|c|}
\hline & $\begin{array}{c}\mathbf{1}^{\mathbf{a}} \text { medida } \\
(\mathbf{m m})\end{array}$ & $\begin{array}{c}\mathbf{2}^{\mathbf{a}} \text { medida } \\
(\mathbf{m m})\end{array}$ & $\begin{array}{c}\mathbf{3}^{\mathbf{a}} \mathbf{m e d i d a} \\
(\mathbf{m m})\end{array}$ & $\begin{array}{c}\text { Média } \\
(\mathbf{m m})\end{array}$ \\
\hline terço superior (raiz do cabelo até meio das sobrancelhas) & & & & \\
\hline terço médio da face (meio das sobrancelhas a sub-nasal) & & & & \\
\hline terço inferior da face (sub-nasal a gnatio) & & & & \\
\hline
\end{tabular}

Movimento Mandibular e Oclusão(usar paquímetro e lápis cópia, tomar cada medida 3 vezes e calcular a média)

\begin{tabular}{|l|l|l|l|l|}
\hline & $\begin{array}{c}\mathbf{1}^{\mathbf{a}} \text { medida } \\
(\mathbf{m m})\end{array}$ & $\begin{array}{c}\mathbf{2}^{\mathbf{a}} \text { medida } \\
(\mathbf{m m})\end{array}$ & $\begin{array}{c}\mathbf{3}^{\mathbf{a}} \text { medida } \\
(\mathbf{m m})\end{array}$ & $\begin{array}{c}\text { Média } \\
(\mathbf{m m})\end{array}$ \\
\hline Sobremordida (TV) & & & & \\
\hline $\begin{array}{c}\text { Sobresaliência } \\
\begin{array}{c}\text { distância interincisal máxima ativa - DIMA (do incisivo central } \\
\text { ou lateral superior ao inferior com a máxima abertura da boca) }\end{array}\end{array}$ & & & & \\
\hline $\begin{array}{c}\text { Abertura da boca (DIMA +TV) } \\
\text { DIMA com o ápice da língua tocando a papila incisiva } \\
\text { (DIMALP) }\end{array}$ & & & & \\
\hline $\begin{array}{c}\text { calcular: (DIMALP) } \times 100 \\
\text { DIMA }\end{array}$ & & & & \\
\hline
\end{tabular}

\section{EXAME EXTRA-ORAL}


Temporal [ ] (melhor resultado $=0$ e pior $=1$ ). Deve-se realizar via palpação
Recrutamento na contração isométrica:
(0) simultâneo
(1) primeiro lado $D$
(1) primeiro lado $E$

Masseter [ ] (melhor resultado $=0$ e pior $=1$ ). Deve-se realizar via palpação

\begin{tabular}{|llll}
\hline Recrutamento na contração isométrica: & (0) simultâneo & (1) primeiro lado $D$ & (1) primeiro lado $E$
\end{tabular}

Mandíbula [ ] Somar todas as pontuações (melhor resultado = 0 e pior = 2)

$\begin{array}{llll}\text { Postura: (0) normal } & \text { (1) semi-abaixada } & \text { (2) abaixada } & \text { (2) apertamento dentário }\end{array}$

Lábios [ ] Somar todas as pontuações (melhor resultado $=0$ e pior $=19$ )

\begin{tabular}{|c|c|c|c|}
\hline Posição habitual: & $\begin{array}{l}\text { (0) fechados } \\
\text { (2) entreabertos }\end{array}$ & $\begin{array}{l}\text { (1) fechados com tensão } \\
\text { (3) fechados em contato dentário }\end{array}$ & $\begin{array}{l}\text { (2) ora abertos ora fechados } \\
\text { (4) abertos }\end{array}$ \\
\hline Saliva:(0)deglutida & $\begin{array}{l}\text { (1)acumulada na } \\
\text { comissura D }\end{array}$ & (1)acumulada na comissura $E$ & $\begin{array}{l}\text { (1)acumulada no lábio } \\
\text { inferior }\end{array}$ \\
\hline Mucosa: (0)normal & $\begin{array}{l}\text { (1)com marcas } \\
\text { dentárias }\end{array}$ & (1)ressecada & (1) ferida \\
\hline $\begin{array}{c}\text { Forma- Superior: } \\
\text { - Inferior: }\end{array}$ & $\begin{array}{l}\text { (0) normal } \\
(0) \text { normal }\end{array}$ & $\begin{array}{l}\text { (1) em asa de gaivota }\left(1^{\circ} \text { e } 2^{\circ}\right. \\
\text { arco do cupido) } \\
\text { (1) com eversão discreta }\end{array}$ & (2) com eversão acentuada \\
\hline
\end{tabular}

\section{EXAME INTRA-ORAL}

Lábios [ ] Somar todas as pontuações (melhor resultado $=0$ e pior $=3$ )

\begin{tabular}{|lll|}
\hline Mucosa: & (0)normal & (1) ferida \\
\hline Frênulo superior: & fixação: $\quad(0)$ normal & (1) baixa \\
& espessura: (0) normal & (1) alterada (descrever): \\
\hline
\end{tabular}

Bochechas [ ]Somar todas as pontuações (melhor resultado $=0$ e pior $=10$ )
Mucosa: (0) normal
(1) marcas dentárias $D$
(1) linha Alba D
(1) ressecada $D$
(2) ferida D
(1) marcas dentárias $E$
(1) linha Alba E
(1) ressecada $E$
(2) ferida $E$

Língua[ ]Somar todas as pontuações (melhor resultado = 0 e pior =21)

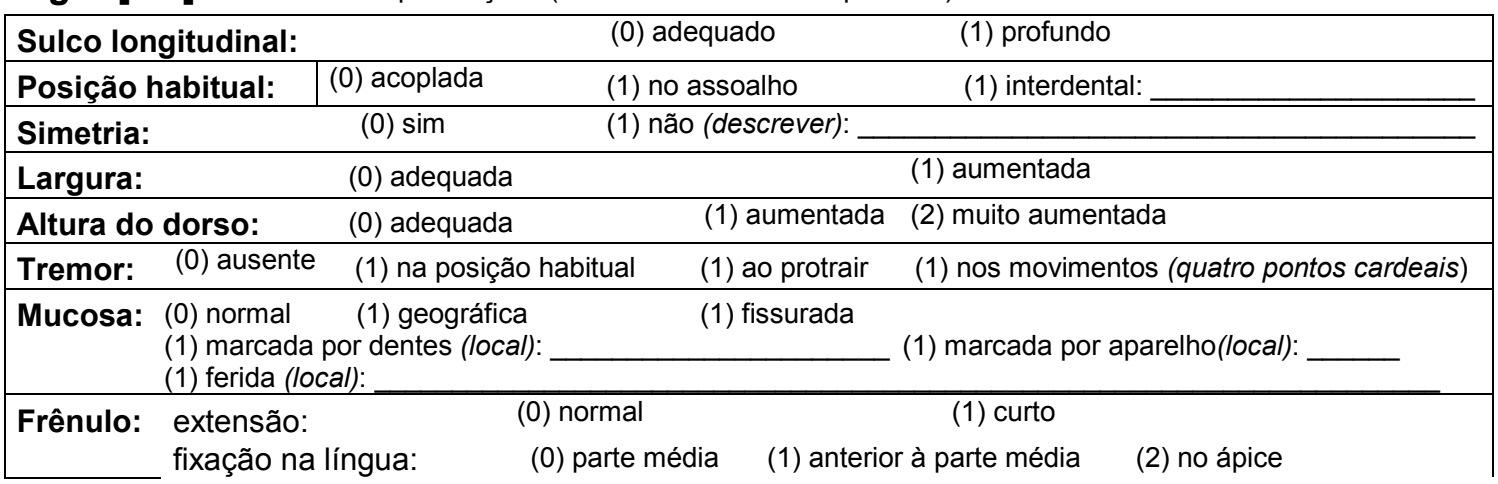

\section{Friedman tongue position:}
(0)
(1)
(2)
(3) 


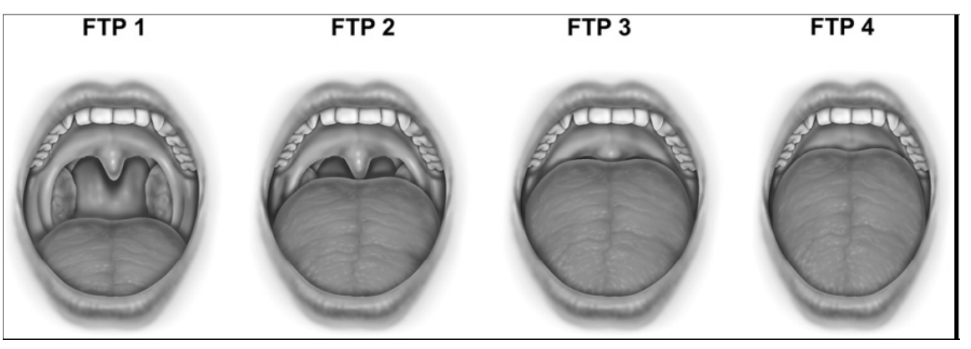

Palato[ ] Somar todas as pontuações (melhor resultado $=0$ e pior $=10$ )

\begin{tabular}{|c|c|c|c|c|}
\hline Duro: & $\begin{array}{l}\text { Profundidade: } \\
\text { Largura: }\end{array}$ & $\begin{array}{l}(0) \text { normal } \\
(0) \text { normal }\end{array}$ & $\begin{array}{l}\text { (1) reduzida (baixo) } \\
\text { (1) aumentada (larga) }\end{array}$ & $\begin{array}{l}\text { (2) aumentada (alto) } \\
\text { (2) reduzida (estreitada) }\end{array}$ \\
\hline Mole: & $\begin{array}{l}\text { Simetria: } \\
\text { Extensão: }\end{array}$ & $\begin{array}{l}\text { (0) presente } \\
\text { (0) adequada }\end{array}$ & $\begin{array}{l}\text { (1) ausente }-D+\text { alto } \\
\text { (1) longo }\end{array}$ & $\begin{array}{l}\text { (1) ausente }-E+\text { alto } \\
\text { (2) muito longo }\end{array}$ \\
\hline Úvula: & & (0) normal & (1) longa (2) muito longa & $\begin{array}{ll}\text { (1) desviada para } \mathrm{D} & \text { (1) desviada para } \mathrm{E}\end{array}$ \\
\hline
\end{tabular}

Tonsilas palatinas(amídalas)[ ]Somar todas as pontuações (melhor resultado $=0$ e pior $=4$ )

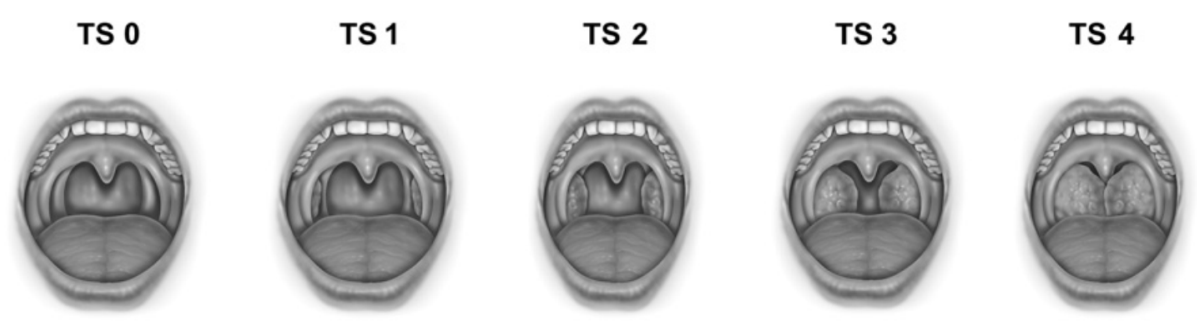

Dentes e Oclusão[ ]Somar todas as pontuações (melhor resultado = 0 e pior = 18)

(1)

\begin{tabular}{c}
8.7 .6 .5 .4 .3 .2 .1 \\
\hline$(4)$ \\
8.7 .6 .5 .4 .3 .2 .1
\end{tabular}

(2) 1.2.3.4.5.6.7.8

\begin{tabular}{|c|c|}
\hline Conservaçãodentária: (0) boa & Conservaçãogengival:(0) boa \\
\hline Linha média: & (1) desviada E \\
\hline Oclusão: & (1) alterada \\
\hline Classificação de Angle: & $\begin{array}{lll}\text { Lado D (0) Classe I } & \text { (1) Classe II div.1 } & \text { (1) Classe II div. } 2^{\mathrm{a}} \\
\text { Lado E (0) Classe I } & \text { (1) Classe II div.1 } & \text { (1) Classe II div. } 2^{\mathrm{a}}\end{array}$ \\
\hline Alteração horizontal: $(0)$ ausente & $\begin{array}{cc}\text { (1) mordida de topo } & \text { (1) sobressaliência } \\
(T H=0 m m) & (1) \text { mordida cruzada anterior } \\
(T H>3 m m) & (T H<0 m m) \\
\end{array}$ \\
\hline Alteração vertical: $(0)$ ausente & $\begin{array}{lc}\text { (1) mordida de } & (1) \text { sobremordida } \\
\text { topo } & (1) \text { mordida aberta } \\
(T V>3 m m) & \left.\begin{array}{c}\text { anterior } \\
(T V\end{array}<0 m m\right)\end{array}$ \\
\hline Alteração transversal: $(0)$ ausente & (1) mordida cruzada posterior direita $\quad$ (1) mordida cruzada posterior esquerda \\
\hline Uso de prótese: $\square$ não & $\square$ removível \\
\hline Uso de aparelho: $\square$ não & $\square$ móvel \\
\hline
\end{tabular}

Descrever o aparelho e/ou prótese:

Outras alterações:

5. MOBILIDADE(Quando o movimento solicitado for alterado, se necessário, descrever)

Lábios [ ] Somar todas as pontuações (melhor resultado $=0$ e pior $=21$ )

\begin{tabular}{|lcccc|}
\hline & normal & aproximado & tenta realizar & não realiza \\
\hline 1. Protrair fechados = "bico fechado" & $(0)$ & $(1)$ & $(2)$ & $(3)$ \\
\hline 2. Protrair abertos = "bico aberto" & $(0)$ & $(1)$ & $(2)$ & $(3)$ \\
\hline
\end{tabular}




\begin{tabular}{|lllll|}
\hline 3. "Sorriso fechado" & $(0)$ & $(1)$ & $(2)$ & $(3)$ \\
\hline $\begin{array}{l}\text { 4. "sorriso aberto elevando as } \\
\text { bochechas" }\end{array}$ & $(0)$ & $(1)$ & $(2)$ & $(3)$ \\
\hline 5. "Lábios estirados para dentro" & $(0)$ & $(1)$ & $(2)$ & $(3)$ \\
\hline 6. "Mostrar dentes inferiores" & $(0)$ & $(1)$ & $(2)$ & $(3)$ \\
\hline 7. "cara de cheiro ruim" & $(0)$ & $(1)$ & $(2)$ & $(3)$ \\
\hline
\end{tabular}

Língua [ ] Somar todas as pontuações (melhor resultado $=0$ e pior $=39$ )

Nos movimentos alternados, executar 3 vezes e com ritmo.

\begin{tabular}{|lcccc|}
\hline & normal & aproximado & tenta realizar & não realiza \\
\hline Protrair & $(0)$ & $(1)$ & $(2)$ & $(3)$ \\
\hline Elevar na papila incisiva & $(0)$ & $(1)$ & $(2)$ & $(3)$ \\
\hline Elevar no lábio superior & $(0)$ & $(1)$ & $(2)$ & $(3)$ \\
\hline Tocar a comissura labial D & $(0)$ & $(1)$ & $(2)$ & $(3)$ \\
\hline Tocar a comissura labial E & $(0)$ & $(1)$ & $(2)$ & $(3)$ \\
\hline Tocar internamente a bochecha D & $(0)$ & $(1)$ & $(2)$ & $(3)$ \\
\hline Tocar internamente a bochecha E & $(0)$ & $(1)$ & $(2)$ & $(3)$ \\
\hline Estalar o ápice & $(0)$ & $(1)$ & $(2)$ & $(3)$ \\
\hline Estalar o corpo & $(0)$ & $(1)$ & $(2)$ & $(3)$ \\
\hline Sugar a língua no palato & $(0)$ & $(1)$ & $(2)$ & $(3)$ \\
\hline Vibrar & $(0)$ & $(1)$ & $(2)$ & $(3)$ \\
\hline Abaixar o dorso espontaneamente & $(0)$ - normal & $(1)$ - lentificado & $(2)-$ muito & $(3)$ - ausente \\
\hline lentificado & $\begin{array}{l}\text { lentificado } \\
\text { Abaixar o dorso através da estimulação do reflexo }\end{array}(0)$ - normal & $(1)$ - lentificado & ausente \\
\hline
\end{tabular}

Bochechas [ ] Somar todas as pontuações (melhor resultado $=0$ e pior $=9$ )

\begin{tabular}{|lcccc|}
\hline & normal & aproximado & tenta realizar & não realiza \\
\hline Inflar & $(0)$ & $(1)$ & $(2)$ & $(3)$ \\
\hline Inflar o lado direito & $(0)$ & $(1)$ & $(2)$ & $(3)$ \\
\hline Inflar o lado esquerdo & $(0)$ & $(1)$ & $(2)$ & $(3)$ \\
\hline
\end{tabular}

Véu palatino [ ] Somar todas as pontuações (melhor resultado $=0$ e pior $=4$ )

\begin{tabular}{|lcccccc|}
\hline & normal & movimento reduzido & movimento ausente & Observação \\
\hline Falar [a] repetidamente & $(0) \mathrm{D}$ & $(0) \mathrm{E}$ & $(1) \mathrm{D}(1) \mathrm{E}$ & $(2) \mathrm{D}$ & $(2) \mathrm{E}$ & \\
\hline
\end{tabular}

Úvula - contração [ ] Somar todas as pontuações (melhor resultado = 0 e pior $=4$ )

\begin{tabular}{|llccl|}
\hline & normal & movimento reduzido & movimento ausente & Observação \\
\hline Falar [a] repetidamente & $(0)$ & $(1)$ & $(2)$ & \\
\hline Bocejo & $(0)$ & $(1)$ & $(2)$ & \\
\hline
\end{tabular}

Mandíbula [ ] Somar todas as pontuações (melhor resultado $=0$ e pior $=9$ )

\begin{tabular}{|lcccccc|}
\hline & normal & reduzido & aumentado & não realiza & \multicolumn{2}{c|}{ com desvio } \\
\hline Abertura da boca & $(0)$ & $(1)<40 \mathrm{~mm}$ & $(1)>55 \mathrm{~mm}$ & $(2)$ & $(1) \mathrm{D}$ & $(1) \mathrm{E}$ \\
\hline Fechamento da boca & $(0)$ & - & - & - & $(1) \mathrm{D}$ & $(1) \mathrm{E}$ \\
\hline Lateralidade à direita & $(0)$ & $(1)<6 \mathrm{~mm}$ & $(1)>12 \mathrm{~mm}$ & $(2)$ & - & - \\
\hline Lateralidade à esquerda & $(0)$ & $(1)<6 \mathrm{~mm}$ & $(1)>12 \mathrm{~mm}$ & $(2)$ & - & - \\
\hline Presença de desvio (em algum movimento) & $(0)$ não & $(1) \mathrm{sim}$ & & & \\
\hline Presença de dor(em algum movimento) & $(0)$ não & $(1) \mathrm{sim}$ & & & \\
\hline
\end{tabular}

6. TÔNUS [ ] ] omar todas as pontuações (melhor resultado $=0$ e pior $=7$ )

\begin{tabular}{|lccc|}
\hline & Normal & Diminuído & Aumentado \\
\hline Lábio superior & $(0)$ & $(1)$ & $(1)$ \\
\hline Lábio inferior & $(0)$ & $(1)$ & $(1)$ \\
\hline Mento & $(0)$ & $(1)$ & $(1)$ \\
\hline Sulco mento labial & $(0)$ & $(1)$ & $(1)$ \\
\hline $\begin{array}{l}\text { Assoalho da boca } \\
\text { (supra-hióideos) }\end{array}$ & $(0)$ & $(1)$ & $(1)$ \\
\hline Bochecha direita & $(0)$ & $(1)$ & $(1)$ \\
\hline Bochecha esquerda & $(0)$ & $(1)$ & \\
\hline
\end{tabular}


Realizar palpação e observação visual, exceto do assoalho que deve ser apenas observado.

7. Língua - ativação [ ] Somar todas as pontuações (melhor resultado = 0 e pior = 2)

\begin{tabular}{|lccc|}
\hline & Normal & Reduzida & Aumentada \\
\hline $\begin{array}{l}\text { Musculatura } \\
\text { propulsora }\end{array}$ & $(0)$ & & $(1)$ \\
\hline Musculatura retratora & $(0)$ & $(1)$ & \\
\hline
\end{tabular}

8. DOR À PALPAÇÃO [ ] Somar todas as pontuações (melhor resultado $=0$ e pior $=10$ )

\begin{tabular}{|llllll|}
\hline & \multicolumn{2}{c}{ ausente } & \multicolumn{3}{l|}{ presente } \\
\hline Temporal anterior & $(0) D$ & $(0) E$ & (1) $D$ & $(1) E$ \\
\hline Masseter superficial & $(0) D$ & $(0) E$ & (1) $D$ & $(1) E$ \\
\hline Trapézio & $(0) D$ & $(0) E$ & $(1) D$ & $(1) E$ \\
\hline Esternocleidomastóideo & $(0) D$ & $(0) E$ & (1) D & $(1) E$ \\
\hline ATM & $(0) D$ & $(0) E$ & (1) D & $(1) E$ \\
\hline
\end{tabular}

\section{FUNÇÕES ORAIS}

Respiração [ ] Somar todas as pontuações (melhor resultado = 0 e pior $=9$ )

\begin{tabular}{|c|c|c|c|}
\hline Tipo: $\quad(0)$ médio/inferior & (1) médio/superior & (1) outro (descrever): & \\
\hline Modo: $(0)$ nasal & (1) oronasal & (2) oral & \\
\hline \multirow[t]{2}{*}{ Fluxo nasal (usar o espelho) } & ao chegar: $(0)$ simétrico & (1) reduzido à direita & (1) reduzido à esquerda \\
\hline & após limpeza: (0) simétrico & (1) reduzido à direita & (1) reduzido à esquerda \\
\hline \multicolumn{2}{|c|}{ Possibilidade de uso nasal: (0) 2 minutos ou mais } & (1) entre 1 e 2 minutos & (2) menos que 1 minuto \\
\hline
\end{tabular}

Observações:

Mastigação: Dadequada Galterada: de origem [ ] funcional [ ] anatômica [ ] articular [ ] outro (mastigatória utilizar sempre o mesmo alimento)

Mastigação Habitual [ ] Somar todas as pontuações (melhor resultado $=0$ e pior $=10$ )

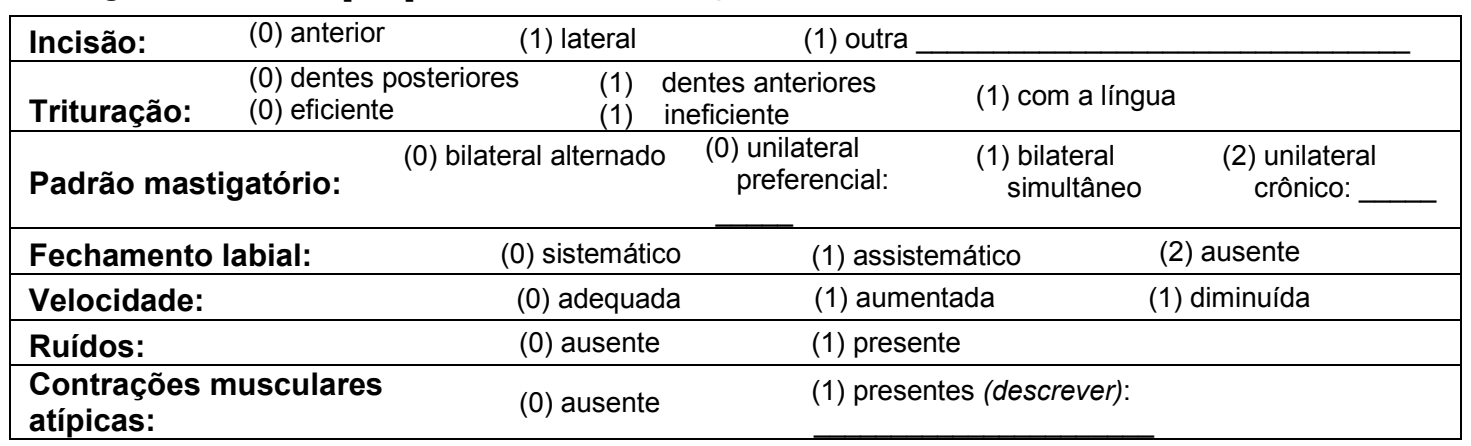

Outros:

\begin{tabular}{|c|c|c|c|c|}
\hline $\begin{array}{l}\text { Lado preferencial de } \\
\text { mastigação: }\end{array}$ & (0) direito e esquerdo & (1) direito & (1) esquerdo & (0) não sabe \\
\hline Dor ao mastigar: & (0) ausente & (1) direito & (1) esquerdo & \\
\hline Ruído na ATM: & (0) ausente & (1) direita & (1) esquerda & \\
\hline
\end{tabular}

Observações: 
Deglutição: $\square$ adequada $\quad \square$ alterada: de origem[ ] funcional [ ] anatômica [ ] articular [ ] outro $-$

$1^{\text {a }}$ Prova (habitual de sólidos) [ ] Somar todas as pontuações (melhor resultado $=0$ e pior $=18$ )

\begin{tabular}{|c|c|c|c|}
\hline Fechamento labial: & $(0)$ adequado & (1) parcial & (2) ausente \\
\hline Postura da língua: $\square$ não se vê & (0) atrás dos dentes & \multicolumn{2}{|c|}{ (1) contra os dentes (2) entre os dentes } \\
\hline Postura do lábio inferior: $\quad(0)$ contat & to com o superior & \multicolumn{2}{|c|}{ (1) atrás dos incisivos superiores } \\
\hline Contenção do alimento: & (0) adequada & (1) parcial & (2) inadequada \\
\hline Contração do orbicular: & (0) adequada & (1) pouca & (2) acentuada \\
\hline Contração do mentual: & (0) ausente & (1) pouca & (2) acentuada \\
\hline Contração da musculatura cervical: & (0) ausente & (1) pouca & (2) acentuada \\
\hline Movimento de cabeça: & (0) ausente & \multicolumn{2}{|c|}{ (1) presente } \\
\hline Ruído: & & \multicolumn{2}{|l|}{ (1) presente } \\
\hline Coordenação: & (1) enga & \multicolumn{2}{|c|}{ (1) tosse } \\
\hline Resíduos após deglutir: & (0) ausente & \multicolumn{2}{|c|}{ (1) presente } \\
\hline
\end{tabular}

Observações:

$\mathbf{2}^{\mathrm{a}}$ Prova (líquido dirigida) [ ] Somar todas as pontuações (melhor resultado $=0$ e pior $=16$ )

Colocar água na boca e deglutir somente após ordem do avaliador

\begin{tabular}{|c|c|c|}
\hline Selamento labial: $\quad(0)$ adequado & (1) parcial & (2) ausente \\
\hline Postura da língua: $(0)$ atrás dos dentes & (1) contra os dentes & (2) entre os dentes \\
\hline \multicolumn{2}{|c|}{ Postura do lábio inferior: $\quad(0)$ contato com o superior } & (1) atrás dos incisivos superiores \\
\hline Contenção do líquido: $\quad(0)$ adequada & (1) parcial & (1) inadequada \\
\hline Contração do orbicular: & (0) adequada & (2) acentuada \\
\hline Contração do mentual: & (0) ausente & (2) acentuada \\
\hline Contração da musculatura cervical: & (0) ausente & (2) acentuada \\
\hline Movimento de cabeça: & (0) ausente & (1) presente \\
\hline Ruído: & (0) ausente & (1) presente \\
\hline Coordenação: & (0) adequada & (1) engasgo \\
\hline
\end{tabular}

Observações:

\section{Perguntar ao paciente}

\begin{tabular}{|lllll|}
\hline Dificuldade para deglutir: & $(0)$ não & (1) sim (descrever): & \\
\hline $\begin{array}{l}\text { Posição da língua: }(0) \text { atrás dos dentes } \\
\text { superiores }\end{array}$ & (1) atrás dos dentes inferiores & (2) entre os dentes & (0) não sabe
\end{tabular}

Observações:

Fala: Dadequada $\square$ alterada. Descrever:

Voz: Dadequada $\square$ alterada. Descrever:

Observações:

Fga. Responsável: 
9. Referências 
1. Patil S, Schneider H, Schwartz A, Smith P. Adult obstructive sleep apnea: Pathophysiology and diagnosis. Chest 2007;132(1):325-37.

2. Maspero C, Giannini L, Galbiati G, Rosso G, Farronato G. Obstructive sleep apnea syndrome: a literature review. Minerva Stomatol 2015;64(2):97-109.

3. Omachi T, Claman D, Blanc P, Eisner M. Obstructive sleep apnea: a risk factor for work disability. Sleep 2009;32(6):791-8.

4. Appleton S, Vakulin A, McEvoy R, Vincent A, Martin S, Grant J, et al. Undiagnosed obstructive sleep apnea is independently associated with reductions in quality of life in middle-aged, but not elderly men of a population cohort. Sleep Breath 2015;21.

5. Edwards C, Mukherjee S, Simpson L, Palmer L, Almeida O, Hillman D. Depressive symptoms before and after treatment of obstructive sleep apnea in men and women. $\mathrm{J}$ Clin Sleep Med 2015;17(Mar).

6. Floras J. Sleep apnea and cardiovascular risk. J Cardiol 2014;63(1):3-8.

7. Kushida C, Littner M, Morgenthaler T, Alessi C, Bailey D, Coleman JJ, et al. Practice parameters for the indications for polysomnography and related procedures: an update for 2005. Sleep 2005;28(4):499-521.

8. AASM. Sleep-related breathing disorders in adults: recommendations for syndrome definition and measurement techniques in clinical research. The Report of an American academy of Sleep Medicine task force. Sleep 1999;22(5):667-89.

9. Karakoc O, Akcam T, Gerek M, Genc H, Ozgen F. The upper airway evaluation of habitual snorers and obstructive sleep apnea patients. Orl 2012;74(3):136-40.

10. Tufik S, Santos-Silva R, Taddei JA, Bittencourt LRA. Obstructive sleep apnea syndrome in the Sao Paulo Epidemiologic Sleep Study. Sleep Med 2010;11(5):441-6.

11. Lindberg E, Berne C, Elmasry A, Hedner J, Janson C. CPAP treatment of a populationbased sample-what are the benefits and the treatment compliance? Sleep Med 2006;7(7):553-60.

12. Gay P, Weaver T, Loube D, Iber C. Evaluation of positive airway pressure treatment for sleep related breathing disorders in adults. Sleep 2006;29(3):381-401.

13. Berry RB. Improving CPAP compliance - man more than machine. Sleep Med 2000;1(3):175-8.

14. Weaver T, Sawyer A. Adherence to continuous positive airway pressure treatment for obstructive sleep apnoea: implications for future interventions. Indian J Med Res 2010;131(Feb):245-58.

15. Engleman HM, Wild MR. Improving CPAP use by patients with the sleep apnoea/hypopnoea syndrome (SAHS). Sleep Med Rev 2003;7(1):81-99. 
16. Oksenberg A, Gadoth N. Are we missing a simple treatment for most adult sleep apnea patients? The avoidance of the supine sleep position. J Sleep Res 2014;23(2):204-10.

17. Raunio A, Mattila P, Huuskonen U, Oikarinen K, Sándor GK. The influence of a mandibular advancement plate on polysomnography in different grades of obstructive sleep apnea. J Oral Maxillofac Res 2015;6(1):1-9.

18. Vecchierini M, Léger D, Laaban J, Putterman G, Figueredo M, Levy J, et al. Efficacy and compliance of mandibular repositioning device in obstructive sleep apnea syndrome under a patient-driven protocol of care. Sleep Med 2008;9(7):762-9.

19. Tuomilehto H, Seppä J, Uusitupa M. Obesity and obstructive sleep apnea clinical significance of weight loss. Sleep Med Rev 2013;17(5):321-9.

20. Newman AB, Foster G, Givelber R, Nieto FJ, Redline S, Young T. Progression and regression of sleep-disordered breathing with changes in weight: the Sleep Heart Health Study. Arch Intern Med 2005;165(20):2408-13.

21. Guimarães KC. Efeitos dos exercícios orofaríngeos em pacientes com apneia obstrutiva do sono moderada: Estudo controlado e randomizado [tese]. São Paulo: Faculdade de Medicina da Universidade de São Paulo; 2008.

22. Guimarães KC, Drager LF, Genta PR, Marcondes BF, Lorenzi-Filho G. Effects of oropharyngeal exercises on patients with moderate obstructive sleep apnea syndrome. Am J Respir Crit Care Med 2009;179(10):962-6.

23. Diaféria GLA. Terapia fonoaudiológica como coadjuvante do tratamento com o uso do aparelho de pressão aérea positiva contínua em pacientes com a síndrome de apneia obstrutiva do sono [tese]. São Paulo: Universidade Federal de São Paulo; 2012.

24. Diaferia G, Badke L, Santos-Silva R, Bommarito S, Tufik S, Bittencourt L. Effect of speech therapy as adjunct treatment to continuous positive airway pressure on the quality of life of patients with obstructive sleep apnea. Sleep Med 2013;14(7):628-35.

25. Ieto V, Kayamori F, Montes M, Hirata R, Gregório M, Alencar A, et al. Effects of oropharyngeal exercises on snoring: a randomized trial. Chest 2013; May(7).

26. Davidson TM. The great leap forward: The anatomic basis for the acquisition of speech and obstructive sleep apnea. Sleep Med 2003;4(3):185-94.

27. Edwards B, White DP. Control of the pharyngeal musculature during wakefulness and sleep: Implications in normal controls and sleep apnea. Head Neck 2011;33(Suppl 1):1-17.

28. Zemlin W. Princípios de fisiologia e anatomia em fonoaudiologia. 4a Edição. Porto Alegre: 2000.

29. Sanders I, Mu L. A three-dimensional atlas of human tongue muscles. Anat Rec 2013;296(7):997-1003. 
30. Schwab RJ, Pasirstein M, Pierson R, Mackley A, Hachadoorian R, Arens R, et al. Identification of upper airway anatomic risk factors for obstructive sleep apnea with volumetric magnetic resonance imaging. Am J Respir Crit Care Med 2003;168(5):52230 .

31. Chi L, Comyn F, Mitra N, Reilly M, Wan F, Maislin G, et al. Identification of craniofacial risk factors for obstructive sleep apnoea using three-dimensional MRI. Eur Respir J 2011;38(2):348-58.

32. Nashi N, Kang S, Barkdull GC, Lucas J, Davidson TM. Lingual fat at autopsy. Laryngoscope 2007;117(8):1467-73.

33. Kim AM, Keenan BT, Jackson N, Chan EL, Staley B, Poptani H, et al. Tongue fat and its relationship to obstructive sleep apnea. Sleep 2014;37(10):1639-48.

34. Welch K, Foster G, Ritter C, Wadden T, Arens R, Maislin G, et al. A novel volumetric magnetic resonance imaging paradigm to study upper airway anatomy. Sleep 2002;25(5):532-42.

35. Chan ASL, Sutherland K, Schwab RJ, Zeng B, Petocz P, Lee RWW, et al. The effect of mandibular advancement on upper airway structure in obstructive sleep apnoea. Thorax 2010;65(8):726-32.

36. Sittitavornwong S, Waite PD. Imaging the upper airway in patients with sleep disordered breathing. Oral Maxillofac Surg Clin North Am 2009;21(4):389-402.

37. Togeiro SMGP, Chaves CM, Palombini L, Tufik S, Hora F, Nery LE. Evaluation of the upper airway in obstructive sleep apnoea. Indian J Med Res 2010;131(Feb):230-5.

38. Humbert I, Reeder SB, Porcaro EJ, Stephanie A, Brittain JH, Robbins J. NIH Public Access. J Magn Reson Imaging 2009;28(2):504-8.

39. Schwab RJ, Kim C, Siegel L, Keenan BT, Black J, Farid-moayer M, et al. Examining the Mechanism of Action of a New Device Using Oral Pressure Therapy for the Treatment of Obstructive Sleep Apnea. Sleep 2014;37(3):1237-47.

40. Chiffer R, Schwab R, Keenan B, Borek R, Thaler E. Volumetric MRI analysis pre- and post Transoral robotic surgery for obstructive sleep apnea (OSA-TORS). Laryngoscope 2015;Apr.

41. Ryan CM, Bradley TD. Pathogenesis of obstructive sleep apnea. J Appl Physiol 2005;99(6):2440-50.

42. Horner R. Motor control of the pharyngeal musculature and implications for the pathogenesis of obstructive sleep apnea. Sleep 1996;19(10):827-53.

43. Horner R, Innes J, Murphy K, Guz A. Evidence for reflex upper airway dilator muscle activation by sudden negative airway pressure in man. J Physiol 1991;436:15-29. 
44. Mateika JH, Millrood DL, Kim J, Rodriguez HP, Samara GJ. Response of human tongue protrudor and retractors to hypoxia and hypercapnia. Am J Respir Crit Care Med 1999;160(6):1976-82.

45. Mortimore I, Douglas N. Palatal muscle EMG response to negative pressure in awake sleep apneic and control subjects. Am J Respir Crit Care Med 1997;156(3 I):867-73.

46. Tangel D, Mezzanotte W, White D. Respiratory-related control of palatoglossus and levator palatini muscle activity. J Appl Physiol 1995;78(2):680-8.

47. Worsnop C, Kay A, Pierce R, Kim Y, Trinder J. Activity of respiratory pump and upper airway muscles during sleep onset. J Appl Physiol 1998;85(3):908-20.

48. Mezzanotte WS, Tangel DJ, White DP. Waking genioglossal electromyogram in sleep apnea patients versus normal controls (a neuromuscular compensatory mechanism). J Clin Invest 1992;89(5):1571-9.

49. Mezzanotte W, Tangel D, White D. Influence of sleep onset on upper-airway muscle activity in apnea patients versus normal controls.Influence of sleep onset on upperairway muscle adivity in apnea patients versus normal controls. Am J Respir Crit Care Med 1996;153(6):1880-7.

50. Fogel R, Malhotra A, Pillar G, Edwards J, Beauregard J, Shea S, et al. Genioglossal activation in patients with obstructive sleep apnea versus control subjects: Mechanisms of muscle control. Am J Respir Crit Care Med 2001;164(11):2025-30.

51. Fogel RB, Trinder J, Malhotra A, Stanchina M, Edwards JK, Schory KE, et al. Withinbreath control of genioglossal muscle activation in humans: effect of sleep-wake state. J Physiol 2003;550(Pt 3):899-910.

52. Fogel RB, Trinder J, White DP, Malhotra A, Raneri J, Schory K, et al. The effect of sleep onset on upper airway muscle activity in patients with sleep apnoea versus controls. J Physiol 2005;564(Pt 2):549-62.

53. Eckert D, Malhotra A, White D, AS J. The influence of obstructive sleep apnea and gender on genioglossus activity during rapid eye movement sleep. Chest 2009;135(4):997-1003.

54. McGinley BM, Schwartz AR, Schneider H, Kirkness JP, Smith PL, Patil SP. Upper airway neuromuscular compensation during sleep is defective in obstructive sleep apnea. J Appl Physiol 2008;105(1):197-205.

55. Jordan AS, White DP, Lo Y-L, Wellman A, Eckert DJ, Yim-Yeh S, et al. Airway dilator muscle activity and lung volume during stable breathing in obstructive sleep apnea. Sleep 2009;32(3):361-8.

56. BuSha B, Strobel R, England S. The length-force relationship of the human genioglossus in patients with obstructive sleep apnea. Respir Physiol Neurobiol 2002;130(2):161-8. 
57. Eckert DJ, Lo YL, Saboisky JP, Jordan AS, White DP, Malhotra A. Sensorimotor function of the upper-airway muscles and respiratory sensory processing in untreated obstructive sleep apnea. J Appl Physiol 2011;111(6):1644-53.

58. McSharry D, O'Connor C, McNicholas T, Langran S, O'Sullivan M, Lowery M, et al. Genioglossus fatigue in obstructive sleep apnea. Respir Physiol Neurobiol 2012;183(2):59-66.

59. Montemurro LT, Bettinzoli M, Corda L, Braghini A, Tantucci C. Relationship between critical pressure and volume exhaled during negative pressure in awake subjects with sleep-disordered breathing. Chest 2010;137(6):1304-9.

60. Sforza E, Bacon W, Weiss T, Thibault A, Petiau C, Krieger J. Upper airway collapsibility and cephalometric variables in patients with obstructive sleep Apnea. Am J Respir Crit Care Med 2000;161(2):347-52.

61. Gold A, Schwartz A. The pharyngeal critical pressure. The whys and hows of using nasal continuous positive airway pressure diagnostically. Chest 1996;110(4):1077-88.

62. Patil SP, Schneider H, Marx JJ, Gladmon E, Schwartz AR, Smith PL. Neuromechanical control of upper airway patency during sleep. J Appl Physiol 2007;102(2):547-56.

63. Gold AR, Marcus CL, Dipalo F, Gold MS. Upper airway collapsibility during sleep in upper airway resistance syndrome. Chest 2002;121(5):1531-40.

64. Kirkness JP, Schwartz AR, Schneider H, Punjabi NM, Maly JJ, Laffan AM, et al. Contribution of male sex, age, and obesity to mechanical instability of the upper airway during sleep. J Appl Physiol 2008;104(6):1618-24.

65. Schwartz a R, Gold a R, Schubert N, Stryzak A, Wise R a, Permutt S, et al. Effect of weight loss on upper airway collapsibility in obstructive sleep apnea. Am Rev Respir Dis 1991;144(3):494-8.

66. Edwards BA, Wellman A, Sands SA, Owens RL, Eckert DJ, White DP, et al. Obstructive sleep apnea in older adults is a distinctly different physiological phenotype. Sleep 2014;37(7):1227-36.

67. Joosten S, Edwards B, Wellman A, Turton A, Skuza E, Berger P, et al. The effect of body position on physiological factors that contribute to obstructive sleep apnea. Sleep 2015;31(Jan).

68. Ong J, Touyz G, Tanner S, Hillman D, Eastwood P, Walsh J. Variability of human upper airway collapsibility during sleep and the influence of body posture and sleep stage. J Sleep Res 2011;20(4):533-7.

69. Netzer N, Stoohs R, Netzer C, Clark K, Strohl K. Using the Berlin Questionnaire to identify patients at risk for the sleep apnea syndrome. Ann Intern Med 1999;5(131):485-91.

70. Johns M. A new method for measuring daytime sleepiness: the Epworth sleepiness scale. Sleep 1991;14(6):540-5. 
71. Buysse DJ, Reynolds CF, Monk TH, Berman SR, Kupfer DJ. The Pittsburgh Sleep Quality Index: a new instrument for psychiatric practice and research. Psychiatry Res 1989;28(2):193-213.

72. Marchesan I, Berretin-Félix G, Genaro K. MBGR protocol of orofacial myofunctional evaluation with scores. Int J Orofac Myol 2012;38(Nov):38-77.

73. Friedman M, Schalch P. Surgery of the Palate and Oropharynx. Otolaryngol Clin North Am 2007;40(4):829-43.

74. Berry R, Budhiraja, RGottlieb D, Al E. Rules for scoring respiratory events in sleep: update of the 2007 AASM Manual for the Scoring of Sleep and Associated Events. Deliberations of the Sleep Apnea Definitions Task Force of the American Academy of Sleep Medicine. J Clin sleep Med JCSM 2012;8(5):597-619.

75. Vanderwegen J, Guns C, Van Nuffelen G, Elen R, De Bodt M. The influence of age, sex, bulb position, visual feedback, and the order of testing on maximum anterior and posterior tongue strength and endurance in healthy belgian adults. Dysphagia 2013;28(2):159-66.

76. Jordan AS, Wellman A, Edwards JK, Schory K, Dover L, MacDonald M, et al. Respiratory control stability and upper airway collapsibility in men and women with obstructive sleep apnea. J Appl Physiol 2005;99(5):2020-7.

77. Camacho M, Certal V, Abdullatif J, Zaghi S, Ruoff CM, Capasso R. Myofunctional therapy to treat obstructive sleep apnea: a systematic revtew and meta-analysis. Sleep 2015;38(5):669-75.

78. Puhan M a, Suarez A, Lo Cascio C, Zahn A, Heitz M, Braendli O. Didgeridoo playing as alternative treatment for obstructive sleep apnoea syndrome: randomised controlled trial. BMJ 2006;332(7536):266-70.

79. Ieto V. Efeitos da terapia miofuncional orofacial sobre o ronco e a qualidade de sono em pacientes com ronco primário e apneia obstrutiva do sono leve a moderada [tese]. São Paulo: Faculdade de Medicina da Universidade de São Paulo; 2014.

80. Engelke W, Jung K, Knösel M. Intra-oral compartment pressures: A biofunctional model and experimental measurements under different conditions of posture. Clin Oral Investig 2011;15(2):165-76.

81. Lazarus C, Logemann J, Huang C, Rademaker A. Effects of two types of tongue strengthening exercises in young normals. Folia Phoniatr Logop 2003;55(4):199-205.

82. Clark H, O'Brien K, Calleja A, Corrie S. Effects of directional exercise on lingual strength. J Speech Lang Hear Res 2009;52(4):1034-47.

83. Clark H. Specificity of training in the lingual musculature. J Speech, Lang Hear Res 2012;55(April):657-68. 